Portland State University

PDXScholar

Fall 11-18-2013

\title{
The Impacts of Urban Renewal: The Residents' Experiences in Qianmen, Beijing, China
}

Yongxia Kou

Portland State University

Follow this and additional works at: https://pdxscholar.library.pdx.edu/open_access_etds

Part of the Public Affairs, Public Policy and Public Administration Commons, Rural Sociology Commons, and the Urban Studies and Planning Commons Let us know how access to this document benefits you.

\section{Recommended Citation}

Kou, Yongxia, "The Impacts of Urban Renewal: The Residents' Experiences in Qianmen, Beijing, China" (2013). Dissertations and Theses. Paper 1497.

https://doi.org/10.15760/etd.1496

This Dissertation is brought to you for free and open access. It has been accepted for inclusion in Dissertations and Theses by an authorized administrator of PDXScholar. Please contact us if we can make this document more accessible: pdxscholar@pdx.edu. 
The Impacts of Urban Renewal:

The Residents' Experiences in Qianmen, Beijing, China

\author{
by \\ Yongxia Kou
}

A dissertation submitted in partial fulfillment of the requirements for the degree of

\author{
Doctor of Philosophy \\ in \\ Urban Studies
}
Dissertation Committee:
Carl Abbott, Chair
Karen Gibson
Charles Heying
Connie Ozawa
Sharon Carstens

Portland State University

2013 


\begin{abstract}
The study examines the influences of the Qianmen urban renewal project on its original residents, which is one of a few demonstration projects under the new policy orientation of urban renewal practices in Beijing, China, entering the new century. It employs "residential satisfaction" as an evaluative indicator to understand the residents' experiences before and after urban renewal. Seventy-two residents were interviewed. Among them, 25 remained in Qianmen; 20 relocated to Hongshan, a neighborhood in the central city area; 21 moved to Longyue, a neighborhood in one of the suburban areas; and 6 residents relocated to other locations.
\end{abstract}

The study found that the participants' level of residential satisfaction was skewed toward dissatisfaction before the urban renewal, whereas participants showed a much higher satisfaction level after the urban renewal, which means that overall the Qianmen urban renewal project had positive impacts on the residents' residential environment. However, among the three neighborhoods, there are no statistically significant differences. The policy arrangements of the Qianmen urban renewal project contribute to the results. Under the new policy orientation, the policy arrangements of the Qianmen urban renewal project featured a government-led approach with a large amount of public investment, which formed a good basis to provide better compensation to the residents, in particular to provide extra aid to low income residents. Therefore, the residents got their housing conditions improved to a large extent contributing to their higher level of residential 
satisfaction after the project was implemented. Because of the extra aid, the low income residents were even more satisfied than the middle-high income residents. On the other hand, the policy arrangements took into account the opinions of the original residents, in other words, most residents made their own decision about where to live after the urban renewal. In this circumstance, they actually saw the urban renewal as an opportunity to improve their residential environment, in spite of the fact that the urban renewal project was initiated by the municipal government. Therefore residents stayed or relocated voluntarily, which significantly predicts the resulting higher level of residential satisfaction. The findings in the Qianmen case remind us that we do need a more open, balanced perspective for analysis of urban renewal processes and outcomes, rather than a predominantly negative displacement view embedded in a gentrification discourse; and that policy arrangements toward more redistribution and social equity are more likely to achieve positive outcomes for disadvantaged people.

However, the improvements in unit size and housing quality are the main achievements of the urban renewal. Many residents still face the shortage of community facilities in the short run, and in the long run they might continue to suffer from poorer accessibility to public facilities and other resources. Furthermore, the urban renewal inevitably caused social disturbances for many residents, in particular for disadvantaged people (low income residents, and the elderly, etc), although the negative impacts of relocation on social networks were mitigated by the benefits of escaping the social conflicts and annoyance in the original neighborhood, and were compensated by the improved housing 
conditions. Generally, the key argument of this study is that policy makers need to pay more attention to the disadvantaged class; in other words, the government needs to assume its role more actively in redistribution and social equity. 


\section{Acknowledgements}

This work couldn't be completed without the help from the following people.

I would like to express my sincere gratitude to all the members of my dissertation committee: Professor Carl Abbott, Professor Karen Gibson, Professor Charles Heying, Professor Connie Ozawa, and Professor Sharon Carstens. Prof. Carl Abbott, my chair, has always been a great source of support. For years, his guidance and encouragement propelled me get through the challenging process of pursuing $\mathrm{Ph} . \mathrm{D}$. He devoted an enormous amount of time reading and criticizing several drafts of the dissertation. The substantive comments and grammatical corrections from the other members helped a great deal to make this work better. I own much to this great support.

My cordial thanks also go to Jingxia Wang, Xinxiang Tan and others. Without them, the field work of this study in Beijing would have been much harder. I want to thank in particular the respondents of my interviews for sharing their experiences with me, which made this study possible. I am also grateful to my friends Hongwei Dong, Yiping Fang, and Liang Ma, among others. They provided numerous support in my writing and defending of the dissertation.

Finally, I want to deeply thank my family for all of their support and love through the years. Particularly, my heartfelt thanks belong to my daughter, Amy. Her big smile is the warmest for me to overcome any difficulties through the process. 


\section{Table of Contents}

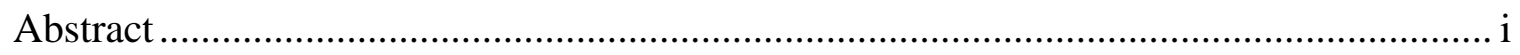

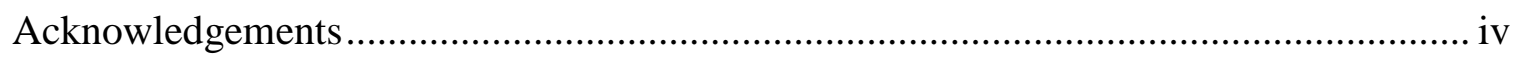

List of Tables .................................................................................................. viii

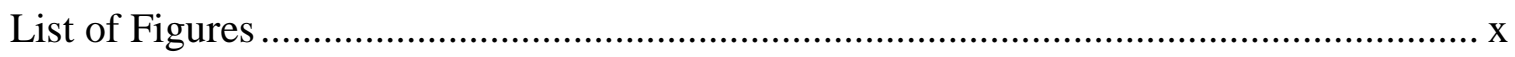

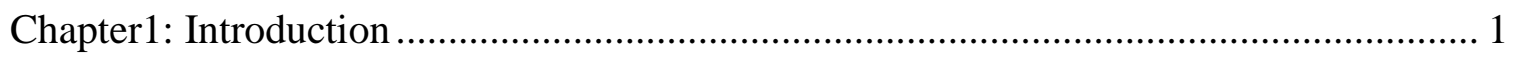

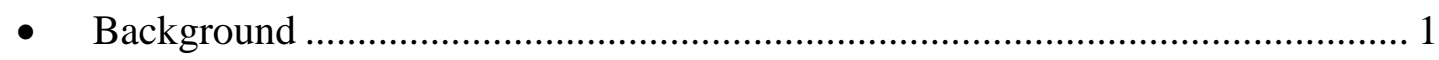

- Overview of the Dissertation .......................................................................... 7

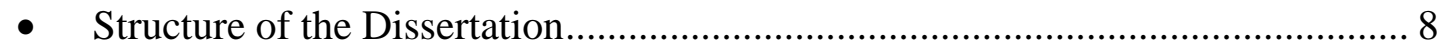

Chapter 2: Residential Satisfaction Literature ......................................................... 12

2.1 The Conceptualizing of Residential Satisfaction ............................................ 12

2.2 Residential Environment Typologies: Hierarchical Spatiality and Multi-

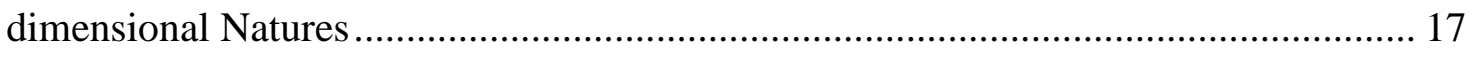

2.3 The Predictors of Residential Satisfaction ....................................................... 20

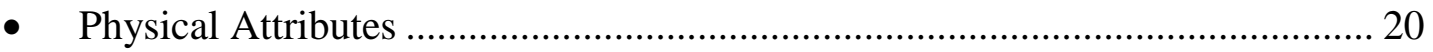

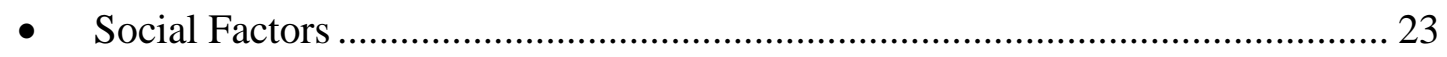

- Individual and Household Characteristics...................................................... 27

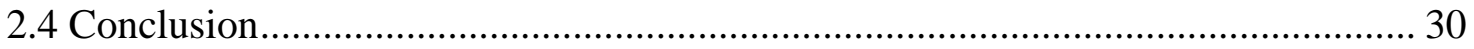

Chapter 3: Urban Renewal in the Beijing Context ................................................... 33

3.1 The Evolution of the Urban Renewal Practices in Beijing ................................ 33

- $\quad$ Large Scale Market-oriented Phrase in the 1990 .............................................. 33 


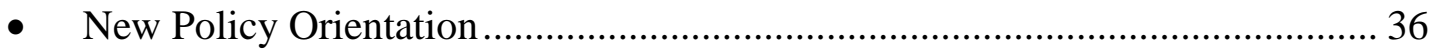

3.2 The Qianmen Urban Renewal Project..................................................................... 39

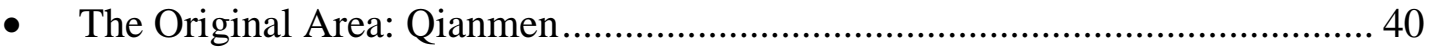

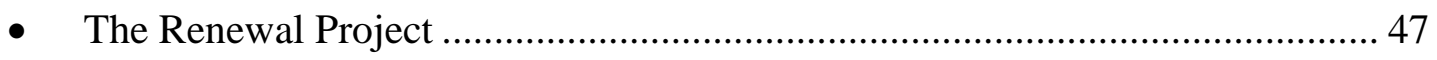

Chapter 4: Research Design ..................................................................................... 56

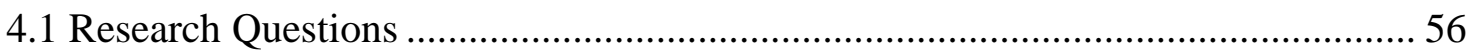

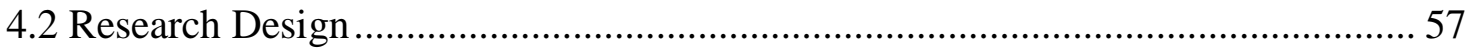

- The Population ……………………………………………………………..... 57

- Data Collection and Analyses ........................................................................... 59

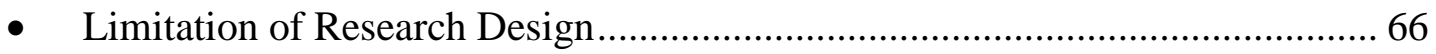

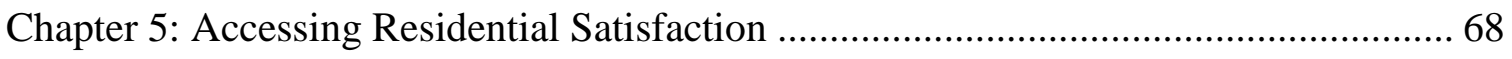

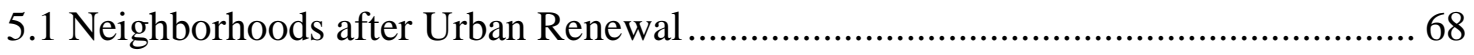

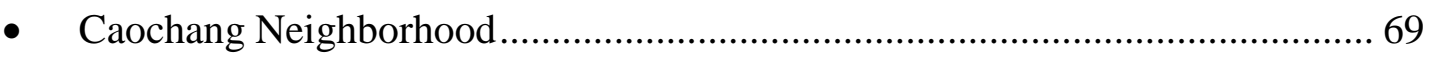

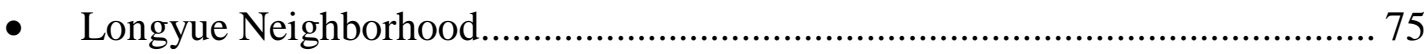

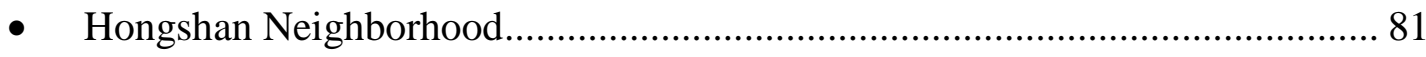

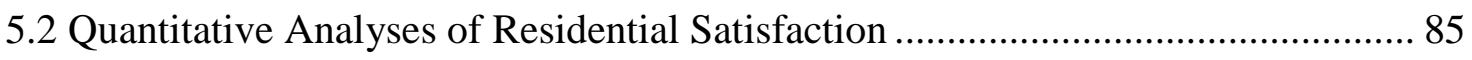

Chapter 6: Significant Factors Attributing to Residential Satisfaction.............................. 92

6.1 Unit Size and Other Physical Factors................................................................. 92

6.2 Income and Other Economic Attributes ............................................................. 99

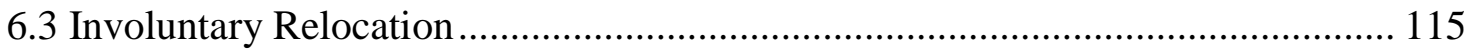

Chapter 7: Social Attributes and their Significance Predicting Residential Satisfaction 122

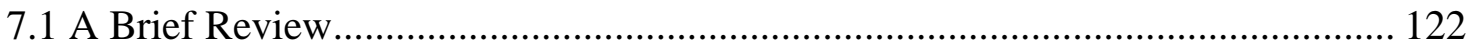

7.2 The Original Qianmen Residents' Local Social Interactions and Intimates ......... 126

- Before the Urban Renewal .............................................................................. 126

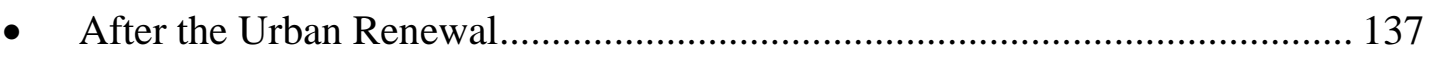

7.3 Do Social Networks Predict Residential Satisfaction ........................................... 155 
- The Housing Needs Hierarchy ........................................................................ 157

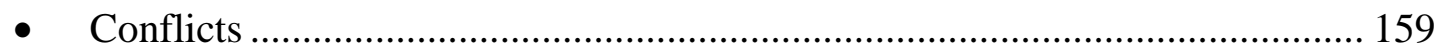

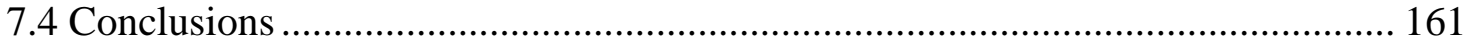

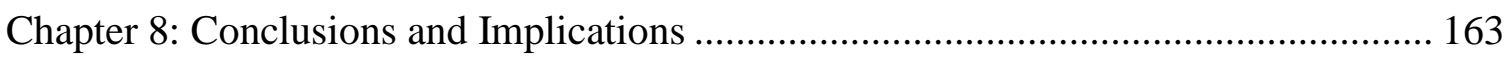

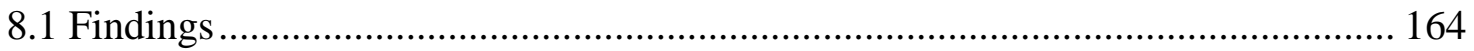

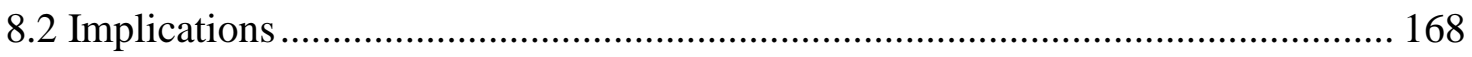

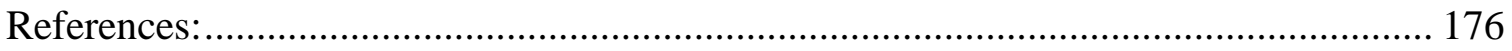

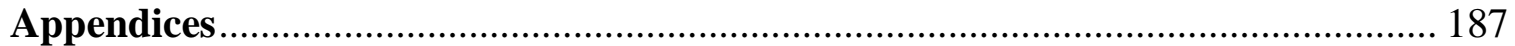

Appendix A: interview questions for the officials ............................................... 187

Appendix B: interview questions for the residents .................................................. 188

Appendix C: sample characteristics of study participants by income and by age ...... 192 


\section{List of Tables}

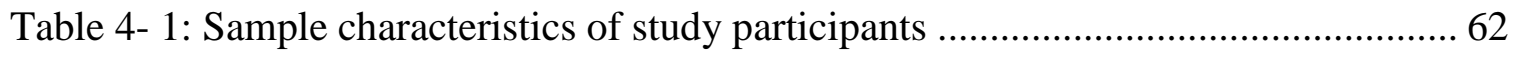

Table 5-1: The public facilities: Caochang, Hongshan and Longyue.............................. 69

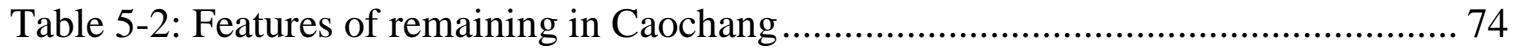

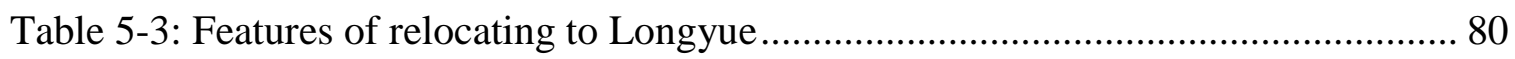

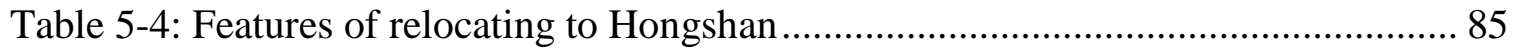

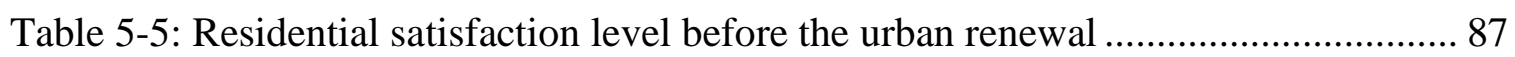

Table 5-6: Residential satisfaction level after the urban renewal .................................. 87

Table 5-7: The residential satisfaction of residents with different demographic and

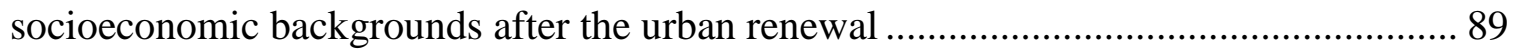

Table 5-8: The significance of physical, social and policy factors predicting residential

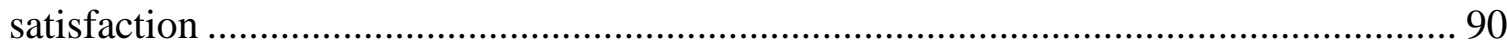

Table 5-9: The parameter of unit size, involuntary relocation and income predicting

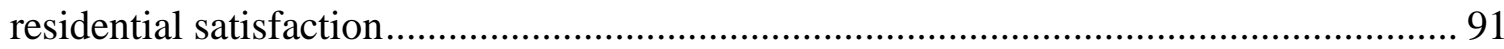

Table 6-1: Housing unit size before and after........................................................... 93

Table 6-2: The percentage of the interviewees who listed the attributes making them

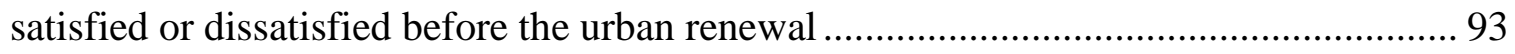

Table 6-3: The percentage of the interviewees who listed the attributes making them satisfied or dissatisfied after the urban renewal ......................................................... 94

Table 6-4: The residential satisfaction of different income groups ............................. 100

Table 6-5: The parameter of income predicting residential satisfaction with middle-high

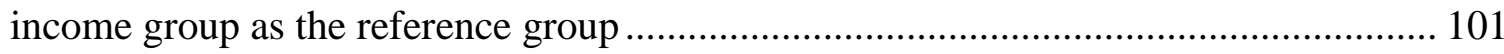

Table 6-6: The parameter of income predicting residential satisfaction with high income

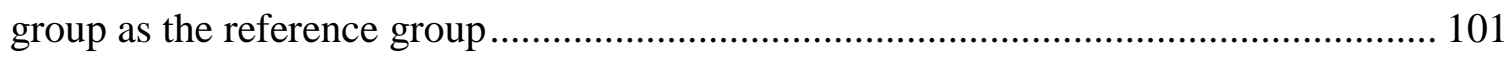

Table 6-7: The unit size of different income groups.................................................. 104

Table 6-8: The involuntary relocation of different income groups.............................. 112

Table 6-9: Involuntary relocation across the three neighborhoods .............................. 118

Table 7-1: The residents' local intimates within their overarching social networks before the urban renewal 
Table 7-2: The residents' local intimates within their overarching social networks after

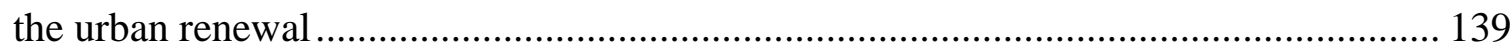

Table 7-3: Social impacts of the urban renewal across the three neighborhoods........... 139

Table 7-4: Social impacts of the urban renewal across different social groups.............. 150

Table 7-5 The impacts of social factors on residential satisfaction ................................. 161 


\section{List of Figures}

Figure 2-1: A conceptual framework of residential satisfaction.................................. 16

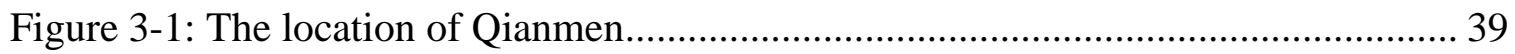

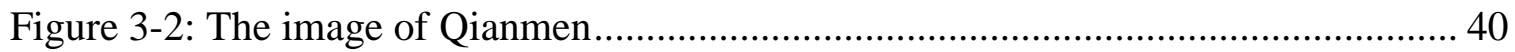

Figure 3-3: The street life in Qianmen before the urban renewal................................. 42

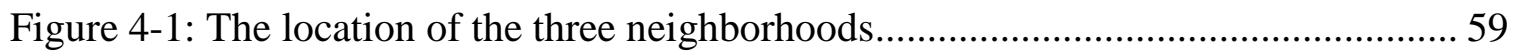

Figure 5-1: The images of Caochang neighborhood before and after .......................... 70

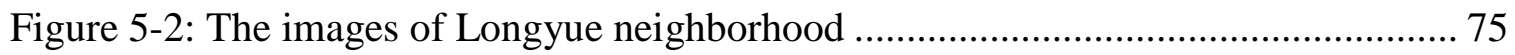

Figure 5-3: The images of Hongshan neighborhood ................................................ 81 


\section{Chapter1: Introduction}

\section{- Background}

Since 1978, China's transition from a planned to a market economy has impacted the country economically, socially, and physically in profound ways. Economically, China's remarkable growth rate has impressed the world, with average annual growth rate of more than 9 percent from 1978 to 2003(America 2004). Corresponding with its remarkable economic growth is the social restructuring. A different structure of social groups has been emerging (Wang 2005), and the increasing social inequity has gained substantial concerns.

As a reflection of the dramatic economic growth and intensive social restructuring, cities in China have undergone profound changes since the economic reform. On the one hand, economic growth is accompanied by an accelerated urbanization and urban expansion. On the other hand, intensive inner-city redevelopment programs have prevailed in cities across the country (Zhang and Fang 2004; Acharya 2005; Qian 2009). The putting into place of a series of market-oriented transformations, in particular, land reform and housing commodification, have stimulated extensive urban (re)development in the postreform era (Wu 1997; Qian 2009). Millions of households were impacted.

According to the World Bank, 8.5 million urban households were relocated in the 1980s across the country( $\mathrm{Li}$ and Song 2009).It is estimated that some 760,000 people were affected by inner-city redevelopment in Beijing, the capital city of China, from the end of 
1980s to the beginning of 2000s (S.Jakes. 2002). Between 1990 and 1999, the redevelopment process was carried out in 150 areas in Beijing, and over 4 million square meters (about 43 million square feet) of old housing were demolished(Qian 2009). Zhang, $\mathrm{He}$ and $\mathrm{Wu}$ reported an even greater scale of relocation and displacement in Shanghai, the largest city in China: from 1991 to 1997, the destruction of 22.5 million square meters(about 242 million square feet) of housing led to the relocation of more than 1.5 million residents--one-seventh of the city's population in the early 1990s(Zhang 2002); from 1995 to 2004, more than 745 thousand households were relocated, and over 33 million square meters (about 355 million square feet) of housing were demolished in Shanghai(He and $\mathrm{Wu}$ 2007).

Under this context, what are the experiences of the residents affected by the large scale of urban redevelopment? If they are indeed impacted negatively, how to ameliorate their sufferings and how to improve future policy arrangements have been increasingly becoming a major concern of policy makers and researchers.

Although the scale of forced moving in Chinese cities is phenomenal, these are not unique problems to Chinese cities. In the immediate post-WWII years, large scale urban clearance both in the U.S. and many of the European countries inspired a tradition of research connected to forced moving. Since the 1980s, a substantial number of studies on the displacement problem attributed to gentrification in the new economic and social paradigm enhanced the understanding in this field. How to evaluate the effects of various 
urban regeneration policies since the 1990s requires new insights on involuntary (forced) moving (Qian 2009; Kleinhans and Kearns 2013).

The negative outcomes of urban clearance (gentrification) have been widely investigated and reported in the western literature. Scholars found that urban clearance in the context of the U.S. exacerbated the segregation of the urban poor in public housing in city centers(Halpern. c1995). Correspondingly, with the decentralization of jobs to the suburbs since the Second World War, scholars found that the spatial mismatch between living places and working places contributed to high unemployment and low earnings(Kain 1968). In the gentrified neighborhood, the inflation of housing prices and the decrease of affordable housing units make the stayers face higher rent burdens and fewer housing opportunities(Freeman 2005; Lees, Slater et al. 2008). Although gentrification can bring benefits to the stayers in the form of improved local services, they often feel the improvements out of sync with their needs(Atkinson and Bridge 2005; Freeman 2005). At worst, for those displaced who cannot afford any kinds of houses and fail to get access to public housing, homelessness is their only destiny (Marcuse 1985; Lees, Slater et al. 2008)

Beyond these physical and economic problems, much greater attention was paid to negative social impacts of urban clearance (gentrification) (Fried 1967; Hartman 1979; Marcuse and Kempen 2000; Wu 2004; Sassen c1994). One of the classical studies is Fried's investigation on the West End of Boston. He found that within a community, "a vast and interlocking set of social networks is localized" and "the physical area has 
considerable meaning as an extension of home, in which various parts are delineated and structured on the basis of a sense of belonging." Thus, communities are indeed invested with considerable, "multiply-determined meaning". Therefore, relocation represents "a disruption in one's relationship to the past, to the present, and to the future" (Fried 1967: 361). Many scholars share a similar point of view with Fried, that displacement means moving from a supportive, long-term environment to an alien area(Hartman 1979; Atkinson 2000; Lees, Slater et al. 2008), which may make the displaced lose their social support in the previous neighborhood, thus unfavorably impacting their mental health (Fauth, Leventhal et al. 2004).

However, the literature in the field is far from conclusive (Cameron and Doling 1994; Susnik and Ganesan 1997; Engels 1999; Wu 2004; Kleinhans and Kearns 2013). Kleinhans reported the results of empirical research into the experiences and satisfaction of movers who had been confronted with forced relocation in the Netherlands. Many respondents took the opportunity of relocation to improve their residential environment due to their priority rights in the housing market (Kleinhans 2003). In some cases, forced relocation may not be perceived as forced at all (Kearns and Mason 2013; Kleinhans and Kearns 2013). In Hong Kong, due to rapid economic growth and mass public housing provisions in the early 1990s, the outcome of urban renewal was favorable for over $55 \%$ of those displaced. Therefore, Susnik and Ganesan concluded that urban renewal partially mitigates negative residential displacement(Susnik and Ganesan 1997; Wu 2004). 
Recognizing these debates on the results of involuntary (forced) moving, scholars called for a more open, balanced perspective for analysis of urban renewal processes and outcomes, rather than a predominantly negative displacement view embedded in a gentrification discourse, for urban renewal processes and outcomes are very dependent on the local social, economic and institutional context(Kleinhans and Kearns 2013). Inspired by similar curiosity, this study is interested in investigating urban renewal outcomes in the Chinese context.

Scholars examining urban renewal in Chinese cities do report findings consistent with the negative outcomes identified in the Western world: moving from inner-city areas to peripheral estates limits the displaced movers' access to good public facilities and employment opportunities, and makes them lose their old established social and kinship networks (Ya Ping and Alan 2000; Wu 2004). Fang surveyed 105 households in four neighborhoods in Beijing. The relocation of all the interviewees was involuntary in terms of both moving decision and moving choice. Fang's study suggests an overall low level of satisfaction across all the four neighborhoods(Fang 2006).

On the other hand, other scholars identify positive parts of the outcomes. Based on a sample of some 500 households in Shanghai, Wu investigated the overall level of residential satisfaction, and further compared the satisfaction level of households relocated actively and passively. Although the passively relocated households have lower levels of residential satisfaction than those actively relocated, residents are generally happy with the relocation(Wu 2004). The study by $\mathrm{Li}$ and Song on residential satisfaction 
of displaced residents in Shanghai as well found that generally the displaced residents are more satisfied with their residential conditions (in terms of both dwelling and neighborhood) than the stayers and the movers from outside of Shanghai, and just slightly less satisfied compared with voluntary movers. Therefore, $\mathrm{Li}$ and Song concluded that the displaced residents at least in Shanghai are not the underprivileged and oppressed group(Li and Song 2009). Qian investigated the outcomes of urban renewal in Jinyuchi neighborhood, Beijing, at the beginning of the new century. Qian found that under the new round of public-led urban renewal model, a great number of original households finally returned, and benefited from the many benefits of the project, in particular, the substantial positive physical changes related to living space and basic facilities, though the outputs of the project missed some of the important local needs(Qian 2009).

These mixed finding indicates that since urban renewal processes and outcomes are very dependent on the local social, economic and institutional context which evolves over time, the processes and outcomes of each program could vary from country to country, from city to city, even from case to case. Therefore, it is worth doing in-depth exploration into concrete cases, that way, through understanding households' experiences - their benefits and costs, scholars could identify mechanisms and/or policy arrangements which help them achieve positive effects and/or make them suffer, and then make recommendation for improvements. Moreover, theoretically, scholars could contribute to help build a more open and balanced frame for better understanding the phenomenon of forced moving, through comparing and contrasting the processes and outcomes of various cases. 


\section{- Overview of the Dissertation}

This study examines the outcomes of the urban renewal project in Qianmen area, Beijing. As discussed before, Beijing has undergone intensive urban renewal during the last several decades. The evolution of urban renewal practices in Beijing and its outcomes have drawn concerns from scholars and policy makers, which forms a good base for this study to continue the topic. Moreover, as the capital city, the experiences of Beijing would have good effects of demonstration to other cities in the country. Qianmen is located in the core area of the capital city, just a short walk from the Forbidden City, Tiananmen Square, and many political, cultural and commercial attractions. It is one of "Beijing's historically and culturally significant precincts". These merits made it one of a few demonstration projects under the new policy orientation entering the new century. The urban renewal project is also one of many projects preparing for the Beijing 2008 Olympics. In this context, the local government put special efforts to the urban renewal project to achieve positive results, which makes it the perfect case to understand the impacts of policy arrangements.

The study looks into the influences of the Qianmen urban renewal project on its original residents. What were their experiences before and after the urban renewal? Did they suffer from the physical, social and/or economic costs of displacement which are widely documented by the available literature, or have they taken the opportunity of relocation to improve their residential environment? It is particularly concerned with the social impacts of urban renewal, as with previous seminal works. And further how did policy 
arrangements contribute to these outcomes? Did the featured policy arrangements in China make a difference, and how can the policy arrangements be improved in the future?

A direct way to achieve the goals is to examine how residents feel and think about the residential environment before and after the urban renewal, in other words, how satisfied they are(were), and what they are(were) satisfied with, what they are(were) not. Furthermore, the research will compare the residential satisfaction level of those residents who remain in Qianmen with those who relocated to different neighborhoods, and identify the different experiences of residents' with various demographic and socioeconomic backgrounds. In addition, the research will test the significance of physical determinants, social attributes and policy factors in predicting residential satisfaction.

Through the investigation, this study has two goals: informing policy makers to improve future policy arrangements; and contributing to the understanding of forced moving from the experience of a developing country, since most of the studies in the field explored the phenomenon in advanced capital economies.

\section{- Structure of the Dissertation}

This dissertation includes seven chapters after this introduction. Chapter two gives a review of literature on residential satisfaction. It first discusses the conceptualizing of residential satisfaction. Then it analyzes the hierarchically spatial and multi-dimensional natures of the residential environment. It also provides a review of how the physical and 
social factors of the residential environment and the characteristics of an individual and a household impact residential satisfaction in residential satisfaction research. This review establishes an intellectual basis for the research.

Chapter three reviews the evolution of urban renewal practices in Beijing, which featured large scale market-oriented practices in the 1990s and a new public orientation entering the new century. Following the discussion of the context of the Qianmen urban renewal project, the short history of Qianmen and its physical, social and economic situations before the urban renewal, the urban renewal project and its related policy arrangements are introduced to provide the setting against which the life of the residents was impacted.

Chapter four, after presenting the research questions, introduces the population of the study and the data collection methods - the sampling strategies and the design of the interview questions. It also explains the quantitative and qualitative analyses that are mainly employed in the study. The limitation of the research design is discussed at the end.

Chapter five starts with a discussion of the three neighborhoods--Caochang, Longyue and Hongshan--where the participants live after the urban renewal. This provides the overall picture of the impacts of the urban renewal project and the advantages and disadvantages of living in these three neighborhoods. Based on this descriptive analysis, it uses quantitative analyses to look into the following questions: whether the residents are more satisfied than before; whether the residents living in different neighborhoods after urban renewal differ in their level of residential satisfactions; whether the residents with various 
demographic and socioeconomic backgrounds have different levels of residential satisfaction; and what is the significance of physical determinants, social attributes and policy factors in predicting residential satisfaction?

The quantitative analyses in Chapter five point to the variables significantly contributing to residential satisfaction: unit size, income and involuntary relocation. Mainly based on qualitative analyses, chapter six tries to clarify and explain the patterns of these variables impacting residential satisfaction. It starts by looking into the impacts of unit size and other related physical attributes. Then it discusses how residents with different incomes have different levels of residential satisfaction. The last part investigates how involuntary relocation contributes to a low level of residential satisfaction, and discusses how to obtain positive results when households are impacted by passive relocation.

The result of the simple ordinal logistic analysis in chapter five shows that residents' subjective evaluation of the impact on their social networks significantly contributes to the level of residential satisfaction. However, it does not significantly predict residential satisfaction when unit size, income and involuntary relocation are held constant. With the purpose of concerning social impacts of urban renewal as with previous seminal works, chapter seven further discusses the social outcomes of the Qianmen urban renewal project and how social factors impact residential satisfaction. It starts with a brief review of the existing literature, and then analyzes the original Qianmen residents' social interactions with their neighbors and their local intimates within their overarching social networks 
before and after the urban renewal. The last part looks into how social factors impact residential satisfaction. 


\section{Chapter 2: Residential Satisfaction Literature}

\subsection{The Conceptualizing of Residential Satisfaction}

Residential satisfaction has been identified as an important component of the broader concept of the quality of life, and compared with other aspects of quality of life, it is subject to potential influence by policy makers (Marans and Rodgers 1975; Campbell 1981; Lu 1999; Vera-Toscano and Ateca-Amestoy 2008). Therefore, residential satisfaction evaluations have been widely used in Europe and North America to inform public actions; and the issue of satisfaction with residential environment has long been one of the major topics in disciplines such as environmental psychology, sociology, and planning (Bonaiuto, Aiello et al. 1999; Lu 1999).

Referring to the three general categories of responses to any social object - affective, cognitive and behavioral---- residential satisfaction is understood as the affective response of residents to their social-physical environment where they live(María Amérigo and Juan Ignacio Aragoné 1997; Weidemann and Anderson c1985). In the view of Weidemann et al., this affective response is a function of a variety of variables: the characteristics of the residents, the objective characteristics of the residential environment, and the residents' perceptions about their residential environment. The perceptions represent the subjective characteristics of the residential environment, which is the cognitive aspect of three general categories of individual-residential environment interaction(Weidemann and Anderson c1985). They posit that apart from being treated as a residential quality evaluation criterion, residential satisfaction (affective) is also seen as 
a predictor of residential mobility behavior (behavioral) among factors such as subjective attributes of residential environment (cognitive) and objective attributes of residential environment and so on.

The model of Weidemann et al. helps us understand that the characteristics of the residents, the objective characteristics of the residential environment, and the residents' perceptions about their residential environment impact on residential satisfaction. However, what the model of Weidemann et al.neglected is the other side of an assessment involving the affective process of residential satisfaction, that is comparison standards. As Marans and Rodgers pointed out, how individuals assess their environment not only depends on how they perceive the environment but also the standards against which they judge the environment(Marans and Rodgers 1975). Actually, comparison standards are the benchmark based on which scholars conceptualize the notion of residential satisfaction--residential satisfaction measures the differences between households' actual and desired housing and neighborhood situations or how well the residential environment meets their needs or expectations(Galster and Hesser 1981; Lu 1999; Varady D. P. and Carrozza M. A. 2000). More specifically, if the actual situation is perceived to be in close congruence with households' needs or expectations, satisfaction is higher(Galster and Hesser 1981; Galster 1987); conversely, an incongruity results in a "housing deficit" in the words of Morris and Winter or an "actual-aspirational gap" in the words of Galster, which gives rise to residential dissatisfaction (Morris and Winter 1975; Galster 1987). 
Evidently, an individual's needs and expectations are not constant; therefore, residential satisfaction is a dynamic process. For Rossi, housing needs and aspirations change as households go through their life-cycle stages which causes the transition of family composition(Rossi c1955). Correspondingly, households continuously evaluate their housing, given their life cycle stages. When their housing does not fit with normatively derived needs and aspirations, the "housing deficit" will lead to one or more of the following three behavioral responses(1) residential mobility, (2)residential adaptation or (3) family adaptation (Morris and Winter 1975).

In addition, new experiences and increased levels of awareness might lead to new levels of expectations, and thus impact the residential satisfaction levels even holding all other environmental attributes constant (Varady D. P. and Carrozza M. A. 2000), whereas, the lack of options may lead to reduced expectations and high satisfaction levels (Heywood 1997; Varady D. P. and Carrozza M. A. 2000). This is particularly true, according to Birks and Southan, for residents of public housing who have few choices (Birks and Southan 1992; Varady D. P. and Carrozza M. A. 2000).

Scholars also found that residential satisfaction depends not only on the current actual situation, but also on households' past experiences(Galster 1987). For example, people who experienced low levels of service will have low expectations; as a result, they will be satisfied with levels of services that would be unacceptable elsewhere(Conway and Knox 1990).Using a survey conducted in Spain, Vera-Toscano et al. studied the relevance of social interaction on housing satisfaction. They found that renters tend to have lower 
housing satisfaction level when their neighbors mostly are homeowners. Thus, they concluded that social interaction (social comparison with a reference group) significantly contributes to housing satisfaction, since they believe that social norms(external norms) which are based on characteristics of the group members do play a major role in explaining individual behaviors(Vera-Toscano and Ateca-Amestoy 2008).

Actually an early seminal theory pointed out by Morris and Winter has addressed how external forms and family norms impact residential satisfaction. They theorize that households' judgments of their residential environment depend on normatively defined cultural norms (external norms)and family norms(internal norms)(Morris and Winter 1975). The family norms are dictated by the households' own needs and standards, therefore, they vary in the emphasis the households place on their own norms(Morris and Winter 1975), whereas the cultural norms are dictated by societal standards or rules. For example, according to Max $\mathrm{Lu}$, in the United States, a single-family, detached home surrounded by a well-landscaped lawn is perceived by the mainstream culture as the housing norm (cultural norm)(Lu 1999). In the view of Morris and Winter, people holding this cultural norm are likely to have a low level of residential satisfaction when they cannot achieve their desires due to financial or other constraints. Morris and Winter's theory helps the understanding of researchers interested in doing comparative studies on residential satisfaction in different cultural contexts (different cultural norms). 
Figure 2-1: A conceptual framework of residential satisfaction

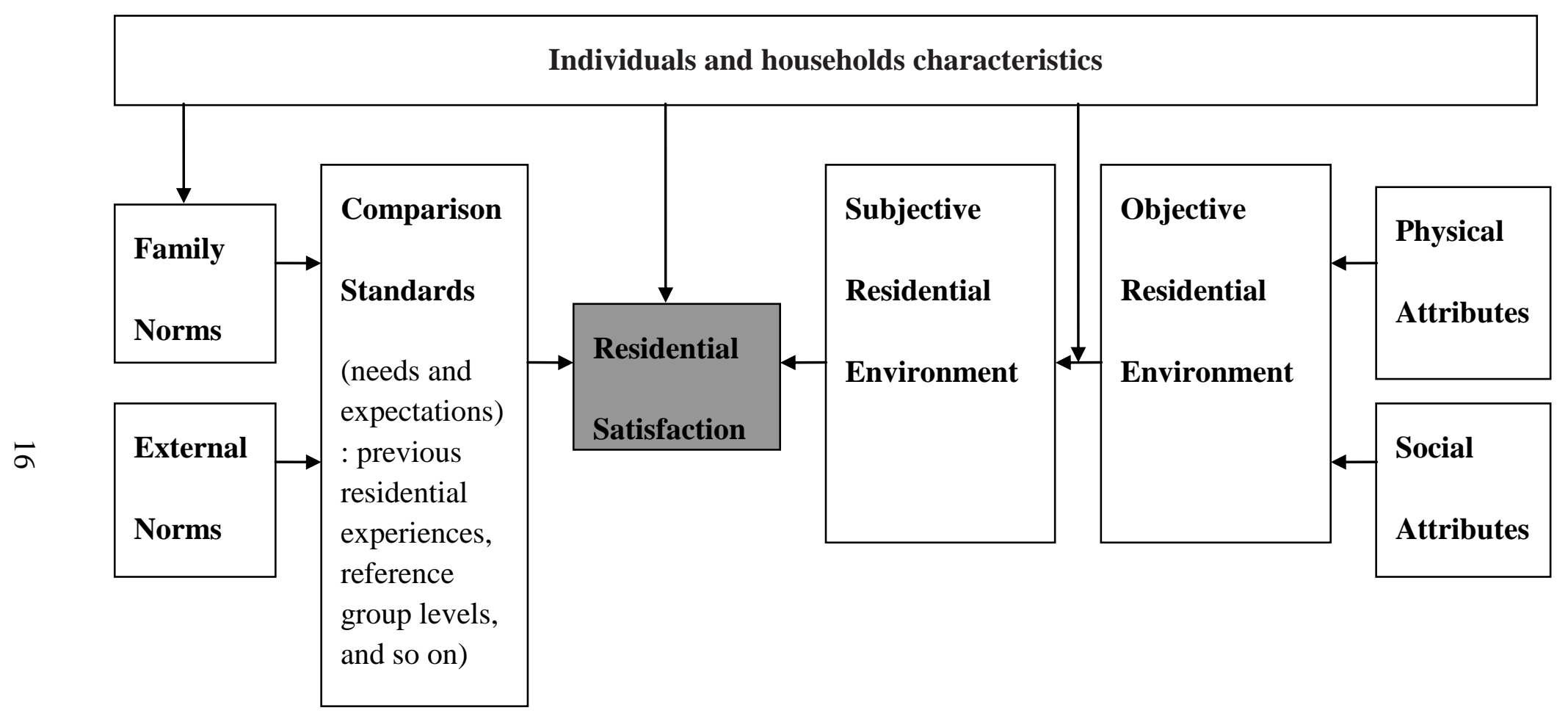

Resources: the framework was based on the works of Weidemann, Marans, Morris and others. 


\subsection{Residential Environment Typologies: Hierarchical Spatiality and Multi- dimensional Natures}

The other side of the construct of residential satisfaction is the residential environment, which has hierarchical spatiality and multi-dimensional natures. There appears to be a general agreement that residential environment is a hierarchical spatial system. For Campbell, the layers of the residential environment include a region, a community, a neighborhood, and a dwelling unit(Campbell 1981). In the model of Marans et al., the residential milieu is a system consisting of the community, the macro-neighborhoood, the micro-neighborhood, and the dwelling unit (Marans and Rodgers 1975). Practically, the layers of residential environment that mostly have been operationally measured in the existing literature are the neighborhood and the housing unit, although the satisfaction with the region and the community were sporadically addressed.

However, the spatial expression of each environmental layer has not been clearly defined and depends on the specific contexts in the existing literature. Nevertheless, the conceptual model of Marans et al. provides an effective way to operationalize the layers of the residential environment, in particular the layers of the neighborhood. For them, the macro-neighborhood refers to an area defined by grade-school districts or by major thoroughfares; while the micro-neighborhood means the immediate cluster of perhaps six or so adjacent houses(Marans and Rodgers 1975). 
On the other hand, as Campbell pointed out, "everyone occupies a location in space, a location which has physical, social and psychological characteristics." (Campbell 1981: 159), so residential environment has multi-dimensional natures.

Residential environment is firstly a physical entity. As one of the most important physical contexts for people's diverse roles and relationships, the location of residential environment mediates people's access to a variety of resources in the region----access to jobs, non-local public facilities, and natural areas among other resources. Other physical attributes of residential environment involve, for example, the layout, density and quality of the houses, the location, number and quality of facilities( schools, local grocery stores), gyms and open spaces (parks, public squares), and transportation convenience, among others.

Beyond the physical context, residential environment is also "the complex system of friendship and kinship networks and formal and informal associational ties rooted in family life and the needs of personal socialization" (Janowitz and Kasarda 1974). Social networks in residential setting, an indispensable component of personal networks in society, are vital to individuals' well-being; and on the other hand, individuals can suffer unpleasant social relations, annoyance and social problems in their residential environment.

Psychologically, through the interaction with the residential physical and social environment over time, individuals develop positive affective bonds toward their 
residential environment, which are expressed as a heartfelt attachment to place; and the main characteristic of place attachment is the tendency of the individual to maintain closeness to that residential environment (Kasarda and Janowitz 1974; Hunter 1978; Lee, Campbell et al. 1991; Mesch and Manor 1998; Bonaiuto, Aiello et al. 1999; Hidalgo and Hernandez 2001). Place attachment is thought to be multidimensional. Running through the literature, two dimensions widely identified are physical attachment and social attachment (Riger and Lavrakas 1981; Hidalgo and Hernandez 2001; Scannell 2003).

Furthermore, there is the distinction between the objective environmental attributes and the subjective (perceived) environmental conditions. For a number of scholars, such as Campbell, individual's feelings of satisfaction depend more on the subjective characteristics of the environment than on the objective attributes(Campbell 1981; Galster and Hesser 1981; Lu 1999; Parkes, Kearns et al. 2002; Grogan-Kaylor, Woolley et al. 2006), since, as mentioned previously, underling the construct of residential satisfaction is individuals' subjective evaluation, therefore, perception is more salient than reality. But still, objective attributes (such as neighborhood location, neighborhood density, housing size and so on), do have a certain level of power in predicting residential satisfaction. Therefore, to ignore the indirect relationship between objective attributes and residential satisfaction would risk the misinterpretation that objective attributes of residential environment are almost irrelevant to individuals' evaluation (Marans and Rodgers 1975; Fried 1982; Weidemann and Anderson c1985). 


\subsection{The Predictors of Residential Satisfaction}

As Rapoport argued, when home environments are evaluated, people choose or create a particular environmental quality profile(Rapoport 1985). This profile includes a variety of factors and varies in spatial scale. Most scholars arranged the factors around two dimensions, physical and social, and two spatial scales, housing unit and neighborhood (María Amérigo and Juan Ignacio Aragoné 1997; Weidemann and Anderson c1985). Furthermore, just as pointed out, the characteristics of individuals and households influence individuals' family norms such as needs and expectations among others; their subjective perception of the residential environment; and their evaluation process (the weight assigned to each attribute). Exiting studies have informed us that these characteristics may determine the level of residential satisfaction to a great degree.

\section{- Physical Attributes}

\section{Housing Space, Housing Quality and Tenure}

Scholars have identified the size of the housing unit as one of the most important factors predicting residential satisfaction. Family size, composition and stage in the life cycle determine the amount of space needed. In the U.S., it is often measured by the number of bedrooms, a living room, a kitchen and bath rooms; it is also directly measured by the area of the housing unit in some other contexts. The lack of space or overcrowding can lead to tension among family members and make them susceptible to disease(Meeks 1980; Liu 2005). Therefore, the size of the housing unit is a basic need for healthy living, thereby, a factor of great importance for the evaluation of residential satisfaction. Morris 
and others found that the amount of space available is positively associated with housing satisfaction(Morris, Crull et al. 1976; Liu 2005). Yiping Fang investigated the residential satisfaction of the original residents in four redeveloped inner-city neighborhoods in Beijing. She reported that unit size is among the factors most significantly predicting residential satisfaction(Fang 2006).

Another important housing attribute is housing quality. Researchers have attempted to measure housing quality by a number of factors. The physically inadequate housing stipulated by HUD in 1981, are housing units with possible deficiencies in the areas of plumbing, kitchen facilities, physical structure, common area fixtures, heating, and electronic systems(Liu 2005). Golant and others designed another measure including: dwellings without kitchens, without plumbing, with inadequate heating or cooling equipment, with plumbing or sewer breakdowns, with common-area deficiencies, and in a general state of disrepair(Golant and La Greca 1995; Liu 2005). Dwellings with various deficiencies are barriers to healthy living, thereby the inhabitants' well-being; whereas dwellings with sound quality allow them better to enjoy residential activities. Therefore, existing literature documented that housing quality significantly impacts residential satisfaction (Morris, Crull et al. 1976; Fried 1982; Zhu and Shelton 1996; Liu 2005).

In addition, studies have shown that tenure status is an important factor predicting housing satisfaction (Fried 1982; Crull, Bode et al. 1991 ). White and others for instance, found that home ownership increases individuals' well-being by producing a sense of stability and trust; therefore they more likely increase interactions with their neighbors 
and economic investment in their neighborhood (White and Schollaert 1993; Oh 2003; Liu 2005). Given the increase in well-being, to achieve home ownership many home movers would be willing to sacrifice other amenities (Burnley, Murphy et al. 1997; Wu 2004). Therefore, as shown in the literature, individuals who own homes express higher levels of residential satisfaction than those who rent (Fried 1982; Oh 2003).

\section{Neighborhood Density and Neighborhood Quality}

The significance of neighborhood attributes in predicting residential satisfaction has long been recognized by scholars. The study of Marans and Rogers identified satisfaction with the micro-neighborhood as the single most important contributor to the overall residential satisfaction(Marans and Rodgers 1975). For Fried, the impact of neighborhood and community variables on predicting residential satisfaction is even greater than that of housing variables(Fried 1982).

Neighborhood physical factors can be arranged around two dimensions: (1) density and related neighborhood environmental conditions, and (2) other attributes of neighborhood physical environment. Density has received considerable attention in the studies of residential satisfaction. Scholars found that individuals don't like living in high-density, and that those who do tend to experience lower residential satisfaction (Parkes, Kearns et al. 2002; Yang 2007). The investigation on the effects of high-density might be traced to studies as early as the 1930s. Wirth argued that high-density living causes individuals' undesirable behaviors and psychological problems, and increases social disorders, which put tensions on their daily life(Wirth 1938; Parkes, Kearns et al. 2002; Yang 2007). 
Furthermore, researchers acknowledged that the impact of high-density might not be direct, rather it is mediated by its related neighborhood environmental conditions such as lack of sunlight, noise, traffic congestion, crowding, and crime(Rossi 1955; Merry 1987; Yang 2007).

Other attributes of neighborhood physical environment that have received empirical support in relation to residential satisfaction include (Parkes, Kearns et al. 2002): (1)the availability and accessibility of public facilities: shops, community centers (or other leisure facilities), schools (Campbell 1981; Sirgy and Cornwell 2002; Liu 2005; Yang 2007); (2) transportation convenience: convenience to work, public transportation, parking(Campbell 1981; Sirgy and Cornwell 2002; Liu 2005; Fang 2006; Yang 2007); (3) environment: green spaces, outdoor play spaces or open spaces in the neighborhood; access to parks or other open spaces in large districts(Fried 1982; Sirgy and Cornwell 2002); (4)neighborhood appearance: buildings, landscape, and street lighting, pavement and sidewalks(Sirgy and Cornwell 2002); (5) upkeep of neighborhood properties and neighborhood environment(Sirgy and Cornwell 2002).

\section{- Social Factors}

As shown by the existing literature, local social interaction is an indispensable component of personal networks in the overarching society, and is vital to individuals' well-being. Thus, it is it is reasonable to expect that residents' relationships with their neighbors influence their residential satisfaction (Weidemann and Anderson c1985). 
The empirical findings about the significance of social factors predicting residential environment satisfaction could be traced as far as the well-known central city development area in Boston. Gans reported that because of the existence of families and friends, three out of four residents in the area had high satisfaction with the place which was considered a slum by outsiders(Gans 1982). Concurring with Gans, Janowitz and Kasarda found that people with more intensive friendship, kinship and associational bonds within the residential environment tend to have stronger feelings of attachment to the environment(Janowitz and Kasarda 1974). Campbell et al. identified neighbors as the strongest predictor of residential satisfaction(Angus Campbell, Philip E. Converse et al. 1975). Conversely, according to Marans et al, without neighbors who at least warrant neutral responses, an individual's feelings of satisfaction with his neighborhood would be relatively low, even in environment which offered good housing and other environmental amenities(Marans and Rodgers 1975).

Most recently, using Dutch Housing Demand Data, Adriaanse found that satisfaction with neighborhood social climate ( including the factors of socializing level, contact frequency, neighborhood cohesion), is the most significant component of overall residential satisfaction (Adriaanse 2007). A number of scholars sharing similar views with Adriaanse, agree that local social interaction is one of the most important factors contributing to people's residential satisfaction (Parkes, Kearns et al. 2002; Oh 2003; Grogan-Kaylor, Woolley et al. 2006). 
However, the findings of Campbell et al. were criticized by Fried and others. Fried argued that Campbell et al. did not note whether the positive evaluation of neighbors resulted from friendly social interaction or from interpersonal distance and respect for privacy, when treating neighbor as the strongest predictor of residential satisfaction(Fried 1982). Fried's own investigation reported that social interaction in neighborhood only plays a minor part in predicting residential satisfaction and its effects are limited to those individuals who value local social interaction(Fried 1982). The more recent findings of Baker and Arthurson echoed Fried's point of view. They investigated the social connections and housing outcomes for public housing tenants relocated due to the largest urban regeneration projects in Australia, and reported that compared with the factors of location and housing quality, friendship network is a less important component in the formation of residential satisfaction (Baker and Arthurson 2006).

These mixed findings remind us that the significance of social factors in predicting residential satisfaction warrants further investigation, and what might be more helpful for the understanding are two things. Firstly, since some individuals prefer privacy, while others prefer close social interaction, different population groups value social interaction to different degrees; therefore, the significance of social factors depends on population sub-groups. For instance, the lower SES individuals rely more on local social ties than individuals with high SES status; thus, it is reasonable to expect for the lower SES individuals friendly local social interaction is more important a factor to predict their residential satisfaction. This is supported by existing literature to some extent. The study 
of Amérigo and Aragonés on the residents of low socioeconomic status in the south of Madrid, Orcasitas, reflected that relationship with the neighbors is one of the two variables predicting most satisfaction(Amérigo and Aragonés 1990). However, the gap that still needs to be bridged is to measure the extent to which different sub-groups value friendly local social network, and then to look into the relative significance of social factors among other variables in predicting residential satisfaction.

Secondly, the effects of negative social factors in residential environment on lowering satisfaction level need to be look into systematically. As the existing literature has shown, beyond the positive effects of neighborhood interactions, neighboring does have its negative phenomena like conflicts and annoyance which make people dislike their neighbors. Some of negative factors have been identified as significant variables impacting residential satisfaction. For instance, the regression analyses of Amérigo and Aragonés shows that the factor of "Your neighbors meddle in your private life" significantly contributes to residential satisfaction. In addition, there is also evidence indicating that other neighborhood social problems, such as crime and unsafety, influence residential satisfaction (Sirgy and Cornwell 2002; Grogan-Kaylor, Woolley et al. 2006). However, systematic studies on the effects of these negative social factors are lacking in the established literature. This neglect might be a problem for the understanding of the influences of social factors on residential satisfaction, when these negative factors are prominent enough to neutralize the impacts of positive ones, or even are dominant in significantly lowering residential satisfaction level. 


\section{- Individual and Household Characteristics}

Existing studies have informed us that characteristics of individuals and households (socioeconomic status, life stage, gender, family composition, length of residence, and so on) may determine the level of residential satisfaction to a great degree, through impacting their family norms; their subjective perception of the residential environment; and their evaluation process (the weight assigned to each attribute). Scholars have identified two mechanisms to explain how these characteristics influence residential satisfaction.

The resources individuals have indicate the extent to which they can choose their residential environment congruent with their needs and expectations, thereby influencing their level of satisfaction. More specifically, resources, financial resources for instance, give individuals the power to choose or control the neighborhood where they live, in a competitive housing market; therefore, the more resources they have, the more likely they are satisfied with their residential environment (Parkes, Kearns et al. 2002; GroganKaylor, Woolley et al. 2006). This mechanism has obtained substantial empirical support.

The findings of a number of scholars show that individuals with higher incomes have greater residential satisfaction(Galster and Hesser 1981; Galster 1987; Lu 1999; Parkes, Kearns et al. 2002; Grogan-Kaylor, Woolley et al. 2006). However, although the study of Fried revealed that the higher the social class, the higher the level of residential satisfaction, he further argued that the level of residential satisfaction is not impacted directly by social status or minority status, but results largely from variations in 
residential environment (Fried 1982; Parkes, Kearns et al. 2002). Congruent with the points of Fried, Parkes et al., made similar arguments that in spite of the empirical findings of greater residential dissatisfaction among lower-income groups, socialdemographic variables alone are relatively poor predictors; rather, perceived residential environment attributes are a much better guide(Parkes, Kearns et al. 2002). The points of Fried and others might help us to understand why some scholars reached the conclusion that there are no big differences in the level of residential satisfaction between individuals of different social status(Amérigo and Aragonés 1990). Researchers further argued that individuals with higher social status tend to have higher standards and aspirations due to their social mobility, contributing to lowering their level of satisfaction (Freeman 1998; Liu 2005; Fang 2006).

Besides social status, Michelson identified another dimension-- stage in life cycle among others-- along which to distinguish individual or household preferences for specific residential environment attributes (Michelson 1977; Yang 2007).

With respect to stage in life cycle, Michelson noted that households without dependent children assign more weight on the access to consumer goods and services than do families with growing children(Michelson 1977; Yang 2007). Whereas, on the other hand, it is reasonable to anticipate that households with dependent children rate access to kindergartens, schools and outdoor play spaces or open spaces in the neighborhood more highly than their counterpart. The elderly tend to live longer in the neighborhood, and they often experience social isolation due to the loss of social ties with family members, 
friends, co-workers, and due to limited mobility impacted by poor health conditions; therefore they strongly attach to their neighborhoods physically and socially, and their neighborhoods offer them one of the main sources of social interaction and social support (Parkes, Kearns et al. 2002; Oh 2003). In addition, the elderly not only value neighborhood social interaction and social support more than young people in evaluation of residential satisfaction, but they are also more likely to have lower expectations and be more reluctant to undergo the strains of moving, which make them have greater residential satisfaction than their counterparts (Galster and Hesser 1981; Galster 1987; Lu 1999; Parkes, Kearns et al. 2002).

In terms of other characteristics like race and gender, their relationship with residential satisfaction has been inconsistent across the literature(Grogan-Kaylor, Woolley et al. 2006). The findings do not indicate that individuals with these characteristics do not have the needs and preferences for particular kinds of residential environment, it is just that the needs or preferences might be different even within the same sub-group categories, and the context conditions vary across the cases investigated. The investigation of Cook reveals that suburban single mothers value neighborhood quietness, access to local shops, and friendly neighbors more, while their counterparts in urban neighborhoods pay more attention to housing opportunities and discrimination in the housing market, although both of them are concerned with the neighborhood safety(Cook 1988; Parkes, Kearns et al. 2002; Liu 2005). 
There are also inconsistent findings as to the relationship between the factor of length of residence and residential satisfaction. For some scholars, length of residence is positively correlated with neighborhood satisfaction, since as mentioned foregoing, longer tenure facilitates community attachment physically and socially(Lu 1999; Oh 2003; Parkes and Kearns 2003; Fang 2006; Grogan-Kaylor, Woolley et al. 2006). However, a number of scholars do find inconsistent results, since, over time, the residential physical environment might be deteriorating; individuals might not get along with their neighbors; and their needs or expectations might be changed. Onibokun found that longer stays in subsidized housing in Canada are related to lower levels of residential satisfaction(Onibokun 1976; Fang 2006). Fang's investigation of the residential satisfaction of the original residents in four redeveloped inner-city neighborhoods in Beijing shares some similarities with Onibokun. Her study showed that length of stay (the number of months that households have lived in the neighborhoods) is one of the two factors among others significantly predicting residential satisfaction, and that households living in newer neighborhoods seem to be a little more satisfied than those living in older ones(Fang 2006).

\subsection{Conclusion}

Residential satisfaction has been identified as an important component of the broader concept of the quality of life, and compared with other aspects of the quality of life, it is subject to potential influence by policy makers. Therefore, residential satisfaction evaluations have been widely used in Europe and North America to inform public 
actions. Inspired by the view of Parkes et al. that "a single, unifying, subjective measure of the quality of neighborhood life appears to be an appropriate benchmark against which to measure the impact of many neighborhood attributes.” (Parkes, Kearns et al. 2002), this study is going to employ "residential satisfaction" as an evaluative indicator to understand the original residents' experiences before and after urban renewal.

The existing literature informs us that (1) residential satisfaction measures how well the residential environment meets the residents' needs or expectations; (2) the residential environment has hierarchical spatiality (neighborhood and housing unit) and multidimensional natures (physical, social and psychological), and factors of these multiple dimensions at various spatial levels predict the level of residential satisfaction to various degrees; (3) impacted by their external norms and internal norms, the residents' needs or expectations(comparison standards) are not constant and residents with different economic, social and demographic status might have various needs or expectations, thereby their different evaluations of residential satisfaction; and (4) the characteristics of individuals and households (socioeconomic status, life stage, gender, family composition, length of residence, and so on) may determine the level of residential satisfaction to a great degree, through impacting their family norms, their subjective perception of the residential environment, and their evaluation process (the weight assigned to each attributes).

The review of this chapter establishes an intellectual basis for the study. It will look into how the residents' residential satisfaction in the Qianmen case is predicated by the 
physical attributes of the residential environment in terms of both the neighborhood and the housing unit, and the social factors of the residential environment; and how the demographic and socioeconomic characteristics of the residents contribute to their residential satisfaction. Beyond the coverage of this review, the study will also explore the impacts of policy arrangements on residential satisfaction, in particular the outcomes of involuntary moving. 


\section{Chapter 3: Urban Renewal in the Beijing Context}

This chapter reviews the evolution of urban renewal practices in Beijing, which featured large scale market-oriented practices in the 1990s and a new public orientation entering the new century. Following the discussion of the context of the Qianmen urban renewal project, the situations in Qianmen area before the urban renewal project and its related policy arrangements provide the setting against which the life of the residents was impacted.

\subsection{The Evolution of the Urban Renewal Practices in Beijing}

The evolution of urban renewal practices in Beijing can be divided into three phases: a public-led experimental phrase in the 1980s; a large scale market-oriented phrase in the 1990s; and a new policy orientation entering the new century.

The program of urban renewal in Beijing was initiated in the late 1980s with the purpose of improving the dilapidated living conditions of inner city residents. The public sector was in the dominant position. Constrained by limited financial resources, just a few projects were implemented in the way of keeping large portions of original residents on site and respecting the historic contexts of the inner city(Fang 2006; Qian 2009).

\section{- $\quad$ Large Scale Market-oriented Phrase in the 1990}

After the experimental phrase, large scale inner city urban renewal practices, thus residents' displacement in Beijing, occurred in the 1990s, which was imbedded in the overarching theme of China's economic reform. 
Along with a series of market-oriented reforms, the underlying forces of urban (re)development in China were fundamentally changed. As an important part of the economic reform, fiscal and administrative decentralization endowed the local state with a significant role to play in economic and urban growth. In this context, local governments feature entrepreneurial actions to pursue rapid economic growth/revenue raising in the post-reform era. Scholars found that land and housing (re)development became a major source of local revenue(He 2007). Tingwei Zhang (2000) explored the factors encouraging the actions of local governments eager to get revenues from leasing land. According to Zhang, one of the important arrangements of the economic reform was the fiscal reform where a tax sharing arrangement between the central government and local governments was adopted. Before the reform, the central government provided funding to almost all local development projects. The new revenue distribution regulation entitled local governments to share tax revenue, but it cut most development funding from the central government under the tendency of decentralization. A local municipal government now has to find its own funding for infrastructure projects and most of its welfare programs. Since land is the most valuable "commodity" under the control of a local government, generating revenue from leasing land use rights and charging land use fees has become the most popular practice of local governments (Zhang 2000).

Clearly, local governments have vested interests in urban (re)development because they can expand local tax base by leasing land. On the other hand, under the decentralized urban governance, local governments find that they have to rely more on the market to 
achieve governance functions. In order to solve the problem of financial deficiency in urban renewal projects, local governments justified "property-led" urban renewal in the 1990s (He and Wu 2007; Lees, Slater et al. 2008; Qian 2009). However, the involvement of real-estate developers led to the demolishing of many old neighborhoods to make room for commercial buildings and/or high-end housing. To capture a greater share of benefits from the redevelopment, developers also tried to reduce the compensation standard and constrain the amount of returned households. As a result, a large scale of original residents was displaced to low-cost suburban areas.

We can see local governments play a dual role in market-oriented urban renewal: on the one hand, local governments undertake the responsibility of maintaining social stability by ensuring the improvement of housing conditions for the residents; on the other hand, local governments achieve other purposes, such as generating revenue and improving urban images to promote local economic development, by facilitating urban renewal projects. In the words of $\mathrm{Wu}$, such a dual role causes a dilemma between the government behaviors of delivering welfare and redistributing wealth and the entrepreneurial behaviors of pursuing maximum benefits(Wu 2004).

What happened in China shares some similarities with gentrification phenomena in the western cities in the neoliberal era. In the western world, the predominance of urbanentrepreneurialism urban policy in the neoliberal era makes strong government involvement an important factor affecting urban renewal by providing incentives and financial subsidies to attract private capital (He 2007; Lees, Slater et al. 2008)) The role 
of the government in the process is more as an entrepreneurial agent of market processes and capital accumulation, rather than as a regulator of the market, protecting marginalized residents(Lees, Slater et al. 2008). Its profound influence on restructuring social and physical landscapes in Western cities aroused intense theoretical and ideological debates.

As in many cities in China, during the 1990s, the Beijing municipal government played a dual role in market-oriented urban renewal practices. On the one hand, in the face of the severe housing shortages and the need to increase housing, the Beijing municipal government involved private investment and market forces to solve the problem of financial deficiency in urban renewal. On the other hand, the market-oriented urban renewal practices generated a large amount of revenue for the government through leasing land use rights and charging land use fees. The investigation of Li shows that the sales revenue of land use rights in Beijing reached more than twenty percent of municipal government income in the middle of 1990s( $\mathrm{Li} 1999)$. However the cost of this urban renewal model is that to maximize profits, real-estate developers bulldozed historic urban areas to build high-rise commercial buildings and residential buildings for high-income people, while most of the original residents were displaced to the suburban areas and suffered from the negative social and economic results of the relocation.

\section{- New Policy Orientation}

Entering the new century, recognizing the increasing inequity and related social problems, China's central government initiated the national policy of building a harmonious society. 
Under this political context, also due to the constant complaints about disappearing historic Beijing features and the bitterness of original residents and other corresponding social problems during the last decade, urban renewal practices in Beijing experienced a big change entering the new century. This change was built upon a series of policy arrangements. The Master Plan of Beijing (2004-2020) was approved by the central government in 2005. Before that, several government regulations and official documents had been put into place, among them, "Conservation Planning for Beijing's 25 historically and culturally significant precincts" issued in 2002, and "The Way of Urban Housing Demolition and Management in Beijing City” issued in 2001 (No. 87 Document) are the most important.

The new policy arrangements feature a government-led approach rather than a marketoriented one, which was the mainstream approach dominating urban renewal projects during the previous decades(Liu 2005; Qian 2009). More specifically, the new policy arrangements require that the implementation of urban renewal projects is more government-led with a large amount of public investment and only a very limited involvement of real-estate developers; and its purpose is not for profit but for the improving of residents' living conditions, for the protection of historic urban areas, and for other social considerations. Furthermore, urban renewal projects in old historical neighborhoods should be practiced in small-scale gradually, named "microcirculation" (weixunhuan): depending on the conditions of housing units (courtyard houses), those in good conditions are rehabilitated rather than demolished, those in very dilapidated 
conditions are removed to build new buildings consistant with the surrounding courtyard houses. This is quite different from the previous practices of displacing historic buildings with new high-rise buildings.

The new policy arrangements also require that urban renewal projects take into account the extensive opinions of the original residents. As a legal requirement, the urban renewal plan must be posted publicly in the neighborhood so that the residents know what will happen next and have an opportunity to express their ideas to the decision-making body(Qian 2009). Except in a few special cases, such as public infrastructure construction, relocation is no longer compulsory. A household can make its own decision about where to live after urban renewal. They can remain in the original neighborhood; get monetary compensation and find a housing unit on the market or apply for an affordable housing unit (one type of subsidized housing also called "Economical and Suitable Housing"); or be re-housed in a "similar" housing unit which is located within the boundary of the urban area with floor space no less than the original housing unit. The standard of monetary compensation for housing demolition was calculated using a formula which reflected the market value of the property. Therefore, urban renewal projects under the new policy orientation involve a high degree of residents' participation. 


\subsection{The Qianmen Urban Renewal Project}

Under the new urban renewal policy orientation, a few demonstration projects were beginning in 2005. Qianmen is one of them. With an area of 1.09 square kilometers (109 ha), Qianmen is located in the core of the capital city, just a short walk from the Forbidden City, Tiananmen Square, the Great Hall of the People, and Tiantan Park among many political, cultural and commercial attractions. It is an urban area with rich historic and cultural significance. Based on these merits, Beijing municipal government listed it as one of "Beijing's historically and culturally significant precincts" in 2002 . The urban renewal project is also one of the many projects in preparation for the Beijing 2008 Olympics. In this context, the local government put special efforts to the urban renewal project to achieve positive results, which makes it the perfect case to understand how policy arrangements can make positive outcomes.

\section{Figure 3-1: The location of Qianmen}

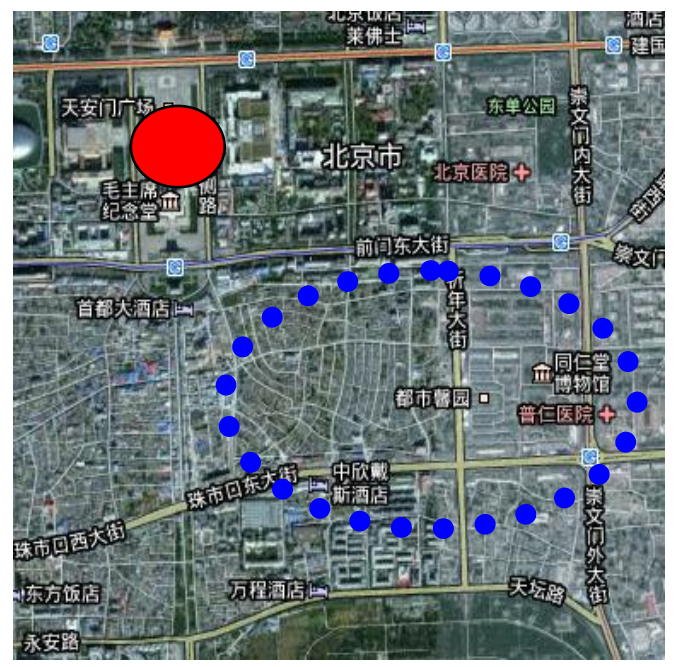

Note: Tiananmen Square is located at the red dot; Qianmen is the area surrounded by the circle. 
Figure 3-2: The image of Qianmen

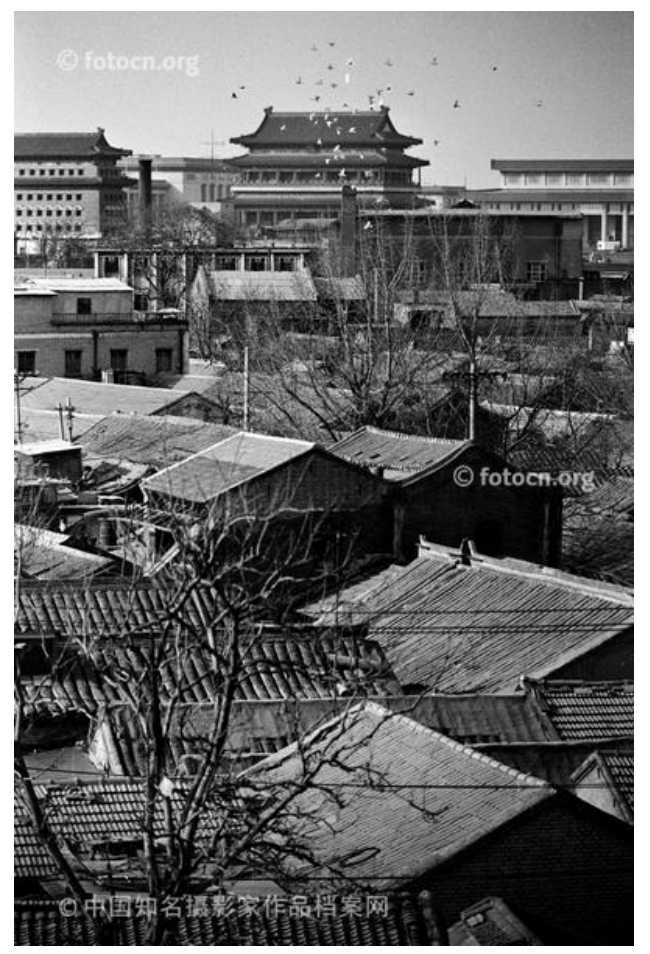

Resource: Liu, Yingyi. (1999). Qianmen area [Photo].Retrieved from http://www.fotocn.org/liuyingyi/32484

\section{- The Original Area: Qianmen}

Historically, this area got its name from the towering gate-- Qianmen (front gate), the grand south gate, one of the important landmarks and entrances to the old imperial city. The booming of this area dates back more than 400 years to the Ming Dynasty. Since then it gradually became one of the three traditional commercial areas in Beijing with markets and shops selling featured foods, traditional Chinese medicines, fine silks, and so on. The main commercial street--Qianmen street-- has been famous across the country, 
and the names of several alleys, such as Xianyukou(fresh fish) lane and Buxiangzi(clothing) lane are still indicative of the past .To the east of Qianmen Street was the neighborhood where merchants and ordinary Beijing people lived.

Entering into the reform era, the old residential neighborhood became marginalized during the dramatic economic growth process. Before the renovation started in 2005, around 50,000 residents (20, 000 households) lived in this area, with the majority of them low income people. The investigation by Beijing Academy of Social Sciences shows that $71 \%$ of the residents were either retired or unemployed; therefore, the average individual income was 1000 Yuan per month(Zhu 2005), compared with the city-wide average of 1471 Yuan(Lu, Tang et al. 2011). Many residents (more than 40\%) were in their forties and fifties, with average age 55.2 years(Tomohiko Yoshida 2005?), while the city-wide percentage of residents in their forties and fifties was 31.1\%(Qian 2009). As "the Master Plan of Beijing (2004-2020)"documented, this was a neighborhood where the elders and low income people concentrated.

Within the historic neighborhood, hutongs formed by the joining of traditional Chinese courtyard houses were situated either along or toward a stream that used to wind through the neighborhood, which made them feature curved lines. Due to this special layout embodied mostly by Caochang neighborhood, and the strong commercial tradition of the area introduced above, Beijing municipal government listed it as one of "Beijing's historically and culturally significant precincts" in 2002. Most of the hutongs were too narrow for cars, thus walking and cycling were the major travel options. Besides their 
transportation role, hutongs were also the frontage of some small family-owned grocery shops, barbershops and small restaurants. In addition, hutongs were lively places where children used to play, old men exchange stories, and vendors sell goods. Clearly, they used to function as neighborhood living rooms accommodating the life of ordinary people and their vibrant street cultures.

Figure 3-3: The street life in Qianmen before the urban renewal
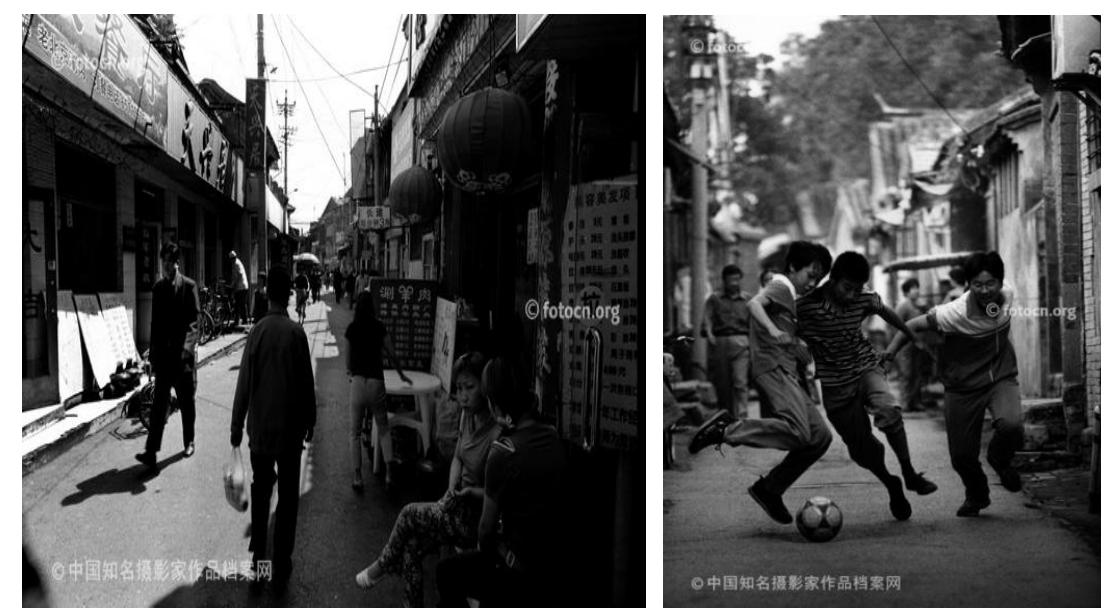

Resource (Left): Liu, Yingyi. (2005). Xianyukou [Photo].Retrieved from http://www.fotocn.org/topic/83-32663

Resource (Right): Liu, Yingyi. (1999). Qianmen area [Photo].Retrieved from http://www.fotocn.org/liuyingyi/32507

The majority of the residential buildings in the historical neighborhood were courtyard houses (Si-He-Yuan) with the feature of low buildings grouping around one or several central courtyards. A courtyard house was originally owned by and built to house one family, but since the 1950s, many were converted to house several families. Their tenure status mainly evolved into two types: public housing rental (government or work-unit 
owned and the rent was low), or owner-occupied (home ownership). An investigation targeting the whole neighborhood showed the percentage of the former was $62.5 \%$ (Tomohiko Yoshida 2005?). Generally, privately owned housing was in relatively good condition; however, public housing was in much worse condition due to high density and lack of maintenance constrained by limited budgets.

In the pre-reform era of China when the socialist government's investment favored the production sector over the consumption sector, investment in the housing sector was limited. Compared with other China's cities, Beijing, as the capital city, was granted substantial resources to provide new housing and rehabilitate existing housing stock(Lian 1995). However, considering its huge population growth, investment in the housing sector was still pitifully limited. This resulted in severe housing shortages and dilapidation. In old city areas, the situation was even worse. It was not uncommon that a family grew over the years but stayed in the same house. Shabby extensions without sunlight or even natural light were built in courtyards to increase living space. Qianmen area was one of the most crowded old city areas in Beijing. Its overcrowded condition was clearly reflected by the fact that the average unit size in Qianmen was only 21 square meters (about 226 square feet) (Zhu 2005), whereas the average living space per capita was 21.55 square meters (about 232 square feet) across the whole capital city(Tomohiko Yoshida 2005?). The high density put tensions on residents' daily life. They were often bothered by various conflicts or/and annoyances with their neighbors, such as fighting each other over space, electricity bills and so on. 
Limited investment in housing and low rent led to housing dilapidation as well, since the costs of high-level maintenance could not be covered. After decades of neglect on repair and maintenance, the investigation of Beijing University of Civil Engineering and Architecture found that housing poorly maintained accounted for $50 \%$ of the total housing stock in Qianmen area, and that 5\% was unsuitable or even dangerous for inhabitation. The poor housing conditions that residents complained of include: unsafe structures, such as crumbling walls and rotting wood beams; leaky roofs that let rain water drips inside in summer whenever there wass a heavy downpour; old wood windows and doors with low energy efficiency and bad soundproofing. Lacking timely maintenance, residents had to do some DIY repair works to keep their homes livable.

Besides high density and poor maintenance, traditional courtyard houses posed modern problems. Courtyard houses did not have adequately equipped kitchens, most of which were in shabby extensions. Most courtyard houses also lacked bathrooms, which meant residents had to use public toilets situated along hutongs. Without gas lines, coal stoves were often used for heating and sometimes used for cooking as well, since electricity was less affordable than coal. Water taps usually had to be shared by several families. Although a few better-off households with bigger unit size equipped their house with relatively modern kitchens and bathrooms, they were criticized by their neighbors at times for using more water or electricity due to the shared water and electricity bills.

At the neighborhood level, the disadvantages of living in Qianmen mainly included: (1) distant transit services because the hutongs and alleys in the area were too narrow for 
buses and cars; (2) the accumulation of rain water in some courtyards and hutongs when there was a heavy downpour in summer, because the drainage system was too old to drain the water away in time; and (3) the vulnerability to fire damages because kitchens were often in shabby extensions and it was extremely difficult for fire trucks to access the house on fire through narrow hutongs.

But were there also good things about living in the neighborhood? The answer is "of course". It was surrounded by the Forbidden City, Tiananmen Square, Tiantan Park and Qianmen Street among other nationally famous attractions. Many residents loved to visit these attractions on a regular basis and were very proud of being in the vicinity of them. In addition, rich first-class public facilities such as key public schools and hospitals were located within or around Qianmen. With its central location, residents could also easily access jobs and other resources. Moreover, grocery stores, barbershops and small restaurants were just around the corner.

Moreover, for many residents whose families had lived there for generations, their neighborhood was cozy and filled with memories, to which they felt strongly attached. They enjoyed the lifestyle in hutongs: chatting with neighbors casually, playing Chinese chess under ancient trees, roaming around in the morning and evening, hearing the voices of the traveling peddlers and watching children playing in the hutongs. So rich and real was the life outside in hutongs. Closing the door, the life inside in courtyards, on the other hand, could be quiet, peaceful, or even secluded (courtyard houses offer privacy from others) for some households who owned the whole courtyard house. And for some 
residents, especially the elderly, the one-story courtyard houses were convenient and one could feel the spirit of the earth (Qi), which was thought to be good for human health due to the human need to be connected with nature.

The residents liked the life here for another reason, that is, the relationships between neighbors were different. As mentioned above, the hutongs served as the living room, many courtyards were shared by several families, and most of the residents needed to use public facilities situated along the hutongs. All these featured built environments which underpinned rich social interactions among neighbors. In addition, many residents in similar social status had lived here for generations with very low level of mobility. Years of common residence created common values to maintain a friendly spirit and help each other readily in everyday life and whenever emergencies occurred. Therefore, not only did people feel friendly and safe in the neighborhood, but the social support networks helped them get through pressures and difficulties, because, for many of them, neighbors were not just neighbors, they were friends, and for some, extended family members.

The above attributes made Qianmen a nice place to live, in particular for the residents with bigger units. With a bigger unit, their housing needs could be basically satisfied, and the above attributes were good enough to offset the shortages; it was even worth sacrificing modern amenities to stay. For low income residents with small units, it also could be a viable place to live for the following reasons. It was an ideal place to run family-owned shops and other informal businesses such as a stand fixing bikes, which would provide extra income. The living costs in Qianmen were low: both rent and the 
corresponding utility fees were rather low with a small unit, and good accessibility to jobs and public facilities saved their transportation costs as well. As shown above, $71 \%$ of the residents were either retired or unemployed, thus, gaining extra money from family-owned shops (and/or other informal businesses) and saving living expenses was crucial for them.

However, for many it came down to the issues of space. The fact that 50,000 residents lived in 1.09 square kilometers (109 ha), 21 square meters (about 226 square feet) each family, had to be changed. And there is no doubt that the dilapidated neighborhood in lack of modern facilities did not fit the needs of most residents. Moreover, due to the deteriorating conditions in the area, some of the better-off moved out gradually and rented their housing units to migrant workers who usually were considered by the original residents as trouble makers. This demographic change undermined the base of local security and community cohesion. The transformation of the once stable homogenous community brought new social problems, such as suspicions on loss of personal belongings. Under these circumstances, it is not difficult to imagine how the residents were eager for the renewal of the neighborhood, which they believed could bring them more living space and better quality.

\section{- The Renewal Project}

As a demonstration project, the Qianmen urban renewal project started around 2005 under the new policy orientation of urban renewal practices in Beijing. It is the first time that a large-scale public-funded (six billion Yuan) urban renewal action targeted this area 
since the founding of the People's Republic of China. As in a few flagship public-initiated projects, the district government took overall responsibility in organizing the renewal project; a public-owned development corporation was established to undertake the project, and some experts and professionals were invited to give suggestions on the project proposals. Although a private real estate company was involved in the early stage, attracting private investment was no longer the prime aim. Instead, the purposes of the project, according to the public documents, were to improve the residents' living conditions and to protect the historic urban area. Meanwhile, what was not included in the public documents, but hard to deny, is that the beautification of "local images" was another big concern of the government, since Beijing Olympic marathon runners would pass through historic Qianmen Street.

In 2005, the urban renewal project started with the redevelopment of the commercial area, the west part of Qianmen area, mainly Qianmen Street and two other hutongs-Xianyukou(fresh fish) lane and Dajiang lan-- connecting directly with Qianmen street. In addition, road construction and infrastructure updating were implemented in the whole area. Caochang neighborhood started to be renovated in 2007. All the above projects were done before the opening of the Beijing Olympics, while the renovation of the courtyard houses in the other neighborhoods of the area was still underway. According to the new version of "Development Plan for Qianmen Historically and Culturally Demonstration Precinct" issued in 2012, the west part of the Qianmen area will feature its traditional commercial function, cultural industries and tourism will be introduced in the 
central area to make the project financially viable, while residential function will be retained in the east part (mainly Caochang neighborhood).

Although relocation was no longer compulsory, the district government encouraged the residents to move out, given the high population density of the area and for the reason that many courtyard houses would be preserved and new construction would be built in a way congruent with the surrounding low-density historic buildings. In addition, the district government has been trying to make room for the development of non-residential functions, to balance the burdens of public finance. In this context, most of the households moved out after urban renewal.

According to the general secretary of Qianmen area, up until the summer of 2009, 17,000 households moved out and 3,000 stayed. Among the households relocated, about one fifth of the households chose Hongshan (an affordable housing neighborhood located in the central city area) and one fifth moved to other affordable housing neighborhoods (Longyue located in a suburban area is one of them) respectively. The other three fifths got monetary compensation and used the compensation to purchase commercial housing or rent from the market. Among the households that stayed, about 1,000 households live in Caochang, and the others are dispersed within the whole Qianmen area. 
In the first round of moving out from 2005 to 2007, residents who did not choose to stay received monetary compensation depending on the size and ownership ${ }^{1}$ of their original housing units. They could use the money to find their own housing in the market or apply for affordable housing which they were given priority to access. The average unit size in Qianmen area was 21 square meters (about 226 square feet) (Zhu 2005). With this unit size, a public housing tenant could get compensation of 300,000 Yuan, which could cover the cost of purchasing an affordable housing unit with the size of 100 square meters (about 1, 076 square feet) (the price of affordable housing located in suburban areas is 2,600 Yuan per square meter, far less than the price of commercial housing) and its remodeling and decorating. However, most of the affordable housing resources were located in suburban areas back then. Therefore, just one fifth of the residents who moved out fell into this category. The residents who were not willing to move to the suburbs and/or did not like other qualities of affordable housing had to purchase commercial housing or rent from the market. Three fifths of the residents who moved out fell into this category and the decision of relocation was by their own choices, except in a few cases where relocation was compulsory for public infrastructure construction and other public interests.

Among the stayers, there were three types of households: (1) Households who wanted to stay, usually households with bigger unit size who were happy to stay after the

1 The formula for calculating monetary compensation is: 8020 Yuan $\times$ net area $\times 1.333+$ other subsidies. The public tenants were required to buy their housing units at a subsidized price (135 Yuan per Square meter) before getting monetary compensation. 
infrastructure and housing facilities got improved: (2) Households who could not afford to move out either because they did not accept the affordable housing's location (qualities), and could not afford commercial housing at the same time; or because they had such a small unit that with the small amount of compensation and low income they could not even afford the affordable housing though they would like to move to suburbs; and (3) Households who were expecting a better offer.

After the first round, to help the stayers who could not afford to move out, the district government provided another way of compensation in 2007: to be rehoused in Hongshan affordable housing neighborhood which is located in the central city area. According to the new compensation policy, when households moved to Hongshan, they could get their unit size increased by $70 \%{ }^{2}$ for free, and they were also offered a subsidized price to buy extra room. The subsidized price was 4,900 Yuan per square meter, about half the price of commercial housing in the area. Considering most of the stayers had small units, the new compensation policy set the baseline of 13.1 square meters (about 141 square feet) as the original unit size to calculate the size of rehoused units in Hongshan, for those households with an original unit size below the baseline. This means that a household, regardless of its income, could get at least 22.27 square meters (about 240 square feet) free of charge in Hongshan. The new policy provided extra aid to low income households. For households who can't afford to buy extra space, up to 20 square meters (about 215 square feet) were provided for them to rent as public housing tenants (the monthly rental

\footnotetext{
${ }^{2}$ For housing owner, the percentage is $85 \%$.
} 
was 3.5 yuan per square meter). Moreover, for those low income households covered by the minimum living allowance, rental-subsidized public housing based on their family size rather than their original unit size was offered in Hongshan. Under these circumstances, the relatively high income households who did not want to relocate to suburban areas and could afford to buy commercial housing in the central city area, got access to affordable housing located in the central city area; with all kinds of aid, the low income households got their living space increased and quality improved in Hongshan as well. As a result, one fifth of the households that relocated moved to Hongshan.

After the two rounds of moving out, the stayers now included households that wanted to stay, and households that still could not afford to move out, mainly low income households which were not covered by the minimum living allowance. They usually had more family members but smaller unit size, which means they needed a larger living space, but would only get a small space in Hongshan for free. They did not have enough money to buy extra space. And according to the compensation policy, they were only qualified to rent up to 20 square meters (about 215 square feet) public housing in Hongshan, rather than a bigger unit size based on their family size, for they were not covered by the minimum living allowance. Under these constraints, what they could get was quite far from meeting their housing needs; thus, they had to stay and hoped that the government could address their problems.

For those stayers dispersing in the other neighborhoods in Qianmen area, the district government encouraged them to relocate to the Caochang neighborhood by offering a 
bigger unit than their original one as an incentive. Up until the end of the field work of this study, 40 households had relocated to Caochang. Certainly, there has been a group of stayers who keep expecting more, for the reason that they might add costly delays to the project by becoming "nail households" (dingzihu). In this way, they sometimes could hold out for better compensation (larger apartments or extra cash), for the negotiation on compensation to some extent operated in a black box, even though there are official documents clearly explaining how households get compensated.

Actually it was not uncommon that residents with better negotiation skills ended up with more compensation. Residents who were not treated fairly complained about this sort of unfairness. The residents were not happy with the fact that although the compensation price was assessed by a third party not the government, which is considered as a way to protect households' benefits, it was still too low because of the out-of-date standards used to assess. The residents also complained that all households got the same compensation price regardless of the quality of their housing.

In spite of these weaknesses, compared with many of the previous practices, it is not hard to see that the policy arrangements implemented in the Qianmen urban renewal project offered more options for the households and provided extra aid to low income households that helped them benefit from the relocation. Under the new policy arrangements, households could get monetary compensation to buy affordable housing which they were given priority to access; could be rehoused in the Hongshan affordable housing neighborhood located in the central city area; or could get monetary compensation to buy 
housing from the market. If households were not happy with all the compensation options, they could stay, except in a few cases where relocation was compulsory for public infrastructure construction or other public interests. They made the decision based on their own needs, which formed a solid base for them to get positive results. Moreover, the new policy arrangements provided extra aid to low income households, in particular in the second round of moving out: increasing their baseline size of compensation to 13.1 square meters (about 141 square feet), offering them up to 20 square meters (about 215 square feet) to rent with subsidized price, and proving rental-subsidized public housing based on family size rather than original unit size to those low income households covered by the minimum living allowance. The above features indicate that as a demonstration project, the policy arrangements in Qianmen project under the new policy orientation of urban renewal in Beijing showed efforts to resume more of its role in delivering welfare and redistributing wealth, and to involve more publics' opinions by offering them multiple options.

Nevertheless, we have to accept that the decision mechanism was still a top-down model- the district government had the dominant power to make decisions on renovation objectives and strategies, as well as the allocation of most public funding and resources. Under this strong institutional constraint, although the residents were empowered with more choices to make decisions based on housing needs to a greater extent rather than forced relocation, they seldom got a say on such important decisions as when they moved, how much the compensation standards were, how Qianmen area was going to be 
developed and how the affordable housing should be designed Some residents tried to express their opinions, but their voices were rarely heard, which means much more still need to be done to promote public participation.

The debate over the "pluses" and the "minuses" of the Qianmen project is still underway. This study looks into the results through investigating the experiences of the original residents before and after the urban renewal. 


\section{Chapter 4: Research Design}

\subsection{Research Questions}

The study examines the influences of the urban renewal project on the original residents of Qianmen area. Did they suffer from the physical, social and/or economic costs of urban renewal as was widely documented by the available literature, or did they take the opportunity of relocation to improve their residential environment? It is particularly concerned with the social impacts of urban renewal as with previous seminal works. And further how did the policy arrangements contributed to these outcomes, and how can the policy arrangements be improved in the future?

Inspired by the view of Parkes et al. that "a single, unifying, subjective measure of the quality of neighborhood life appears to be an appropriate benchmark against which to measure the impact of many neighborhood attributes." (Parkes, Kearns et al. 2002), this study is going to employ "residential satisfaction" as an evaluative indicator to understand the original residents' experiences before and after urban renewal. It is an exploratory inquiry rather than a positivist deductive testing with preconceived hypotheses. More specifically, the study explored the following questions:

(1) Whether or not the residents are more satisfied with their residential environment after the urban renewal than before? And what they are (were) satisfied with, what they are (were) not? 
(2) Do residents relocated to different neighborhoods have different levels of residential satisfaction? And are residents with various demographic and socioeconomic backgrounds different in the level of residential satisfaction?

(3) What is the significance of physical determinants, social attributes and policy factors predicting residential satisfaction?

By examining these questions, the study evaluates the results of Qianmen urban renewal project from the perspective of residents' experiences, based on which policy implications will be made. Related to these empirical questions, the study sheds light on the ongoing debates about the urban renewal processes and outcomes between a predominantly negative displacement view embedded in a gentrification discourse, and a more open, balanced view for analysis of urban renewal processes and outcomes in different social economic and cultural contexts.

\subsection{Research Design}

\section{- The Population}

The study investigated both the residents who remain in Qianmen area and the residents who moved out of Qianmen after the urban renewal.

As introduced in chapter three, among the 20,000 original households in Qianmen, 17,000 households moved out and 3,000 remained as of the summer of 2009. Among the households that stayed, about 1,000 households live in Caochang, and the others are 
dispersed in the whole Qianmen area. Among the households relocated, about one fifth of the households chose Hongshan (an affordable housing neighborhood located in the central city area) and one fifth moved to other affordable housing neighborhoods (Longyue, located in a suburban area, is one of them) respectively; the other three fifths got monetary compensation and used the compensation to purchase commercial housing or rent from the market.

Based on these situations, the study mainly targeted three groups of post-urban-renewal residents who live in Caochang, Hongshan and Longyue (Fig.4-1):

(1) Caochang is the neighborhood where most of the stayers live and which had been renovated by the time the field works of this study started.

(2) Hongshan is the neighborhood which accommodates the most relocated households. They represent the households who were rehoused in the central city area.

(3) Longyue is the suburban neighborhood where the relocated households could be tracked. They represent the households who got monetary compensation and moved to affordable housing neighborhoods in suburban areas after urban renewal. 
Figure 4-1: The location of the three neighborhoods

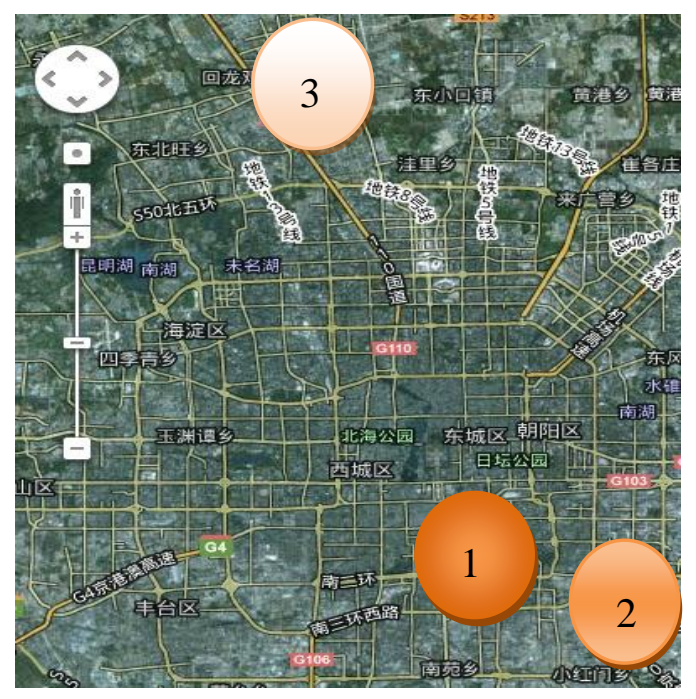

\section{- Data Collection and Analyses}

The research is mostly based on primary data from in-depth interviews, and to a lesser extent based on statistical data, content analysis of public documents and other media. It began with interviewing officials and planners to get background information about the urban renewal project and the targeted population (see appendix 1 for the interview questions). The officials and planners interviewed include: 2 planners from the Beijing Municipal Institute of City Planning and Design, 2 officials from the Qianmen subdistrict (Jiedao) office, 4 officials from the Caochang neighborhood committees, and 2 officials from the Longyue neighborhood committee.

In the second phase, the study did face-to-face in-depth interviews with the original residents of Qianmen. The study initially planned to use random sampling of the home address to choose the subjects. However, getting precise home address information was an impossible task due to the lack of statistical data and the ongoing urban renewal 
project. Therefore, snowball and purposive sampling techniques were used to identify the participants. The initial participants were sought through interactions with the residents through a door-to-door method or in the public spaces of these neighborhoods. Then through snowball sampling, more subjects were identified. To make sure the sample can represent each sub-group (gender, age, education, work status), the investigation sought the cooperation of the neighborhood committees. Through the reference of the neighborhood committees, subjects who were less represented were recruited.

Initially, the study planned to interview 100 residents from discrete households, 30 for each targeted neighborhood respectively, and if possible, another 10 residents who got monetary compensation and bought housing from the market. Constrained by the time availability of the field work and the difficulty of accessing the subjects, in the end, 72 residents from different households were interviewed. Among them, 25 live in Caochang, 20 in Hongshan, 21 in Longyue, and 6 residents relocated to housing they bought from the market. The unit of analysis is the individual interviewed, whose opinion may not represent the opinion of the whole household. Table 4-1 shows the characteristics of the interviewees.

According to the investigation by the Beijing Academy of Social Sciences, $71 \%$ of the original residents in Qianmen were either retired or unemployed, therefore, the average individual income was just 1000 Yuan per month(Zhu 2005). The statistics provided by the Qianmen subdistrict (Jiedao) office shows that the average household size was 2.5 in Qianmen. Based on these numbers, it is estimated that the average household income in 
Qianmen was about 2500 Yuan per month. Fifty six percent of the interviewees of this study were not working (either retired or unemployed), $18.1 \%$ interviewees had a monthly household income less than 2000 Yuan and $47.5 \%$ interviewees had a monthly household income between 2000 and 5000 Yuan. The statistics provided by the Caochang neighborhood committee shows that $52.2 \%$ of the residents in Caochang neighborhood were in their fifties and above, whereas the proportion of the residents in their fifties and above was $58.9 \%$ in this study. The comparisons ${ }^{3}$ between the characteristics of participants in this study with the profile of the general population indicate that higher status groups are likely over-represented and that the elder age groups are slightly over-represented as well in this study.

The study made efforts to balance people of different genders in each age group. The study also put special effort to recruit participants who are young and who are highly educated. Although they still account for a very small portion of the participants, their inclusion in this study did represent the insights of these social groups, which formed a better base for the study to understand the experiences of the residents across the whole spectrum. Taken together, table 4-1 shows that the sample involved residents from a broad range of backgrounds (see appendix 3 for sample characteristics of study participants by income and by age).

3 The income and employment information of the interviewees were collected during 2009-2010, whereas the data of the general population were collected in 2005. Constrained by this limitation, the comparison has limitations. However the data of the general population is the only public-accessible data at this spatial scale, in Beijing, China, and the intention of the comparison is to give reader a general sense of the representativeness of the sample. 
Table 4- 1: Sample characteristics of study participants

\begin{tabular}{|c|c|c|c|c|c|c|}
\hline & & Caochang & Hongshan & Longyue & Other & Total \\
\hline & & $\mathrm{N}=25$ & $\mathrm{~N}=20$ & $\mathrm{~N}=21$ & $\mathrm{~N}=6$ & $\mathrm{~N}=72$ \\
\hline Gender & $\begin{array}{l}\text { Male } \\
\text { Female }\end{array}$ & $\begin{array}{l}54.2 \% \\
45.8 \%\end{array}$ & $\begin{array}{l}50.0 \% \\
50.0 \%\end{array}$ & $\begin{array}{l}52.4 \% \\
47.6 \%\end{array}$ & $\begin{array}{l}14.3 \% \\
85.7 \%\end{array}$ & $\begin{array}{l}48.6 \% \\
51.4 \%\end{array}$ \\
\hline Age & $\begin{array}{l}29 \text { and below } \\
30 \text { to } 39 \\
40 \text { to } 49 \\
50 \text { to } 59 \\
60 \text { above }\end{array}$ & $\begin{array}{l}8.0 \% \\
8.0 \% \\
24.0 \% \\
32.0 \% \\
28.0 \%\end{array}$ & $\begin{array}{l}10.0 \% \\
5.0 \% \\
15.0 \% \\
55.0 \% \\
15.0 \%\end{array}$ & $\begin{array}{l}9.5 \% \\
14.3 \% \\
28.6 \% \\
33.3 \% \\
14.3 \%\end{array}$ & $\begin{array}{l}.0 \% \\
14.3 \% \\
28.6 \% \\
57.1 \% \\
.0 \%\end{array}$ & $\begin{array}{l}8.2 \% \\
9.6 \% \\
23.3 \% \\
41.1 \% \\
17.8 \%\end{array}$ \\
\hline Education & $\begin{array}{l}\text { primary school } \\
\text { middle school } \\
\text { high school } \\
\text { college } \\
\text { graduate and above }\end{array}$ & $\begin{array}{l}15.0 \% \\
10.0 \% \\
50.0 \% \\
25.0 \% \\
.0 \%\end{array}$ & $\begin{array}{l}5.0 \% \\
45.0 \% \\
30.0 \% \\
15.0 \% \\
5.0 \%\end{array}$ & $\begin{array}{l}9.5 \% \\
14.3 \% \\
33.3 \% \\
42.9 \% \\
.0 \%\end{array}$ & $\begin{array}{l}.0 \% \\
.0 \% \\
80.0 \% \\
20.0 \% \\
.0 \%\end{array}$ & $\begin{array}{l}9.1 \% \\
21.2 \% \\
40.9 \% \\
27.3 \% \\
1.5 \%\end{array}$ \\
\hline Occupation & $\begin{array}{l}\text { Not working } \\
\text { blue collar } \\
\text { white collar } \\
\text { self-employed } \\
\text { officials }\end{array}$ & $\begin{array}{l}72.7 \% \\
18.2 \% \\
4.5 \% \\
4.5 \% \\
.0 \%\end{array}$ & $\begin{array}{l}50.0 \% \\
15.0 \% \\
25.0 \% \\
5.0 \% \\
5.0 \%\end{array}$ & $\begin{array}{l}61.9 \% \\
4.8 \% \\
14.3 \% \\
19.0 \% \\
.0 \%\end{array}$ & $\begin{array}{l}.0 \% \\
42.9 \% \\
.0 \% \\
.0 \% \\
57.1 \%\end{array}$ & $\begin{array}{l}55.7 \% \\
15.7 \% \\
12.9 \% \\
8.6 \% \\
7.1 \%\end{array}$ \\
\hline Income & $\begin{array}{l}<1200 \\
1201-2000 \\
2001-5000 \\
5001-8000 \\
>8000 \\
\end{array}$ & $\begin{array}{l}10.5 \% \\
21.1 \% \\
47.4 \% \\
5.3 \% \\
15.8 \% \\
\end{array}$ & $\begin{array}{l}11.8 \% \\
.0 \% \\
47.1 \% \\
23.5 \% \\
17.6 \% \\
\end{array}$ & $\begin{array}{l}.0 \% \\
4.8 \% \\
47.6 \% \\
14.3 \% \\
33.3 \% \\
\end{array}$ & $\begin{array}{l}.0 \% \\
50.0 \% \\
50.0 \% \\
.0 \% \\
.0 \% \\
\end{array}$ & $\begin{array}{l}6.6 \% \\
11.5 \% \\
47.5 \% \\
13.1 \% \\
21.3 \% \\
\end{array}$ \\
\hline
\end{tabular}

The interview questions included both close-ended and open-ended questions. Informed

by the residential satisfaction literature, the questions were trying to cover all possible factors contributing to residential satisfaction, and particular focus was given to social 
interaction factors. These factors include: (1) the residents' social economic and demographic background (gender, age, education, income, occupation) measured objectively; (2) their housing situations before and after (unit size, tenure, length of residence, facility conditions) measured objectively; (3) their social interactions before and after (neighbors and social intimates) measured both objectively and subjectively; (4) their subjective perception of the factors making them like or dislike their residential environment; and (5) their moving willingness and opinions about the policy arrangements. The factors of the first two categories and their evaluations of residential satisfaction were covered by close-ended questions, while the others were covered by open-ended questions, which gave the residents the opportunity to express their views freely.

Appendix 2 shows all the interview questions. Under the general open-ended questions, a few detailed questions are also listed to guide additional questions when these contents were not covered by the respondents. The interviewing process did not necessarily follow the question sequence which was shown in appendix 2 , for some of the questions are related in spite of being listed in different parts. For example, while discussing their social interaction with neighbors and local intimates before the urban renewal, some respondents would also mention their intimates who lived out of their neighborhood. In this circumstance, I would ask them this information first, and then go back to the question of neighborhood social interaction after the urban renewal later. 
Both quantitative and qualitative analyses were employed in the study. The quantitative analyses were trying to identify generality of the specific observations. However, constrained by the limited sample size, the quantitative analysis is more in the sense of providing the basis for the qualitative discussions rather than providing conclusive statistical evidence.

The level of residential satisfaction as the dependent variable was measured in the fivepoint Likert scale: very satisfied $(=1)$, fairly satisfied $(=2)$, okay $(=3)$, slightly dissatisfied $(=4)$, very dissatisfied (=5). Based on the ordinal nature of the dependent variable, (1) A Wilcoxon signed-rank test was used to test the difference of residential satisfaction before and after the urban renewal; (2) Kruskal-Wallis tests were run to test whether residents living in different neighborhoods have different level of residential satisfaction, and whether residents with various demographic and socioeconomic backgrounds differ in their level of residential satisfaction; (3) ordinal logistic regressions were used to test the significance of independent variables predicting the level of residential satisfaction. The findings of these quantitative analyses formed the basis for qualitative discussions.

In the study, the qualitative analysis was intended to deepen understanding and explain the quantitative findings, and discuss the relevance or applicability of the existing theories to the Qianmen case. Informed by the existing literature and the identification of recurring category-grounding phrases in the narratives across the interviewees, the study did inductive coding based on the question I was exploring. After careful coding, the percentages of respondents mentioning the factors were calculated. The attribute that the 
residents were satisfied and/or dissatisfied with before and after the urban renewal is the main concern of this study. The interviewees' responses to the questions were coded into six categories: (1) unit size, (2) unit quality (layout, facing, deficiencies and so on), (3) neighborhood environment (open spaces, landscape, parking, street pavement and sidewalks and so on), (4) access to public facilities and other resources (the access to education resources, healthcare facilities, jobs, neighborhood social services, retail facilities, etc.), (5) good social interaction with neighbors, and (6) social conflicts with neighbors. The neighboring activity between neighbors is another concern of the study. The activities mentioned by the respondents were coded into three types: socializing activities (greetings, chats, home visits, sharing leisure time, etc), social supports activities (exchanging goods and services, emergency care such as taking a neighbor to the hospital, and everyday care such as taking care of a neighbor's children after school), and social bridging activities (providing job information, provide direct referral to a job, provide information for career design).

The narratives of the respondents were quoted ${ }^{4}$ and woven with their background information to demonstrate their feelings and perceptions, and the meaning was further interpreted to clarify and explain the quantitative findings, and to discuss the relevance or applicability of the existing theories to the Qianmen case. By doing so, the researcher was

\footnotetext{
${ }^{4}$ The quotations were translated from Chinese to English. In this circumstance, they are good approximations of what people told you, not exact equivalents.
} 
trying to base the discussions on neutral findings rather than idiosyncratic interpretation. When quoting, the study gives more weight to the informants who are more articulate and reflective, and/or enjoy talking about events in detail and therefore whose narratives carry richer information clarifying the quantitative findings and existing theories.

\section{- Limitation of Research Design}

The study was trying to investigate the experiences of both the residents who remain in Qianmen area and the residents who relocated after the Qianmen urban renewal project. However, three fifths of the latter got monetary compensation and used the compensation to purchase commercial housing or rent from the market. Except for a few, this group of residents could hardly be tracked, and therefore was not been focused in the study. This fact should be kept in mind when analyzing data and reaching conclusions. Future research should attempt to include this group of households to make better grounded arguments on urban renewal processes and outcomes.

Snowball sampling and purposive sampling were used to identify the participants in the data collection process. These methods facilitated access to the subject and showed the deliberate effort to obtain representative samples through the inclusion of various groups. However, these methods are subject to numerous biases. Involving participants via the researcher's own interactions with the residents through the door-to-door method or in the public spaces of these neighborhoods might lead to an oversampling of unemployed participants. Seeking participants through neighborhood committees committee might risk a bias toward participants with higher neighborhood involvement. The residents who 
have something in common and /or have more contacts are more likely to be recruited through snowball sampling. These biases and the small sample size limit the potential power of generalization of this study. 


\section{Chapter 5: Accessing Residential Satisfaction}

This chapter starts with a discussion of the three neighborhoods--Caochang, Longyue and Hongshan--where the participants live after the urban renewal. This provides an overall picture of the impact of urban renewal and the advantages and disadvantages of living in these three neighborhoods. Based on this descriptive analysis, the quantitative analyses examines the following questions: whether the residents are more satisfied than before; whether the residents living in different neighborhoods after the urban renewal differ in their level of residential satisfactions; whether the residents with various demographic and socioeconomic backgrounds have different levels of residential satisfaction; and what is the significance of physical determinants, social attributes and policy factors in predicting residential satisfaction?

\subsection{Neighborhoods after Urban Renewal}

This part is a descriptive analysis. Based on the subjective evaluation of the residents shown by the interview data and the objective conditions reflected by other data, the advantages and disadvantages of the residential environment in the three neighborhoods will be discussed. The conditions of the residential environment before and after will be compared to indicate the negative and positive impacts of the urban renewal project. Physical (both housing unit and neighborhood), social and economical attributes of the residential environment are included in the discussion. 


\section{- Caochang Neighborhood}

Caochang neighborhood is located in the east of Qianmen area. With its central location, residents have easy access to rich first-class public facilities, jobs and other resources (table 5-1). It has 14 Hutongs, 533 courtyards, and of 3500 previous households, some 1000 remain. At the time of investigation, about 40 original households living in other neighborhoods of Qianmen area had relocated to Caochang neighborhood, and more will be expected (interview data). For the original residents of Caochang neighborhood, the space of their housing units remain the same as before, but the families relocated to Caochang neighborhood had seen a 50\% increase of their housing unit size according to the compensation policy.

Table 5-1: The public facilities: Caochang, Hongshan and Longyue ${ }^{5}$

\begin{tabular}{lllll}
\hline & & Caochang & Hongshan & Longyue \\
\hline \multirow{3}{*}{$\begin{array}{l}\text { Public } \\
\text { Transit }\end{array}$} & Bus lines(\#) & 30 & 6 & 4 \\
& & $\begin{array}{l}\text { Frequent } \\
\text { service }\end{array}$ & $\begin{array}{l}\text { Frequent } \\
\text { service }\end{array}$ & $\begin{array}{l}\text { Infrequent } \\
\text { service }\end{array}$ \\
\cline { 2 - 5 } & & 2 & 1 & 1 \\
\hline First -class & Subway lines(\#) & 4 (Xiehe, & 2 & 1(Huilongguan) \\
Public & & Tongren, & & \\
Hospital & & Beijing, & & \\
& & Tiantan) & & \\
\hline \multirow{3}{*}{$\begin{array}{l}\text { Education } \\
\text { Institutions }\end{array}$} & Pre-school daycare(\#) & 8 & 3 & 7 \\
\cline { 2 - 5 } Within 1 km & Public & 8 & 2 & 2 \\
\cline { 2 - 5 } & Private & 0 & 1 & 5 \\
\cline { 2 - 5 } & Primary schools(\#) & 15 & 2 & 1 \\
\cline { 2 - 5 } & Middle schools(\#) & 12 & 1 & 1 \\
\hline
\end{tabular}

\footnotetext{
${ }^{5}$ The table was based on the data retrieved from http://www.aibang.com/
} 
The renovation of the neighborhood began at the end of 2007. The renovation improved the general housing quality and infrastructure in the neighborhood. More specifically, the surrounding hutongs were widened, and sidewalk trees were planted. All the other hutongs were re-paved. Water, electrity and gas lines, as well as sewage system and public toilets were upgraded (Fig.5-1).

Figure 5-1: The images of Caochang neighborhood before and after
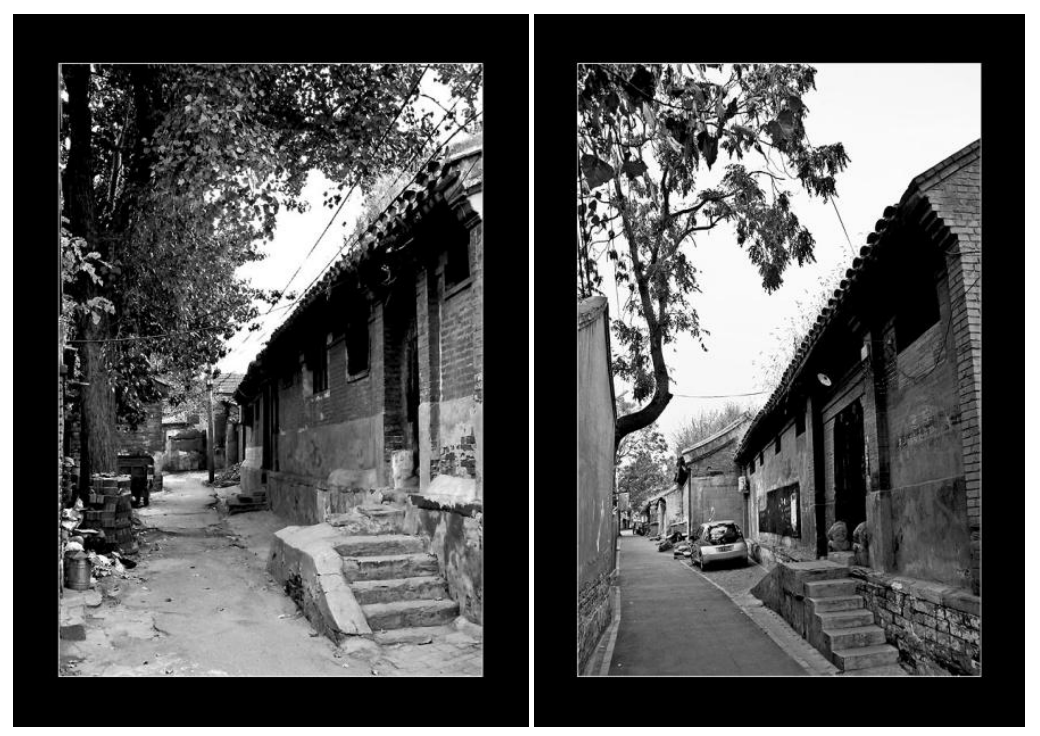

Resource: Yandujicheng.(2009). Caochang Hutong [Photo].Retrieved from http://bbs.zm7.cn/thread-16108-1-1.html

For public housing, some of the mostly dilapidated courtyard houses were demolished and rebuilt in the same way as the original. The surviving courtyards underwent a facelift, giving them a fresh appearance. The courtyard houses were remodeled and refurbished: new windows and doors are more energy efficient; gas stoves for heating were installed; new water and electricity lines and meters make supply more stable and allow for separate bills for each family; and modern kitchens and bathrooms were provided when 
space was available. The shabby extensions owned by residents who moved out were demolished to restore the previous court yards; those owned by the stayers were rebuilt with better construction materials and in a style more congruent with the surrounding historic buildings. For privately-owned housing, the decision of rebuilding or remodeling and refurbishing depended on the owners, who needed to pay $20 \%$ of the costs.

Many residents appreciated the improvements in housing quality and infrastructure. The convenience and comfort brought by the renovation was a constant theme in my conversations with the stayers, although the quality of the construction and the facilities were questioned by some residents at times. For the most part, residents were appreciative of at least some of the changes taking place in their neighborhood such as clean hutongs and public toilets. Furthermore, the physical improvements enabled a few residents to envision the possible rising of their property value and the opportunities through which they might benefit from the further development of the neighborhood after the renovation by opening a family store or even running a food stand if allowed.

Enjoying these improvements and new opportunities, two types of residents are more likely to stay. The first type is the elders or the residents with bigger housing units who have less desire to move out. As the existing literature indicates, elders are more likely to build strong attachment to the neighborhood and have low levels of expectation.

Residents with bigger housing units are not as desperate to increase their living space as the residents who moved out. The second type is residents who have very low household income or special needs for medical care or education facilities in Qianmen. The very 
low income families care more about the opportunity of increasing income by running a family store or even a food stand than a bigger unit, which usually costs more utility fees, while for the latter, the first-class hospitals and schools around Qianmen area are irreplaceable resources. These two types of residents remain in Caochang neighborhood voluntarily. There is another type of resident who stays involuntarily. These residents generally have relatively low household income and live in small public housing with a big family. As mentioned in Chapter three, they need larger living space, but cannot afford to move out due to all kinds of constraints.

For those willing to stay, they are happy that they were not forced to move out. In this way, they can still have access to first-class public facilities, jobs and other resources easily and stay in their home in which they lived for generations and therefore felt strongly attached. In addition, they can still enjoy their ways of social interaction in the neighborhood, such as watching out for each other, helping each other or even just casually chatting with each other. However, they do feel the social interactions are not as dense as before, which they really missed. Similarly, for those who would have preferred to move out to increase living space but were constrained by all kinds of conditions, the moving out of their neighbors made them feel lonely and lose some of the social supports from their neighbors as well, although it did relieve them from some of the tensions with their neighbors due to the overcrowding which previously bothered them very much.

What the stayers are also not happy with is the reality that the newly redeveloped facilities in the commercial area, the west part of the Qianmen area, are not for the local 
people, whereas most of the small neighborhood grocery stores and markets, restaurants and other daily utility shops once scattered in almost every hutong were either closed when the owners relocated or were eliminated for widening the hutongs or making room for infrastructure construction. The inconveniences of losing these amenities within walking distance were a constant complaint of the respondents, though some of the more optimistic interviewees thought it would be getting better in the future.

In addition, the stayers are also annoyed by the dust and noise brought by the ongoing demolition and rebuilding of the courtyard buildings and the infrastructure construction in the surrounding neighborhood. Moreover, some of the stayers have concerns over the cultural heritage of the neighborhood--the renovated buildings lack the fine craftsmanship, ruining the architectural grace of the old courtyard houses to some extent, which is actually a common problem faced by some other renovated historic neighborhoods in Beijing, such as Nanchizi(Qian 2009).

All in all, the renovation of the neighborhood did preserve the traditions and customs of the hutong residential environment in the central city to some extent; improve the physical living conditions of the stayers in some aspects; and raise their property value and offer other opportunities through which they might benefit from the further development of the neighborhood. These improvements led $71 \%$ interviewees of Caochang to report that their general living conditions were better or much better than before. However, some stayers still face the problems of small housing units without modern equipment-- the average unit size after the renovation is only 44 square meters 
(about 474 square feet),, half of housing units were not equipped with modern bathroom.

And the stayers also suffer from losing their social support and the amenities within walking distance among others (table5-2). As a result, many stayers have very mixed feelings about the renovated neighborhood: they enjoy the improvements, but are also annoyed by the remaining problems.

\section{Table 5-2: Features of remaining in Caochang}

\begin{tabular}{|c|c|}
\hline Advantages & $\begin{array}{l}\text { - Good access to rich first-class public } \\
\text { facilities, jobs and other resources } \\
\text { easily } \\
\text { - Stay in their home which they lived in } \\
\text { for generations, therefore felt strongly } \\
\text { attached to } \\
\text { - Enjoy their original way of social } \\
\text { interactions in the neighborhood } \\
\text { - No property maintenance fee, Low } \\
\text { utility fees }\end{array}$ \\
\hline Disadvantages & $\begin{array}{l}\text { - Small housing unit } \\
\text { - } \quad \text { Lack of modern equipment }\end{array}$ \\
\hline Positive effects & $\begin{array}{l}\text { Better housing and infrastructure } \\
\text { conditions ; } \\
\text { - Possible rising of their property value; } \\
\text { - Possible opportunities opening a family } \\
\text { store or running a food stand } \\
\text { - Relieving from the tensions with their } \\
\text { neighbors due to the overcrowding }\end{array}$ \\
\hline Negative effects & $\begin{array}{l}\text { Social interactions are not as intensive } \\
\text { as before } \\
\text { - Lack of some amenities(such as } \\
\text { restaurants barbershops) within } \\
\text { walking distance } \\
\text { - The renovated buildings lack the fine } \\
\text { craftsmanship of the past }\end{array}$ \\
\hline
\end{tabular}




\section{- Longyue Neighborhood}

Longyue is a neighborhood in Huilongguan, one of Beijing's residential suburbs located in Changping district of Beijing, about $30 \mathrm{~km}$ to the north of Qianmen area. Since the end of the 20th century, Huilongguan has been becoming one of the largest areas in Beijing where affordable housing estates are clustered and about 300,000 people now live. As one of these affordable housing estates, Longyue was built in the middle of 2000s. In the sub-neighborhood investigated by this study, there are 22 six-story buildings in the gated community, which accommodate previous residents from both Qianmen and other old city areas who were impacted by urban renewal and thus offered priority to get access to affordable housing; as well as ordinary qualified residents who got their affordable housing apartments after years of waiting.

\section{Figure 5-2: The images of Longyue neighborhood}

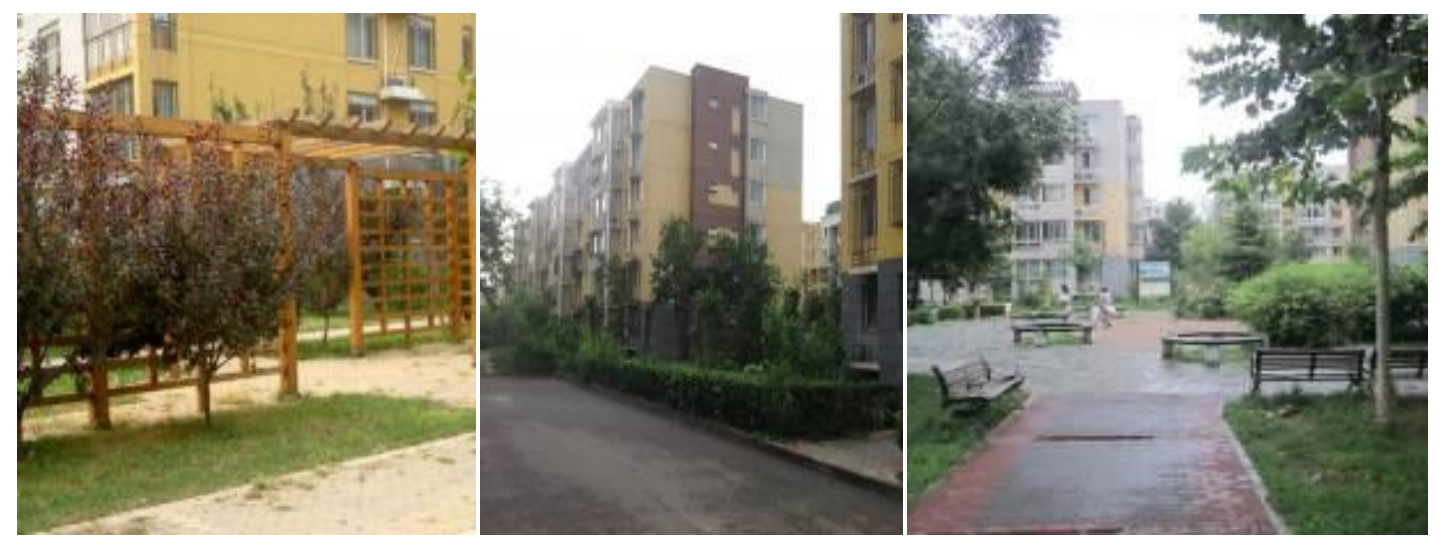

Resources: Longyuesiqu [Photo]. Retrieved from http://beijing.anjuke.com/community/photos2/b/details/372021_3 http://beijing.anjuke.com/community/photos2/b/details/372021_47 http://beijing.anjuke.com/community/photos2/b/details/372021_38 
The apartments in the neighborhood are either two-bedroom with 97 square meters (about 1,044 square feet) or three-bedroom with 127 square meters (about 1,367 square feet). This means for the original residents of Qianmen area there is a big increase in their housing unit size, compared with the previous 22 square meters (about 237 square feet) ${ }^{6}$. Furthermore, the apartments are equipped with private kitchens, bathrooms and gas heating, have a better layout and are south facing. Meanwhile, there are more parking spaces and outdoor spaces in the neighborhood which are carefully designed and are well maintained. Clearly, the bigger and well-equipped and designed apartments with a better outdoor physical environment provide the residents with more comfortable and convenient living conditions than their old dwellings, which was a constant theme in conversations with the interviewees.

The other advantage about the housing frequently mentioned by the interviewees is that they are homeowners now, though there are constraints on the using and selling of their property as affordable housing. And they realized homeownership at a low cost. With the average unit size of 22 square meters (about 237 square feet), most of the interviewees got enough compensation to cover not only the cost of purchasing the housing unit but also its remodeling and decorating.

Furthermore, since it is far away from the central city, it is peaceful and quiet, and has less air pollution, which is a fresh experience for those residents who had suffered

\footnotetext{
${ }^{6}$ This unit size is the one on which the compensation was based. Whether unofficial extensions were counted depended on the negotiation between the resident and the staff in charge of the compensation.
} 
enough from the original noisy and over-crowded neighborhood. But on the other hand, for some people, the suburbs are simply too quiet and too boring; they really miss the vibrant life in the central city.

What most residents also miss is the social support networks in the original neighborhood. Relocating to a suburban area made them lose some of their previous local connections, and they find that it is very hard to replace them with new local connections in the current neighborhood with modern apartment buildings, though a couple of interviewees reported that one or two of their original neighbors relocated to Longyue as well, which comforted them somewhat. Many residents complained that neighbors who used to help each other now lived behind the closed doors. Furthermore, some residents still feel strongly attached to the physical environment of Qianmen area-- they miss the neighborhood enriched with history and culture which they appreciated and were proud of, and they miss the familiar sights and sounds which they experienced for decades. They feel sad about the loss of this kind of sense of belonging and feel that they are country people not city people any more.

In addition, living in the suburbs also means the residents face the problem of inadequate first-class public facilities such as good hospitals and schools. In Beijing, most first-class public facilities are concentrated in the central city area, and it usually takes many years for the relevant services to settle in a newly developed area. It was only since the end of last century that Huilongguan area started to be developed. On the other hand, in the area where affordable housing estates are clustered, public investment in public facilities and 
services has been limited. Therefore, it lags far behind in the provision of public facilities and services. A comprehensive survey conducted to evaluate social service provision in new housing estates shows that Huilongguan was among the top 3 worst areas in 5 categories of service: food and restaurants, healthcare, education, entertainment, and child recreation facilities(Zhang, Yin et al. 2006; Qian 2009). Among the three neighborhoods investigated by this study, Longyue is the worst in terms of first-class public hospitals and schools (table5-1). Family members of some interviewees still need to travel back to the central city for medical care or education.

For those still working, the residential suburb also requires a long commute to work, since the residential satellite strongly depends on the central city for working opportunities. However, public transportation options are limited. As table5-1 shows, just 4 bus lines serve the neighborhood and often with low frequency, compared with 30 serving the Qianmen area. Although the terminal of light rail line 8 is close to Longyue and taking the train is only a short trip, it is crowded with people commuting to work during rush hour, and the cost is also a burden for low income residents. For some of the better-off who own a car, driving to work could take hours, since they have to face rush hour traffic jams every day. Clearly, the time and money cost of commuting between the neighborhood and the central city area is a major source of discontent about living in Longyue.

The impacts of the above advantages and disadvantages for those relocating to Longyue vary across different groups of people. The residents who voluntarily relocated to 
Longyue made the decision based on their own trade-off of the gain and loss. This group of residents is more likely to be those (1) who are retired and still healthy and whose kids have grown up, therefore, don't worry about the commute to work, good schools and hospitals; and (2) who are still in their late twenties or early thirties, so have no kids or have kids who are still too little to go to school, and who have a flexible working schedule or have a job along the light rail line or in the north part of the central city, so commuting to work is still acceptable. These two groups of residents benefit from the relocation the most, for the new housing units fit most of their housing needs in spite of certain sacrifices, and they realized homeownership at low cost, which they could not afford otherwise.

For some of the residents involuntarily relocated due to the infrastructure construction, the result is mostly painful. They were often strongly attached to the original neighborhood economically, socially, psychologically or physically. The disruption from the original neighborhood made them lose extra money from their informal businesses, social support networks they used to rely on, and/or familiar physical environment. And the relocation to Longyue further made some of them subject to challenges such as longdistance traveling back to the central city area (for work, health care and kids going to school), increasing costs of property maintenance fee and utility fees due to the spacious new housing, and so on.

All in all, relocating to the suburban area enabled the previous public tenants to realize homeownership and did improve their living conditions in terms of the quality of the 
housing unit and the neighborhood open spaces. Therefore, among the interviewees of this study, $80 \%$ reported that their general living conditions were better or much better than before. However, the relocation to the suburban area also means disruption of previous social connections, loss of sense of belonging to the original neighborhood, inadequate first-class public facilities, and long distance commuting among others. The residents most strongly attached to the original neighborhood suffered the most from the forced relocation. For the others, mostly they are happy about the improvements, but at the same time complain more or less about the problems (table5-3).

Table 5-3: Features of relocating to Longyue

\begin{tabular}{|lll|}
\hline Advantages & - & Less air pollution than the central city area \\
& - & Peaceful and quiet \\
\hline Disadvantages & - & Lack of first-class public facilities \\
& - & Long distance commuting to jobs and other \\
& & resources \\
\hline Positive effects & - & Better housing units \\
& - & Realizing homeownership at a lower cost \\
& Better neighborhood open spaces and \\
& infrastructure conditions \\
& Relief from tensions with their neighbors due to \\
& overcrowding \\
& - $\begin{array}{l}\text { Disruption of previous social connections } \\
\text { Loss of sense of belonging to the original } \\
\text { neighborhood } \\
\text { loss of extra money from informal businesses, } \\
\text { and increasing costs of property maintenance } \\
\text { fee and utility fees }\end{array}$ \\
&
\end{tabular}




\section{- Hongshan Neighborhood}

Hongshan is located between the southeast second ring road and third ring road, about $5 \mathrm{~km}$ to the southeast of Qianmen area, a much better location than that of Longyue.

Forty-two high-rise buildings with floor area of about 1.44 million square meters (about 15.5 million square feet) have been constructed in the area of 37.03 ha, since Feb. 2006, which will provide 10,000 affordable housing units for middle and low income households. About one third $(3,500)$ of the units accommodate households from the Qianmen area (interview data).

\section{Figure 5-3: The images of Hongshan neighborhood}
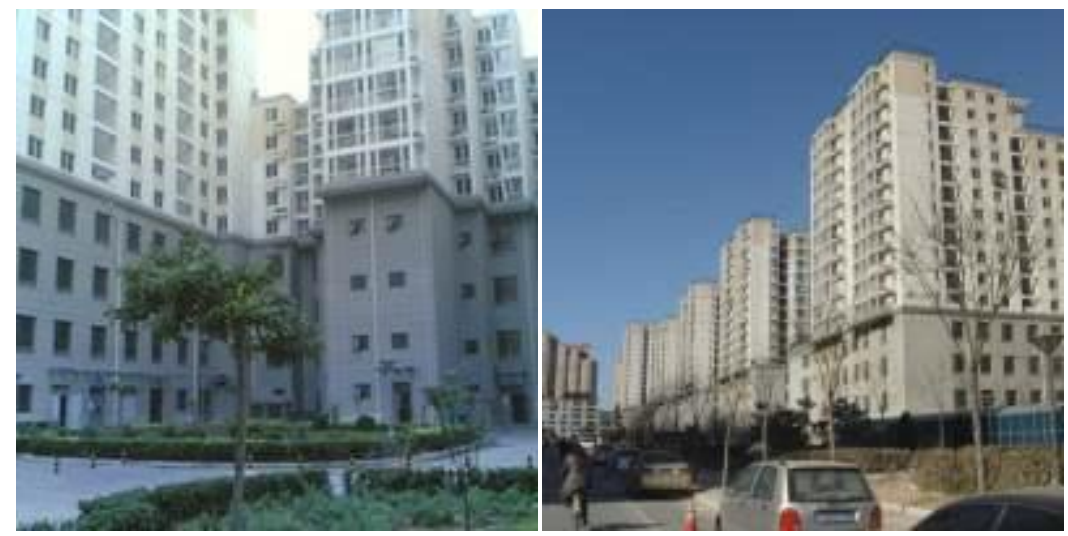

Resources: Hongshanjiayuan [Photo].Retrieved from http://beijing.anjuke.com/community/photos2/b/details/79619_1 http://beijing.anjuke.com/community/photos2/b/details/79619_70

The size of the apartments in the neighborhood varies from one-bedroom (41-61square meters, about 441-657 square feet), to three-bedroom (90-128 square meters, about 9691,378 square feet). For the interviewees of this study, the average unit size is 102 square meters (about 1,098 square feet), which means a more than fivefold increase compared 
with the original 18 square meters (about 194 square feet), the smallest one among the three neighborhoods investigated. Furthermore, the new apartments have all the modern conveniences with private kitchens, bathrooms and gas heating. The bigger, well equipped and designed apartments provide the residents with a more comfortable and convenient living environment than their old dwellings, which was a constant theme in my conversations with the interviewees, though a few residents are not happy about the layout of the apartment and the inconvenience of using crowded elevators due to the high-rise nature of the buildings.

In addition, most of the residents realized full home ownership or part home ownership (a part of the housing unit is owned by the resident and the other part is rented by the resident from the housing authority). For the interviewees of this group, the percentage of the former is $37.5 \%$, the latter $56.2 \%$, compared with the fact that only $26.3 \%$ of the residents owned their housing units before. The residents were appreciative of the home ownership; however, they realized home ownership at a higher cost than the residents relocated to Longyue. More specifically, with the average unit size of 18 square meter, they can get some 40 square meter $\left(18^{*} 1.333^{*} 170 \%\right)$ for free in Hongshan, for the extra space, they paid 4,900 Yuan per square meter, which made the average cost for full home ownership about 300,000 Yuan $(62 * 4,900)$. This was a huge burden for the residents with limited income. Another burden for some of the low income residents is the property maintenance fee and increasing utility fees along with moving to a spacious modern apartment. 
Even though the residents who relocated to Hongshan paid higher costs for the improvement, aside from the bigger and better-equipped apartment and home ownership, the residents chose to move to Hongshan for another important reason----its location. Hongshan is located in the central city area, between the second ring road and the third ring road, just $5 \mathrm{~km}$ from Qianmen, which means the residents have better accessibility to public transit, public services and facilities than their counterparts relocated to most of the other affordable housing neighborhoods in the suburbs (table5-1). However, leaving Qianmen--an area with better schools, nearby hospitals, and convenient shopping-- and moving to a relatively peripheral and newly developed neighborhood does limit their choices. Some of the residents complained that the newly built neighborhood lacked services such as post offices, banks, neighborhood stores and a health center; therefore they still needed to go to the surrounding neighborhoods or back to the original neighborhood for grocery shopping, health care or schooling. However, many of them believe that the problems would be ameliorated gradually in the future.

What the residents are also happy with is the fact that some of their local social contacts moved to Hongshan as well. This let them keep their original social interactions and made their adaptation to the new environment easier. However, some residents do feel that social interactions are different in the newly developed neighborhood that features high-rise buildings. They used to enjoy much more social life in Qianmen. Now, they feel that they live behind closed doors, which makes them somewhat isolated. Therefore, there is no doubt that the frequency of social contact is dropping and the good tradition of "neighborhood watch" is dismissing to some extent. Furthermore, some residents 
expressed grief for leaving the neighborhoood where they lived for decades and thus felt strongly attached to, and which was enriched with history and culture which they appreciated and were proud of.

Overall, most of the residents in Hongshan have mixed feelings about their relocation, even though almost all the residents moved to Hongshan voluntarily, rather than chosing to stay or buying housing from the market. As discussed before, the development of Hongshan was to help the stayers who could not afford and/or had higher expectations after the first round to move out, by providing extra aid to those with the most difficulties and offering affordable housing located in the central city area. This way, both the relatively high income households who did not want to relocate to suburban areas gained access to affordable housing in a better location, and with the subsidies the low income households increased their living space. There is no doubt that the residents appreciate the good location and the improvements in housing. Among the interviewees of this study, 95\% reported that their general living conditions were better or much better than before. However, for some with limited income, the costs could be a big burden, and the quality of high-density affordable housing made some of the residents, in particular those with relatively high income and generally high expectations, less content; and both groups suffer to a certain extent from the disruption of previous social connections and loss of sense of belonging to Qianmen (table 5-4). 
Table 5-4: Features of relocating to Hongshan

\begin{tabular}{|c|c|}
\hline Advantages & - Location is acceptable \\
\hline Disadvantages & $\begin{array}{l}\text { - The less desired quality of high-density } \\
\text { affordable housing }\end{array}$ \\
\hline Positive effects & $\begin{array}{l}\text { - } \text { Better housing units } \\
\text { - } \quad \text { Realizing full homeownership or part } \\
\text { homeownership at a higher cost } \\
\text { - } \quad \text { Better neighborhood open spaces and } \\
\text { infrastructure conditions } \\
\text { - } \quad \text { Relief from tensions with their neighbors } \\
\text { due to the overcrowding }\end{array}$ \\
\hline Negative effects & $\begin{array}{l}\text { Disruption of previous social connections } \\
\text { to some extent } \\
\text { - Loss of a sense of belonging to the original } \\
\text { neighborhood } \\
\text { - Loss of extra money from their informal } \\
\text { businesses, and increasing costs of property } \\
\text { maintenance fee and utility fees }\end{array}$ \\
\hline
\end{tabular}

\subsection{Quantitative Analyses of Residential Satisfaction}

The previous descriptive analysis clearly shows that although most residents reported their general living conditions were better or much better than before, many residents have mixed feelings about the impacts of the urban renewal project on their residential environment. The next part will employ "residential satisfaction" as an evaluative indicator to examine the overall effects of the Qianmen urban renewal, inspired by the view of Parkes et al. that "a single, unifying, subjective measure of the quality of neighborhood life appears to be an appropriate benchmark against which to measure the impact of many neighborhood attributes.” (Parkes, Kearns et al. 2002). It will use quantitative analyses to answer the following questions: whether the residents are more satisfied than before; whether the residents living in different neighborhoods after the 
urban renewal differ in their level of residential satisfactions; whether the residents with various demographic and socioeconomic backgrounds have different levels of residential satisfaction; and What is the significance of physical determinants, social attributes and policy factors in predicting residential satisfaction.

In the five-point Likert scale: very satisfied $(=1)$, fairly satisfied $(=2)$, okay $(=3)$, slightly dissatisfied (=4), very dissatisfied (=5), the participants reported level of residential satisfaction skews toward dissatisfaction before the urban renewal (table 5-5). However they show a much higher level of satisfaction after the urban renewal with mean score of 2.2 compared with 3.4 before (table 5-6). A Wilcoxon signed-rank test further indicates that the Qianmen urban renewal project did elicit a statistically significant change in the households' level of residential satisfaction $(Z=-5.461, p=0.000)$. Indeed, the median level of residential satisfaction was 3 before the urban renewal and 2 after the urban renewal. The result reveals that overall the Qianmen urban renewal had positive impacts on the residents' residential environment, in other words, the residents tend to benefit from rather than suffer from the project. 
Table 5-5: Residential satisfaction level before the urban renewal

\begin{tabular}{llllll}
\hline & Caochang & Hongshan & Longyue & Other & Total \\
& $\mathrm{N}=25$ & $\mathrm{~N}=20$ & $\mathrm{~N}=21$ & $\mathrm{~N}=6$ & $\mathrm{~N}=72$ \\
\hline Very satisfied & $15.8 \%$ & $.0 \%$ & $.0 \%$ & $.0 \%$ & $4.8 \%$ \\
Fairly satisfied & $10.5 \%$ & $21.1 \%$ & $11.1 \%$ & $57.1 \%$ & $19.0 \%$ \\
Ok & $21.1 \%$ & $36.8 \%$ & $50.0 \%$ & $28.6 \%$ & $34.9 \%$ \\
Slightly dissatisfied & $31.6 \%$ & $10.5 \%$ & $16.7 \%$ & $14.3 \%$ & $19.0 \%$ \\
Very dissatisfied & $21.1 \%$ & $31.6 \%$ & $22.2 \%$ & $.0 \%$ & $22.2 \%$ \\
\hline Mean & 3.3 & 3.5 & 3.5 & 2.7 & 3.4 \\
& & & & & \\
\hline
\end{tabular}

Table 5-6: Residential satisfaction level after the urban renewal

\begin{tabular}{llllll}
\hline & Caochang & Hongshan & Longyue & Other & Total \\
& $\mathrm{N}=25$ & $\mathrm{~N}=20$ & $\mathrm{~N}=21$ & $\mathrm{~N}=6$ & $\mathrm{~N}=72$ \\
& & & & & \\
\hline Very satisfied & $21.1 \%$ & $25.0 \%$ & $25.0 \%$ & $57.1 \%$ & $27.3 \%$ \\
Fairly satisfied & $42.1 \%$ & $40.0 \%$ & $55.0 \%$ & $28.6 \%$ & $43.9 \%$ \\
Ok & $10.5 \%$ & $20.0 \%$ & $20.0 \%$ & $14.3 \%$ & $16.7 \%$ \\
Slightly dissatisfied & $10.5 \%$ & $10.0 \%$ & $.0 \%$ & $.0 \%$ & $6.1 \%$ \\
Very dissatisfied & $15.8 \%$ & $5.0 \%$ & $.0 \%$ & $.0 \%$ & $6.1 \%$ \\
\hline Mean & 2.6 & 2.3 & 2.1 & 1.7 & 2.2 \\
& & & & & \\
\hline
\end{tabular}

Among the neighborhoods, there are variations in terms of the mean score after the urban renewal. Interestingly, the residents who remain in Caochang are the unhappiest after the urban renewal, with the mean score of 2.6. The residents relocated to Longyue have the 
highest level of residential satisfaction, with the mean score of 2.1. The residents relocated to Hongshan are in the middle, with the mean score of 2.3. A Kruskal-Wallis test was further run to test the statistic significance of the differences. The result shows that there is not a statistically significant difference between the different neighborhoods $(\mathrm{H}(2)=1.037, \mathrm{p}=0.595)$, with a mean rank of 33.18 for Caochang, 27.88 for Longyue and 30.70 for Hongshan. This is not surprising. Under the policy arrangements of the Qianmen urban renewal project, most of the residents made their own choices about whether to move out and where to move based on their own housing needs, thus they tend to be happy with the results.

A series of Kruskal-Wallis tests were further run to test whether the residents with various demographic and socioeconomic backgrounds have different levels of residential satisfaction after the urban renewal (table 5-7). The variables tested include age, family size, education, occupation and income. The results show income is the only variable that significantly contributes to the level of residential satisfaction (Chi-square=10.223, $\mathrm{p}=.037, \mathrm{n}=61$ ), which means that $17 \%$ of the variability in residential satisfaction is accounted for by income ${ }^{7}$.

\footnotetext{
7 The following formula was used to calculate the variance: Chi-square/(n-1)
} 
Table 5-7: The residential satisfaction of residents with different demographic and socioeconomic backgrounds after the urban renewal

\begin{tabular}{lll}
\hline & Chi-square & P value* \\
\hline Age & & \\
Family size & 2.692 & .611 \\
Education & 7.123 & .130 \\
Occupation & 1.052 & .902 \\
Income & 1.349 & .853 \\
& 10.223 & .037 \\
\hline
\end{tabular}

$*$ The results show income is the only variable that significantly contributes to residential satisfaction at
significance level of .05 .

A series of simple ordinal logistic regressions were run to test the significance of physical determinants, social attributes and policy factors in predicting residential satisfaction. Informed by the residential satisfaction literature, the physical variables tested are unit size and housing tenure. The social attributes include the residents' subjective evaluation of the impact on their social networks, the percentage of their loss of local close contacts, and the percentage of their loss of overarching close contacts. The policy factor examined is involuntary relocation. The results of simple ordinal logistic regressions shows that unit size, residents' subjective evaluation of the impact on their social networks, and involuntary relocation significantly contribute to the level of residential satisfaction (table 5-8). Using these variables and income--the significant socioeconomic variable--as the independent variables, the result of an ordinal logistic regression reveals that social factor does not significantly predict residential satisfaction any more. All the other variables -- 
unit size, involuntary relocation and income (none of them are highly correlated ${ }^{8}$ ) -account for $40 \%$ (Nagelkerke) the variance of residential satisfaction (table 5-9).

Table 5-8: The significance of physical, social and policy factors predicting residential satisfaction

\begin{tabular}{llll}
\hline & & Pseudo R-Square & P value* \\
& & (Nagelkerke) & \\
\hline Physical factor & Unit size & .117 & .007 \\
& Housing tenure & .085 & .081 \\
Social factor & Subjective evaluation & .072 & .038 \\
& Loss of local close contacts & .008 & .481 \\
& Loss of overarching close contacts & .005 & .035 \\
\hline
\end{tabular}

* The results show unit size, subjective evaluation of social impacts, and involuntary relocation are the variables that significantly contribute to residential satisfaction at significance level of .05.

${ }^{8}$ Among the three variables, the correlation between unit size and income is the only significant one at the 0.05 level $(\mathrm{r}=.469)$. 
Table 5-9: The parameter of unit size, involuntary relocation and income predicting residential satisfaction

\begin{tabular}{|l|l|l|l|l|l|l|l|l|}
\hline & & & & & & \multicolumn{2}{|l|}{$95 \%$ Confidence Interval } \\
\cline { 6 - 8 } & Estimate & Std. Error & Wald & df & Sig. & Lower Bound & Upper Bound \\
\hline Very satisfied & -6.656 & 1.381 & 23.221 & 1 & .000 & -9.363 & -3.949 \\
Fairly satisfied & -3.841 & 1.139 & 11.372 & 1 & .001 & -6.074 & -1.609 \\
ok & -2.309 & 1.048 & 4.858 & 1 & .028 & -4.362 & -.256 \\
Slightly dissatisfied & -1.178 & 1.077 & 1.195 & 1 & .274 & -3.289 & .934 \\
\hline Current unit size & -.017 & .007 & 6.178 & 1 & .013 & -.030 & -.004 \\
\hline Voluntary relocation & -2.321 & .701 & 10.973 & 1 & .001 & -3.695 & -.948 \\
Involuntary relocation & $0^{\mathrm{a}}$ & & & & 0 &. &. &. \\
\hline Low income & -2.997 & 1.285 & 5.435 & 1 & .020 & -5.516 & -.477 \\
Low-middle income & -1.772 & 1.096 & 2.613 & 1 & .106 & -3.920 & .377 \\
Middle income & -1.807 & .829 & 4.752 & 1 & .029 & -3.433 & -.182 \\
High income & -1.787 & 1.005 & 3.158 & 1 & .076 & -3.757 & .184 \\
Middle-high income & $0^{\mathrm{a}}$ & & & & & & \\
\hline
\end{tabular}

The previous descriptive analyses indicate that many residents have mixed feelings about the impacts of the urban renewal on their residential environment. Using "residential satisfaction" as an evaluative indicator, the above quantitative analyses suggest overall the Qianmen urban renewal had positive impacts on the residents' residential environment. The results of the quantitative analyses point to the variables significantly contributing to residential satisfaction: unit size, income and involuntary relocation, which will be clarified and explained further in the next chapter. 


\section{Chapter 6: Significant Factors Attributing to Residential Satisfaction}

The quantitative analyses in the previous chapter point to the variables significantly contributing to residential satisfaction: unit size, income and involuntary relocation. Mainly based on qualitative analyses, this chapter tries to clarify and explain the patterns of these variables impacting residential satisfaction. The first part will look into the impacts of unit size and other related physical attributes. The second part will discuss how residents with different incomes have different levels of residential satisfaction. The third part will investigate how involuntary relocation contributes to low levels of residential satisfaction, and discuss how to reach positive results, when households are impacted by passive relocation.

\subsection{Unit Size and Other Physical Factors}

The existing literature informs us that the size of the housing unit is a basic need for healthy living, thereby, a factor of great importance for the evaluation of residential satisfaction (Morris, Crull et al. 1976; Meeks 1980; Liu 2005; Fang 2006). The result of the ordinal logistic analysis in the last chapter shows that for one square meter increase in unit size, we would expect a 0.017 increase in the odds of being in a higher level of residential satisfaction, given the variables of income and involuntary moving in the model held constant. This section will use the subject evaluation of the interviewees to further explore the impacts of unit size and other physical attributes on residential satisfaction. 
The interviewees were asked to report what they were satisfied with and dissatisfied with before and after the urban renewal. The study codes the physical factors into four categories: unit size, unit quality (layout, facing, deficiencies and so on ), neighborhood environment (open spaces, landscape, parking, street pavement and so on), and access to public facilities and other resources (including the access to education resources, healthcare facilities, jobs, neighborhood social services, retail facilities, etc.). The results and the average unit size of the interviewees are listed in table 6-1, 6-2, and 6-3.

Table 6-1: Housing unit size before and after

\begin{tabular}{lllll}
\hline & $\begin{array}{l}\text { Caochang } \\
\mathrm{N}=25\end{array}$ & $\begin{array}{l}\text { Hongshan } \\
\mathrm{N}=20\end{array}$ & $\begin{array}{l}\text { Longyue } \\
\mathrm{N}=21\end{array}$ & $\begin{array}{l}\text { Total } \\
\mathrm{N}=66\end{array}$ \\
\hline $\begin{array}{l}\text { Average Housing Unit size } \\
\text { Before }\left(\mathbf{m}^{2}\right)\end{array}$ & 41 & 18 & 22 & 28 \\
$\begin{array}{l}\text { Average Housing Unit size } \\
\text { After }\left(\mathbf{m}^{\mathbf{2}}\right)\end{array}$ & 44 & 102 & 114 & 84 \\
\hline
\end{tabular}

Table 6-2: The percentage of the interviewees who listed the attributes making them satisfied or dissatisfied before the urban renewal

\begin{tabular}{llllll}
\hline & & $\begin{array}{l}\text { Caochang } \\
\mathrm{N}=25\end{array}$ & $\begin{array}{l}\text { Hongshan } \\
\mathrm{N}=20\end{array}$ & $\begin{array}{l}\text { Longyue } \\
\mathrm{N}=21\end{array}$ & $\begin{array}{l}\text { Total } \\
\mathrm{N}=66\end{array}$ \\
\hline $\begin{array}{l}\text { Factors } \\
\text { dissatisfied }\end{array}$ & Small dwelling & $50 \%$ & $80 \%$ & $60 \%$ & $63 \%$ \\
& Dwelling with deficiencies & $45 \%$ & $85 \%$ & $60 \%$ & $63 \%$ \\
& $\begin{array}{l}\text { Neighborhood with } \\
\text { deficiencies }\end{array}$ & $25 \%$ & $60 \%$ & $65 \%$ & $50 \%$ \\
\hline $\begin{array}{l}\text { Factors } \\
\text { satisfied }\end{array}$ & $\begin{array}{l}\text { Good access to public } \\
\text { facilities and other } \\
\text { resources }\end{array}$ & $75 \%$ & $80 \%$ & $90 \%$ & $82 \%$ \\
\hline
\end{tabular}


Table 6-3: The percentage of the interviewees who listed the attributes making them satisfied or dissatisfied after the urban renewal

\begin{tabular}{llllll}
\hline & Caochang & Hongshan & Longyue & Total \\
& & $\mathrm{N}=25$ & $\mathrm{~N}=20$ & $\mathrm{~N}=21$ & $\mathrm{~N}=66$ \\
\hline $\begin{array}{l}\text { Factors } \\
\text { satisfied }\end{array}$ & Bigger dwelling & $20 \%$ & $90 \%$ & $85 \%$ & $65 \%$ \\
& Better dwelling & $55 \%$ & $80 \%$ & $70 \%$ & $68 \%$ \\
& Better neighborhood & $30 \%$ & $25 \%$ & $70 \%$ & $42 \%$ \\
\hline $\begin{array}{l}\text { Factors } \\
\text { dissatisfied }\end{array}$ & $\begin{array}{l}\text { Worse access to public } \\
\text { facilities and other } \\
\text { resources }\end{array}$ & $35 \%$ & $70 \%$ & $80 \%$ & $62 \%$ \\
\hline
\end{tabular}

As introduced in Chapter three and five, for the original residents in Qianmen area, the average size of housing unit was only 21 square meter (about 226 square feet) before the renewal (Zhu 2005), 28 square meter (about 301 square feet) for the interviewees of this study. It was not rare for a family of two or even three generations to stay in one room with little privacy. To increase space, illegal shanty structures without natural light and/or ventilation were built wherever possible. Besides their small space, most of the courtyard houses did not have adequately equipped kitchens and/or bathrooms. Among the 72 interviewees, only 10 households had a private bathroom. In this circumstance, most of the residents needed to share water taps and other facilities, and therefore the utility bills with their neighbors. In addition, many of the dwellings were lacking in maintenance and in a dilapidated condition with some sort of deficiencies such as unsafe structures, leaky roofs, and so on. These made $63 \%$ of the interviews report that the small unit size was 
one of the aspects they were not satisfied with, and $63 \%$ reported that they suffered a lot from the deficiencies of their dwellings.

At the neighborhood level, most of the hutongs were too narrow for cars, buses and fire trucks. Under this circumstance, there was no place for cars; transit services were quite far away; and the area was very vulnerable to fire damages. Rain water accumulated in hutongs when there was a heavy downpour in summer, because the drainage system was outdated to drain the water away in time. However, the area is surrounded by the Forbidden City, Tiananmen Square, Tiantan Park and Qianmen Street among other nationally famous attractions. It has rich first-class public facilities--key public schools and hospitals. With its central location, residents had easy access to jobs and other resources as well. Moreover, groceries stores, barbershops and small restaurants were just around the corner. Therefore, $82 \%$ of the interviewees reported that the good access to these facilities and other resources was one of the aspects they were satisfied with, whereas $50 \%$ mentioned that other neighborhood physical deficiencies such as narrow hutongs, made them dissatisfied.

Clearly for many residents who used to live in the over-crowded and dilapidated courtyard houses, remaining in the renovated courtyard houses or relocating to newly developed apartments means a much improved life quality in terms of the physical attributes of their living environment. After the urban renewal, the average unit size of the interviewees reached 84 square meters (about 904 square feet), three times of the original one. The housing qualities and neighborhood environment were improved in 
some aspects as well, though the urban renewal also brought new problems. Among the three neighborhoods, there are variations in terms of the extent to which the living space was increased, and the housing quality and neighborhood environment were improved.

The households who remain in Caochang saw just a few more square meters on average, and the unit size of $80 \%$ of the interviewees did not increase at all, which contributes to the fact that just $20 \%$ of the respondents saw bigger unit size as one of the aspects they were satisfied with after the urban renewal, whereas $25 \%$ of the interviewees still saw small unit size as the factor making them less satisfied. The housing quality and neighborhood environment underwent a moderate upgrade. Some of the mostly dilapidated courtyard houses were rebuilt. The surviving ones had a facelift, giving them a fresh appearance. Many courtyard houses were remodeled and refurbished with new windows and doors, gas stoves for heating, new water and electricity lines and meters. The neighborhood environment was improved in some aspects as well: spaces for parking, nicely paved hutongs, clean public restrooms equipped with modern facilities, better electricity, sewage and other infrastructure. Many residents appreciated these improvements. However, the improvements are limited, which is reflected by the simple fact that just 6 more housing units were equipped with a private bathroom after the renovation (which makes it 12 in total, nearly $50 \%$ of the housing units). This is why only $55 \%$ of interviewees reported that better dwelling was one of the aspects they were satisfied with, and only $30 \%$ saw a better neighborhood as one of the aspects they were satisfied with. Furthermore, the urban renewal brought new problems. In particular, 
among others, most of the small neighborhood grocery stores and markets, restaurants, barbershops and other daily utility shops once scattered in almost every hutong were either closed by the owners who relocated or were eliminated for widening the hutongs or making room for infrastructure construction. This made 35\% of the interviews report that the worse access to these facilities and other resources than before was one of the aspects they were unsatisfied with.

For the households relocated to Longyue, the unit size of the interviewees reaches 114 square meters (about 1, 227 square feet), compared with only 22 (about 237 square feet) before. This is why $85 \%$ of interviewees saw bigger unit size as one of the aspects they were satisfied with after the relocation. The new apartments in Longyue are equipped with private kitchens, bathrooms and gas heating, and have better layout and are south facing. The well-equipped apartments provide them a more comfortable and convenient life that their old dwellings can hardly compare with. This made $70 \%$ of the interviewees see better dwelling as one of the aspects they were happy with. At the neighborhood level, since it is far away from the central city, it is peaceful and quiet, and has less air pollution; there are parking spaces and more outdoor spaces in the neighborhood which were well designed and are well maintained. Most residents enjoy these features of the new neighborhood, which is shown by the fact that $70 \%$ of the respondents listed "better neighborhood" as one factor they were satisfied with. However, living in the suburb in Beijing means that the residents face the problem of inadequate first-class public facilities (good hospitals and schools); and for those still working, the residential suburb also 
requires a long commute to work. Under this circumstance, $80 \%$ of the respondents reported that they were unsatisfied with the access to public facilities and other resources.

For the households relocated to Hongshan, the unit size of the interviewees reaches 102 square meters (about 1,098 square feet), compared with only 18 before. This is why $90 \%$ of interviewees saw bigger unit size as one of aspects they were satisfied with after the relocation. The new apartments in Hongshan similar to those in Longyue are equipped with private kitchens, bathrooms and gas heating; however, with the high-density nature of high-rise buildings, the new apartments have minor deficiencies in layout, facing, elevator and other aspects. Under this circumstance, $80 \%$ of the interviewees saw better dwelling as one of the aspects they were satisfied with after the relocation, whereas $45 \%$ listed these deficiencies of the dwellings as factors making them less satisfied. At the neighborhood level, the bus stop is just across the street, parking and more open spaces are available; however, the landscape, some of the open spaces, and a few other facilities are still under construction. Neutralized by these neighborhood deficiencies, only $25 \%$ of the interviewees saw "better neighborhood" as one factor making them satisfied. In addition, the almost brand new neighborhood was in lack of services such as post offices, banks, neighborhood stores and a health center; therefore the residents need to go to the surrounding neighborhoods or back to the original neighborhood for grocery shopping, health care or schooling. This made $70 \%$ of the interviewees list "worse access to public facilities and other resources" as one aspect they were not satisfied with. 
The above analyses point to the following tendencies. First, before the urban renewal, a higher percentage of the interviewees saw "good access to public facilities and other resources" as one factor they were satisfied with; fewer interviewees listed "neighborhood with deficiencies" as one of the aspects making them unsatisfied, compared with the percentage of the interviewees listing "small dwelling" and "dwelling with deficiencies." Second, after the urban renewal, for most of the interviewees, "worse access to public facilities and other resources" became one aspect making them unsatisfied; fewer interviewees saw "better neighborhood" as one of the aspects making them satisfied, compared with the percentage of the interviewees listing "bigger dwelling" and "better dwelling." Together with the fact that the interviewees are significantly more satisfied after the urban renewal than before, these tendencies indicate that (1) dwelling physical factors are more valued than neighborhood physical environment for the interviewees to evaluate their level of residential satisfaction in the Qianmen case; that (2) the improvements in unit size space and housing quality, in particular the former (bigger dwelling was mentioned in the first place by $68 \%$ of the interviewees as the factor they were satisfied with after urban renewal), are the main achievements of the urban renewal; and that (3) more efforts are needed to improve the delivery of public services and the quality of other neighborhood attributes in all the three neighborhoods.

\subsection{Income and Other Economic Attributes}

As discussed in chapter five, the result of the Kruskal-Wallis analysis shows that income among all the demographic and socioeconomic variables is the only variable that 
significantly contributes to the level of residential satisfaction (table 5-7). The residential satisfaction of different income groups is listed in table 6-4. It appears that after urban renewal the residents with high income are the most satisfied, whereas the residents with middle-high income have the lowest level of residential satisfaction. Using the middlehigh income group and high income group as the reference group respectively, the ordinal logistic regressions reveal that when the residents' income increases from middlehigh to high, we would expect a significantly increase in the log odds of being in a higher level of residential satisfaction, whereas when the residents' income increases from low to middle-high, we would expect a significantly increase in the log odds of being in a lower level of residential satisfaction(table 6-5, and table 6-6).

Table 6-4: The residential satisfaction of different income groups

\begin{tabular}{lll} 
& $\begin{array}{l}\text { The Mean of Satisfaction } \\
\text { before }\end{array}$ & $\begin{array}{l}\text { The Mean of Satisfaction } \\
\text { after }\end{array}$ \\
\hline Low income & 4 & 2.25 \\
Low-middle income & 3.25 & 2.5 \\
Middle income & 3.67 & 2.26 \\
Middle-high income & 3.29 & 2.87 \\
High income & 3.25 & 1.69 \\
\hline
\end{tabular}


Table 6-5: The parameter of income predicting residential satisfaction with middlehigh income group as the reference group

\begin{tabular}{|c|c|c|c|c|c|c|c|}
\hline & \multirow[b]{2}{*}{ Estimate } & \multirow[b]{2}{*}{ Std. Error } & \multirow[b]{2}{*}{ Wald } & \multirow[b]{2}{*}{ df } & \multirow[b]{2}{*}{ Sig. } & \multicolumn{2}{|c|}{ 95\% Confidence Interval } \\
\hline & & & & & & Lower Bound & Upper Bound \\
\hline Very satisfied & -2.895 & .759 & 14.551 & 1 & .000 & -4.382 & -1.407 \\
\hline Fairly satisfied & -.401 & .661 & .368 & 1 & .544 & -1.696 & .894 \\
\hline ok & .871 & .678 & 1.649 & 1 & .199 & -.458 & 2.200 \\
\hline Slightly dissatisfied & 1.797 & .793 & 5.141 & 1 & .023 & .244 & 3.351 \\
\hline Low income & -2.397 & 1.194 & 4.032 & 1 & .045 & -4.737 & -.057 \\
\hline Low-middle income & -.697 & .993 & .492 & 1 & .483 & -2.644 & 1.250 \\
\hline Middle income & -1.478 & .763 & 3.754 & 1 & .053 & -2.972 & .017 \\
\hline High income & -2.437 & .891 & 7.483 & 1 & .006 & -4.184 & -.691 \\
\hline Middle-high income & & & & & & & \\
\hline
\end{tabular}

Table 6-6: The parameter of income predicting residential satisfaction with high income group as the reference group

\begin{tabular}{|c|c|c|c|c|c|c|c|}
\hline & \multirow[b]{2}{*}{ Estimate } & \multirow[b]{2}{*}{ Std. Error } & \multirow[b]{2}{*}{ Wald } & \multirow[b]{2}{*}{$\mathrm{df}$} & \multirow[b]{2}{*}{ Sig. } & \multicolumn{2}{|c|}{$95 \%$ Confidence Interval } \\
\hline & & & & & & Lower Bound & Upper Bound \\
\hline Very satisfied & -.457 & .539 & .719 & 1 & .396 & -1.515 & .600 \\
\hline Fairly satisfied & 2.037 & .619 & 10.820 & 1 & .001 & .823 & 3.250 \\
\hline ok & 3.308 & .715 & 21.407 & 1 & .000 & 1.907 & 4.709 \\
\hline Slightly dissatisfied & 4.235 & .850 & 24.822 & 1 & .000 & 2.569 & 5.901 \\
\hline Low income & .040 & 1.095 & .001 & 1 & .971 & -2.105 & 2.185 \\
\hline Low-middle income & 1.740 & .957 & 3.304 & 1 & .069 & -.136 & 3.617 \\
\hline Middle income & .960 & .661 & 2.107 & 1 & .147 & -.336 & 2.256 \\
\hline Middle-high income & 2.437 & .891 & 7.483 & 1 & .006 & .691 & 4.184 \\
\hline High income & $0^{\mathrm{a}}$ & & & 0 & & . & . \\
\hline
\end{tabular}


According to the existing literature, the resources owned by individuals indicate the extent to which they can choose their residential environment congruent with their needs and preference, thereby influencing their level of satisfaction. More specifically, resources, especially financial resources, give individuals the power to choose or control the neighborhood where they live in a competitive housing market. Therefore, the more resources they have, the more likely they are satisfied with their residential environments (Parkes, Kearns et al. 2002; Grogan-Kaylor, Woolley et al. 2006). The findings of a number of scholars show that individuals with higher incomes have greater residential satisfaction(Galster and Hesser 1981; Galster 1987; Lu 1999; Parkes, Kearns et al. 2002; Grogan-Kaylor, Woolley et al. 2006).

The findings of this study reveal that the residents with high income have the lowest mean score of residential satisfaction(highest satisfaction level) among all the income groups (table 6-4), the residents with middle income have a lower mean score of residential satisfaction than the residents with low-middle income (table 6-4), and particularly the residents with high income have significantly higher level of residential satisfaction than the residents with middle-high income (table 6-5 and table 6-6). These echo the findings of the above literature, that is, the higher the social class, the higher the level of residential satisfaction. However, two other tendencies are contradicting with the above literature. The residents with middle-high income have higher mean score of residential satisfaction (low satisfaction level) than the residents with lower income (table 6-4). The residents with low income have lower mean score of residential satisfaction 
(high satisfaction level) than the residents with low-middle income and middle income (table 6-4), and further are significantly more satisfied than the residents with middlehigh income (table 6-5). The above results show us the feature of a curved line relationship between social class and residential satisfaction with the middle-high income group at the bottom, which is in need of exploration in detail.

The existing literature provides insight into these phenomena as well. Researchers have argued that the level of residential satisfaction is not impacted directly by social status or minority status, but results largely from variations in residential environment, the potent intervening variable, due to the marked social inequalities(Fried 1982; Parkes, Kearns et al. 2002). The points of Fried and others might help us to understand why some scholars have reached the conclusion that there were no big differences in the level of residential satisfaction between individuals with different social status (Amérigo and Aragonés 1990). Researchers have further argued that individuals with higher social status tend to have higher standards and aspirations due to their social mobility, contributing to lowering their level of satisfaction (Freeman 1998; Liu 2005; Fang 2006). Furthermore, according to Galster, the evaluation of residential environment is not only affected by the individuals' future aspirations, but also by their experiences of the past. These points are particularly helpful for understanding the phenomena happened in the Qianmen case.

Residents with low income had the smallest unit size to start with (table 6-7), and suffered the most before the urban renewal. This experience of the past made some of them have moderate expectations. Thus they are easily satisfied with the improvements 
which might be quite slight for other people. Mrs. Cheng in her forties was relocated to Caochang from another neighborhood in Qianmen with her husband and her ten-year old daughter. She was rather happy with the results:

"I am very satisfied! Our unit size is almost twice as large as before, and we got a little kitchen, so I do not have to cook in the hallway. The hutongs and public restrooms are much cleaner now ... the greatest thing is that we did not pay any money to make this happen, instead we got a 10,000 moving fee".

\section{Table 6-7: The unit size of different income groups}

\begin{tabular}{lll} 
& & $\mathrm{N}=61$ \\
\hline & Unit size & Unit size \\
& Before $(\mathrm{m} 2)$ & After( $\mathrm{m} 2)$ \\
\hline Low income & 12.65 & 42.52 \\
Low-middle income & 16.54 & 40.59 \\
Middle income & 25.09 & 88.03 \\
Middle-high income & 16.54 & 94.58 \\
High income & 48.46 & 119.25 \\
\hline
\end{tabular}

The current unit size of Ms Cheng's home is only 30 square meters (about 323 square feet), far less than the average unit size of the residents with low income --42.52 square meters (about 458 square feet) (table 6-7). Mr. Zhao, in his late fifties and living with his wife in a 53.1 square meters (about 572 square feet) apartment in Hongshan, expressed his appreciation of the improvements:

"Our house is spacious, you know, I can walk inside instead of going outside for a walk when the weather is not good. It was impossible in my previous house, 
because half space of my old house was occupied by beds. And we have our own kitchen and restroom in our apartment, do not have to cross the open court yard to go to the kitchen and use the public restroom along hutongs as before".

From their words, you can tell that their relative high level of satisfaction is in part a result of their low expectations affected by their past experiences. Mrs. Cheng and Mr. Zhao represent a group of residents who experienced almost the worst residential environment and therefore were desperate for better conditions; however with very low income, they were the most powerless to do so by themselves. In the Qianmen urban renewal project, the compensation policy, as introduced in the chapter three, provided extra aids to low income households: increasing their baseline size of compensation to 13.1 square meters (about 141 square feet); offering them up to 20 square meters (about 215 square feet) to rent with a subsidized price; and providing rental-subsidized public housing based on their family size rather than original unit size to those low income households covered by the minimum living allowance.

It seems that the compensation policy giving special consideration to low income residents has positive effects. The mean score of their satisfaction level decreased from 4 to 2.25 , which means they used to tend to be dissatisfied, but now they are more satisfied. Among all the income groups, they have the second highest satisfaction level. Their low expectations might contribute to the high level of satisfaction as discussed above, but from a perspective of informing public policy, this study would more like to argue the positive effects of the compensation policy showing efforts to resume more of the 
government' role in delivering welfare and redistributing wealth. Constrained by the limited case number of this study, this conclusion certainly needs further inquiry by future studies.

In this study, this argument could be further supported by the experiences of some of the stayers who had a little bit higher income, therefore, were not covered by the minimum living allowance. They usually have a bigger family, which means they need larger living space, and/or smaller unit size to start with, which means they would only get very limited monetary compensation or a small space in Hongshan for free. To buy extra space, they need to spend their savings or pay a heavy mortgage which is quite unaffordable for them with limited income. Under these constraints, what they could get is far from meeting their housing needs; thus, they had to stay and hoped that the government could address their problems in the future. Mr. Xu, in his fifties living with his wife, grown-up daughter and mother, told me his thoughts:

"We have three generations living together and my daughter is a grown up now, we really need more space. However, my mother goes to Tiantan hospital for health care every week, so we cannot move to the suburbs, which is too far away; we don't want to stay in the current small unit as well, but we need to pay 100,000 Yuan to move to Hongshan which is something we cannot afford."

$\mathrm{Mr}$. Xu is one of a group of residents who stayed. Their problem of housing shortage was not solved after the renovation due to their limited family assets and income and the 
compensation policy arrangements. Therefore they have an extremely low satisfaction level ${ }^{9}$. Among the interviewees who stayed, six families fall into this category, the mean score of their residential satisfaction level after the urban renewal is only 4.17, which contributes to the low satisfaction level of the stayers to a large extent.

On the other hand, the residents with limited income who relocated did increase their unit size; however the costs they paid and are paying is a big burden for their family. This affects their satisfaction level as well. More specifically, some of them lost extra money from their informal business in Qianmen; some of them paid a large amount of their savings to buy extra space; and/or need to pay higher transportation costs or utility fees than they used to. For the three interviewees who complained about losing extra income from family business, the mean score of their residential satisfaction is only 4 after the urban renewal. The result of a simple ordinal logistic regression analysis shows that paying money to buy extra space and/ or paying higher transportation costs or utility fees significantly predict low level of residential satisfaction (Pseudo R-Square= .166; $\mathrm{p}=.005)$.

Mr. Wang, in his fifties, is one of the six interviewees who relocated to Hongshan and complained that it took a large amount of their savings to buy the apartment and further

\footnotetext{
${ }^{9}$ It is worth mentioning that the low-middle income and middle income residents' levels of resident satisfaction are not significantly lower than the low income residents. The interpretation of the study is based on the quatitative statistics of the sample rather than the general population. Constrained by the small sample size, this is the limitation of the study.
} 
paid other costs such as property maintenance fee and the increased utility fees regularly for the new apartment. Mr. Wang compared his costs before and after the relocation:

"The total rent for our apartment in Qianmen was only 40 Yuan a month and we did not need to pay property maintenance fee. We spent more than 200,000 Yuan to buy the apartment for which we only have part ownership. We need to pay property maintenance fee for the part of the apartment we owned and rent for the other part rented from the housing authority. In total, we spend more than 2,000 Yuan a year here. It is very hard for a family like us with four members, but limited income."

Residents with limited income who moved out of the central city to the suburban area did not pay much for realizing homeownership; however, they are more concerned about commuting costs. Mr. Liu, in his forties, is one of them. He lives with his wife and school age son in Longyue.

“Before, my wife and I went to work by bike; my son's school was close as well. We travel back to the central city for working and schooling now, usually spend 15 mins to the light rail stop and then 40 mins to go to the central city, which cost about 120 Yuan a month overall. It is a very high expense for our family”.

Even for some of the residents with middle-high income, the money costs they paid still put them under pressure, thus affecting their satisfaction level. Mr. Wang, in his fifties, 
lives in a 77.61 square meters (about 835 square feet) apartment in Hongshan with his wife and grown-up daughter. He elaborated on the things that made him less satisfied:

"We spent 270,000, a large part of our savings, to buy the apartment. I feel the pressures to save money for our future life. You know, my daughter is going to be married soon, which will cost money too. The other thing is that my apartment is not as good as my sister's, who bought commercial housing with better qualities, such as windows with higher efficiency, south-facing and so on. I am a civil engineer, I know these details. Nowadays, people have a higher quality of life and in turn have higher requirements. So, although my apartment is better than my old one which is only 9.4 square meters (about 101 square feet), I am still dissatisfied".

From Mr. Wang's words and the foregoing analyses, we can see how the limited resources individuals have influence their level of satisfaction, which is consistent with the findings of some existing literature. On the other hand, Mr. Wang's narratives also point to the fact that with middle-high income and as a civil engineer, his relatively higher level of social status provides more opportunities to be exposed to higher level experiences, based on which high expectations for residential environment were formed. Thus, it is hard to deny that high level of expectations contributes to his low level of satisfaction. This finding supports the points of Freeman and others that individuals with higher social status tend to have higher standards and aspirations due to their social mobility, attributing to their lower level of satisfaction (Freeman 1998; Liu 2005). 
The study further found that other residents with middle-high income, for whom the cost is not a concern, care about other attributes. Mrs. Zhang in her forties, relocated to Longyue, and talked about her loss of sense of belonging:

"We used to live in the vicinity of the Forbidden City and hear the national song every morning from the Tiananmen Square. We are very proud of that. But now, we are country people not city people anymore. I feel even the street light is not as bright and food in the restaurants does not taste as delicious".

It might be true about the brightness of the street light and the taste of the food in the suburban area. However, behind the literal meaning of her words, Mrs. Zhang conveyed her feeling of sadness about the disruption from the environment she was attached strongly to. For the elders, who were attached to the original neighborhood more deeply and usually have more difficulties to adapt to the new environment, the disruption brought more bitterness. Mr. Zhang, 78 years old, was walking around with his dog when I met him in Longyue:

"We do have a bigger apartment, but when young people go to work during the day, the neighborhood is just too quiet. Walking my dog in the neighborhood is almost the only thing I can do. You can chat with your neighbors while running into each other, but the way is not what it was. In the courtyard house, I saw neighbors all the time and some of them I had known for decades, so they were more like family members rather than just neighbors. I went to Tiantan Park and 
Tiananmen Square every day, and on the way back home, did grocery shopping from shops at the corner and stands in the Hutongs. The life was very vibrant and busy, I really miss it".

Mrs. Zhang and Mr. Zhang represent a group of residents whose family income are relatively high, and most of their basic physical needs for living environment are satisfied. Therefore, they are more concerned with their psychological and social needs which were remained unsatisfied somehow after the relocation, and further impact their residential satisfaction. This finding echoes the arguments of Fang, Turner and others that there is a housing needs hierarchy(Fang 2005), where different income groups show differences in their housing needs (Turner 1972). These perspectives help to explain why residents with middle-high income have a lower level of residential satisfaction.

The above analyses indicate that some of the residents with middle-high income have higher expectations for housing and are more concerned with social and psychological needs for living environment; however, to realize these expectations or needs is still beyond their financial capability, and in a few cases, even realizing their physical needs for living environment still put them under financial pressure. Compared with this income group, residents with high income tend to have higher expectations for housing and be more concerned with social needs for living environment as well; however, they have more financial power to choose or control where they live; thus they are more satisfied. 
In the Qianmen case, it is true that residents with high income are living with other income groups in the same neighborhoods; however, their financial power made them all stay or relocate voluntarily, compared with the fact that at least $20 \%$ of residents in other income groups moved involuntarily (table 6-8). Their financial power also helps them enjoy bigger apartment than all the other income groups (table 6-7). Bigger unit size and voluntarily decision attribute to their higher level of residential satisfaction. The significant difference of residential satisfaction between the residents with high income and the residents with middle-high income robustly supports the argument that the higher the social class, the more likely they are satisfied with their residential environments (Parkes, Kearns et al. 2002; Grogan-Kaylor, Woolley et al. 2006).

\section{Table 6-8: The involuntary relocation of different income groups}

\begin{tabular}{lll} 
& & $\mathrm{N}=61$ \\
\hline & Voluntary & Involuntary \\
& $\%$ & $\%$ \\
\hline Low income & 75 & 25 \\
Low-middle income & 71.4 & 28.6 \\
Middle income & 71.4 & 28.6 \\
Middle-high income & 71.4 & 28.6 \\
High income & 100 & 0 \\
\hline
\end{tabular}

These findings are particularly informative for policy makers in China today, when the significant widening of income gap between different groups of people has become a growing concern. Even in the small sample of this study, six residents were keenly aware of the problem and voiced fairly strong complaints about it. They also have very low levels of residential satisfaction (the mean score is 4). Mr. Wang is one of them. He stays 
in Caochang with his wife, mother and son in a 30 square meters (about 323 square feet) apartment after the renovation, and groaned his bitterness:

"Rich people live in mansions. We cannot even afford to move to Hongshan, so we do not have any other choices but are stuck here in this small room with three generations. We do not daydream of mansions; actually a two-bed room apartment would make us quite satisfied. Premier Wen said 70 square meters (about 753 square feet) should be the basic standard ensuring people's livelihood. We are dreaming about it, but do not know when the dream can come true."

The above elaborations suggest the general tendency that the residents' financial resources shape the extent to which they can choose their residential environment congruent with their needs and expectations, and thereby the extent of their residential satisfaction; in other words the higher the social class, the higher the level of residential satisfaction. However, this general tendency is mediated by other factors: housing needs hierarchy, which has been well addressed by the literature; and public policies of delivering welfare and redistributing wealth, which still need further scrutiny and thus is the major concern of this study.

More specifically, the literature revealed that there is a housing needs hierarchy----the higher the social class, the more likely they have higher needs and expectations, which means higher social class might be less satisfied, when their needs and expectations are too high to be afforded within their financial resource limits. This is clearly demonstrated 
in the case of residents with middle-high income. They have higher expectations for housing and are more concerned with psychological and social needs for living environment after their physical needs were mostly satisfied, however, to realize these expectations or needs is still beyond their financial capability, which contribute to their lower level of residential satisfaction.

Secondly, public policies can ameliorate the less satisfied situation of people in a lower social class by improving policy arrangements. In the Qianmen case, the policy arrangement provided extra aid to those low income residents with the most difficulties, helping them get more positive effects than they would otherwise achieve; therefore they had higher level of residential satisfaction than residents with higher income. However, the coverage of the public policies was limited; thus residents with limited income who did not benefit from the arrangement are the most dissatisfied.

These findings remind us that facing the widening of income gap between different groups of people in China, policy makers need to pay more attention to the disadvantaged class to help them improve their residential environment, by expanding the coverage of public aid to include more people rather than just the residents with low income, and addressing social attributes rather than just physical attributes of the residential environment. In other words, the government needs to show more effort to resume more of its role in delivering welfare and redistributing wealth. 


\subsection{Involuntary Relocation}

The result of the ordinal logistic analysis in last chapter shows that going from involuntary moving to voluntary moving, the odds of having a higher level of residential satisfaction are 2.32 greater, given that all of the other variables in the model are held constant. This section further looks into the effects of involuntary relocation on residential satisfaction in the Qianmen case, based on a brief review of the existing literature. And further it discusses how to reach positive results, when households are impacted by passive relocation.

According to western housing mobility research, moving behavior includes voluntary moving and involuntary moving depending on the moving decision making processes (Rossi 1955). In western countries, involuntary moving means that households are forced to move out of their previous homes. The negative effects of forced moving are widely identified (Marcuse and Kempen 2000; Wu 2004; Freeman 2005; Lees, Slater et al. 2008; Sassen c1994). However, there are exceptions (Kleinhans 2003; Kleit and Manzo 2006; Kleinhans and Kearns 2013). For example, Kleinhans reported the results of empirical research into the experiences and satisfaction of movers who had been confronted with forced relocation in the Netherlands. Most respondents improved their housing situation due to their priority rights in the housing market (Kleinhans 2003). In some cases, forced relocation may not be perceived as forced at all (Kearns and Mason 2013; Kleinhans and Kearns 2013). Nevertheless, the research uncovered the differences between voluntary moving and involuntary moving. Goetz compared the effects of voluntary moving and 
involuntary moving. He found that compared to voluntarily mobile families, families forcedly moving into replacement units report fewer benefits from their moves, in the field of social interaction of children, and several others regarding neighborhood satisfaction (Goetz 2002).

In the Chinese context, involuntary moving has been used to describe the forced departure of original residents either because of urban infrastructure developments or urban renewal projects. Forced departure does not mean moving is carried out by force or eviction; rather, in most cases it refers to moving that does not originate in the households' own decisions(Wu 2004). Therefore, it is also labeled as passive moving. In the planned economy, the majority of residential relocations were led by the government both in terms of the initiation of the moving and in terms of where to move. Along with the economic reforms, more and more relocations are by households' own choices, and even in the case of relocations initiated by the government, households are offered more options on where to move.

Based on a sample of some 500 households in Shanghai, Wu investigated the overall level of residential satisfaction, and further compared the satisfaction level of households relocated actively and passively. Although the passively relocated households have a lower level of residential satisfaction than those actively relocated, residents are generally happy with the relocation (Wu 2004). Fang surveyed 105 households in four neighborhoods in Beijing. The relocation of all the interviewees was involuntary in terms 
of both moving decision and moving choice. Fang's study suggests an overall low level of satisfaction across all the four neighborhoods(Fang 2006).

In the case of Qianmen, the urban renewal project was initiated by the municipal government. However, except for a few who were affected by infrastructure development or other public interests, most residents were offered the option to remain in Qianmen. In terms of where to move, they could choose monetary compensation to buy housing from the market or choose comparable affordable housing. In this way, many households actually saw the relocation as an opportunity to improve their residential environment, and reported that they voluntarily moved to their current housing, in spite of the fact that their relocation was not initiated by themselves. Mrs. Zhang, in her fifties, relocated to Longyue with her husband, grown-up son and mother in law. Her experience reflects the view of a group of residents:

"I am actually glad to be forcibly relocated, because I finally ended up being pretty happy with the life in the new neighborhood. Nothing like in Qianmen, it is very quiet and peaceful, and the sky is blue not grey. So, it is very nice for the life of people who are retired. I can tell you, if they (the government officials) had given me more information about the new neighborhood, they did not need to persuade me to move here".

On the contrary, a few households who remain in Qianmen complained that they wanted to move out but could not due to various barriers, and reported that they stayed 
involuntarily. Certainly, the infrastructure development at the first stage of urban renewal did force a few households to move out involuntarily, who would otherwise have preferred to remain in Qianmen. In this study, involuntary moving refers to these two types and moving that is not by the respondent's ${ }^{10}$ choice but by their family member's, that is, moving households perceive as involuntary. It accounts for $25 \%$ of all the respondents (table 6-9).

Table 6-9: Involuntary relocation across the three neighborhoods

\begin{tabular}{|c|c|c|c|c|}
\hline & Caochang & Hongshan & Longyue & Total \\
\hline & $\mathrm{N}=25$ & $\mathbf{N}=\mathbf{2 0}$ & $\mathrm{N}=\mathbf{2 1}$ & $N=66$ \\
\hline $\begin{array}{l}\text { Voluntary moving } \\
(\%)\end{array}$ & 69.6 & 94.1 & 57.9 & 75 \\
\hline $\begin{array}{l}\text { Involuntary moving } \\
(\%)\end{array}$ & 30.4 & 5.9 & 42.1 & 25 \\
\hline
\end{tabular}

As expected, respondents who relocated voluntarily reported higher levels of residential satisfaction than respondents who relocated involuntarily. The mean score for the former is 1.91 , whereas it is 3.4 for the latter. The result of simple ordinal logistic regression in Chapter five shows involuntary moving accounts for $20.5 \%$ of the variance of residential satisfaction(Pseudo R-Square=.20.5; $\mathrm{p}=.035)$ (table 5-8). Controlling for the variables of unit size and income, it still significantly predicts residential satisfaction as pointed to at the beginning of this section.

\footnotetext{
${ }^{10}$ Many of them are the elderly who were forced to go along with their children's decision.
} 
The findings of this study indicate that although limitation of moving choices does make households perceive the relocation as involuntary moving, therefore are unhappy with the results; moving initiated by the government rather than households themselves, in other words, involuntary (passive) moving in line with the existing literature, does not necessarily bring about bitterness. This echoes the findings of $\mathrm{Wu}$ and the experiences in Netherland that involuntary relocation turns out well for movers, though negative findings and effects dominate many of the existing literature(Kleinhans 2003; Kleinhans and Van der Laan Bouma-Doff 2008).

Therefore, the question that remains is how to reach positive results when households are impacted by passive relocation. Two main aspects are identified in a broad literature review: public interventions at the institutional level, and disposition characteristics of movers from the individual's perspective. Public interventions such as mass public housing provisions and better compensation arrangements(Keating 1985; Susnik and Ganesan 1997; Kleinhans 2003; Manzo, Kleit et al. 2008; Kleinhans and Kearns 2013)are considered as crucial factors generating positive outcomes. In chapter three, this dissertation has discussed the policy arrangements aiming at social equity in the case of Qianmen. In terms of disposition characteristics of movers, researchers point out that households are more likely to achieve beneficial outcomes when they can confront the problems, proactively obtain information, go to the right people, and act strategically (Ekström 1994; Kleinhans 2003). Mrs. Cao, who moved to Longyue after urban renewal, was very happy with the results; she told me: 
"I was in the marketing department of my company. It required me to travel around the city. So, I actually had chances to know this area before the relocation. When I heard that the apartment here was an option for us, I visited on purpose to further make sure this is a place that I like. Then I prepared the documents carefully and talked to the staff in charge many times, which was a very tricky process. I was hoping more information and support could be provided by the government to make it easier... But I was still luckier than some other people; at least I knew the area earlier, and finally got what I want".

The narrative of Mrs. Cao reveals how disposition characteristics of movers impact the results. It also indicates that personal action needs information and assistance from the government, whereas in the case of Qianmen, the government did not take much of this responsibility. Mrs. Cao's experience is not exceptional. Nearly one third of the interviewees complained that the government did not provide enough information to help them make decisions. Half of them thought the government should put more effort into providing supportive services to reduce their suffering from relocation. In the existing literature, providing more relocation counseling and supportive services to minimize negative relocation impacts has been increasingly gaining attention (Ekström 1994; Kleinhans and Kearns 2013; Varady and Kleinhans 2013).

The above analyses imply that passive (involuntary) relocation does not necessarily bring about bitterness. In the case of Qianmen, many households actually saw the relocation as an opportunity to improve their residential environment, and reported that they 
voluntarily moved to the current housing. Whereas the limitation of moving choices did make a few households stay or move to the residential environment involuntarily, leading to unhappiness with the results. The residential satisfaction level between the perceived involuntary moving and voluntary moving is noticeable. Therefore, voluntary moving which accounts for $75 \%$ of all the respondents significantly contributes to the improvement of residential satisfaction after urban renewal. Nevertheless, the government should put more effort into providing intensive information and support to help the households make good use of the opportunity rather than suffer from it. 


\section{Chapter 7: Social Attributes and their Significance Predicting Residential Satisfaction}

The result of the simple ordinal logistic analysis in chapter five shows that residents' subjective evaluation of the impact on their social networks significantly contributes to the level of residential satisfaction (table 5-8). However, it does not significantly predict residential satisfaction, when unit size, income and involuntary relocation are held constant. Therefore, how social factors impact residential satisfaction and furthermore the social outcomes of the Qianmen urban renewal project need additional exploration. With the purpose of concerning the social impacts of urban renewal similar to seminal works, this section will start with a brief review of the existing literature, then analyze the original Qianmen residents' social interactions with their neighbors and their local intimates within their overarching social networks before and after urban renewal, and further look into how these affected their residential satisfaction.

\subsection{A Brief Review}

Researchers found that before China's economic reform close neighborhood relationships were far more common in urban China than in Western cities (Whyte and Parish 1984; Jankowiak 1993). This was attributed, they argued, to factors such as high residential stability, low income inequality, limited spare time and transport and communication methods, various featured neighborhood activities organized by the resident neighborhood committees (jumin weiyuanhui), and the unique work-unit system. Playing a pivotal role in social and political cohesion in socialist China, the work unit compound, 
consisting of working places, housing, and social facilities, used to be the basic cellular structure of urban China. Besides work unit compounds, a large scale of old urban areas also existed in pre-reform Chinese cities. In spite of the lack of work units, long years of common residence and traditional residential spatial environment nurtured rich local interactions in old urban areas like Qianmen.

These features share some similarities with homogeneous low income neighborhoods in the western world, where neighboring tends to be more intense, intimate and multistranded (Fischer 1982; Campbell and Lee 1992; Forrest and Yip 2007). Several perspectives of theories have been developed to explain this phenomenon. For Janowitz and others, local community is an ongoing system of social networks into which new generations and new residents are assimilated. Under this conceptualization of local community, length of residence is the primary factor influencing the forming of local social networks of friendship, kinship, and association, since the assimilation process is necessarily time-consuming(Janowitz and Kasarda 1974). Contact theory contends that in order for interactions to be positive, they usually need to involve equal-status contacts (Ford 1986; Kleit 2001). In other words, similar social status facilitates social interactions. Beyond social features, neighborhood physical features are also identified as factors affecting local interactions. The physical layout of neighborhood, the meeting places (shops, recreation facilities, parks, schools, and so on), and the architecture design (front porch, shared access, for instance) among others have been widely investigated (Skjæveland, Gärling et al. 1996; Bridge, Ray Forrest et al. 2004; Volker, Flap et al. 
2007). Recently, New Urbanist thinking further advocates the importance of neighborhood physical attributes, such as moderately higher density, mixed land uses, and better connected streets, to support close-knit social communities(Yang 2007). The main argument of Fischer's "choice-constraint" model of community(Fischer and [et al.] 1977) is that the limitation on the range and number of possible social relations in the wider society due to spatial, social or other barriers forces local community members to functionally depend on neighborhood relations. For the lower SES sub-group for example, it is widely recognized that their transportation and communication resources are limited due to their uncertain financial situation, therefore, they are less integrated with the wider society and local networks assume more importance in their life (Kleit 2001).

Some of the factors explored by the above western theories and those factors featured in China cultivated rich local social interactions in urban China. However, after the economic reform, the once gemeinschaft-like social relations have been evolving toward gesellschaft-like relations which are based on more specialized, contractual exchanges of support. More specifically, along with the rampant marketization and the increasing income gap between different social groups, old moral codes and conventions tend to break down(Forrest and Yip 2007); "cash nexus", in the words of Whyte and Parish(Whyte and Parish 1984), has more and more impact on personal relations instead. As a result, people no longer feel as close to other people as before, which undermines the base for social interactions. In addition, with increasing residential mobility due to new transportation and communication tools; residents rely on local community to a 
lesser extent, thus, local interactions are not as strong as before. In old urban neighborhoods like Qianmen, along with the increasing income gap, some of the betteroff families moved out of the over-crowded and dilapidated old urban areas to better housing; and in turn, their apartments were rented out to new residents, the majority of whom are rural migrants with low SES. Under this transition and other social trends discussed above, the once homogeneous social composition and social stability of these old urban neighborhoods has been changing. Furthermore strong neighborly trust and social support that rose through long-term residency has been gradually weakened.

In spite of these changes, researchers still identified intensive neighborhood-based social interactions and social cohesion in old urban areas compared with commodified neighborhoods in urban China. A study by $\mathrm{Wu}$ and $\mathrm{He}$ on the social impacts of urban renewal in three traditional neighborhoods in Nanjing found that the traditional neighborhood that had not experienced urban renewal showed the strongest neighborhood-based social interactions; whereas the neighborhood that had experienced large scale redevelopment had the weakest local social interactions(Wu and He 2005). The investigation of Forrest and Yip indicated that the extent of social interactions and mutual assistances among neighbors was greater in the older, more established neighborhood than in commodity housing complexes (Forrest and Yip 2007). And according to, Hazelzet and Wissink, a larger portion of residents in the two central neighborhoods in Guangzhou (one of which is a pre-1949 neighborhood), reported 
neighborhood as their source of social networks than those in other neighborhoods (Hazelzet and Wissink 2012).

However, these intensive social interactions and assistance in the old urban areas have been undermined by the social transitions after the economic reform, and in particular by large scale urban renewal, which has been widely practiced by most of China's local governments, and in many cases, has resulted in the collapse of traditional communities. The following section will analyze how the residents' social interactions with their neighbors and their local intimates within their overarching social networks were impacted by the urban renewal project.

\subsection{The Original Qianmen Residents' Local Social Interactions and Intimates}

\section{- Before the Urban Renewal}

From the description of Qianmen in Chapter three, one can get a general sense of the rich social interactions and assistance in Qianmen. This section will further look into the intensive local interactions among neighbors in Qianmen and the residents' local intimates within their overarching social networks before the urban renewal.

The existing literature informs us that social interactions in neighborhoods which are widely termed as neighboring remain as a significant element of social interactions; and three dimensions of manifest neighboring activities include: (1) socializing, (2) social support, the most recognized dimensions of neighboring activities in existing literature, 
and (3) "bridging" activities, which some researchers, such as Warren and Skjaeveland et al., have emphasized (Warren 1986; Skjæveland, Gärling et al. 1996; Briggs 1998).

More specifically, neighborhood socializing activities range from greetings, chats, home visits, sharing leisure time within or outside the neighborhood, to more intimate conversations. The neighborhood is one of the important places for personal socialization, therefore, neighborhood sociability, as Warren stated, can be an important source of social belonging for the residents, and can mitigate some of the depersonalizing impacts due to the urban context. The information exchange during the process of neighborhood socializing helps neighbors build social norms which influence their living, ranging from home decoration to political attitudes. In addition, neighborhood sociability as a first step can further instigate social support and bridging activities(Warren 1986).

Social support in the neighborhoods consists of both practical (material) help and emotional help. Although for Keller and others, many of the supportive interactions in neighborhoods involve only minor aid (borrowing a cup of sugar for instance)(Keller 1968), Warren, Lee et al, Bridge and others suggested that neighbors can exchange various kinds of goods, small amounts of money, and small services. In particular, a number of scholars stated that individuals turn to their neighbors in a time of emergency (Litwak and Szelenyi 1969; Warren 1986; Berry and Krannich 1990; Mesch and Manor 1998; Bridge, Ray Forrest et al. 2004). For less critical matters as well (driving children to school for instance), physical accessibility makes it easier for neighbors to deliver services. This contributes to the increase in the frequency of contacts; therefore, 
according to Wellman, neighbors are an individual's most frequent contacts, even though they may not be the most intimate members of their personal networks(Wellman 1996; Mesch and Manor 1998).

As both Warren and Skjaeveland et al. emphasized, social interactions in neighborhoods are not limited to socializing and social supports; they also involve "bridging" activities based on face-to-face contacts of the former two kinds of social interactions(Warren 1986; Skjæveland, Gärling et al. 1996). According to Briggs, bridging activities help individuals "get ahead" through providing them information and other supports, such as providing job information or a recommendation for a scholarship (Briggs 1998). For Warren and others, neighbors play a role of "bridging" in two ways: "directly via referrals to organizations and non-neighbor 'experts' and helpers; and indirectly via passing on information gained from the knowledge and experience of other neighbors" (Warren 1986: 326).

Based on the above review, the study codes the neighboring activities into three types: socializing activities, social supports activities and social bridging activities. The results shows that all the respondents were involved in intensive socializing activities with their neighbors; $80 \%$ of the respondents reported that they exchanged various kinds of goods and services, and helped each other with both emergency and everyday care regularly(such as taking a neighbor to the hospital and taking care of a neighbor's children after school); and a few respondents stated that they found a job with the referrals of their neighbors or informed their neighbors of resources needed for career 
design. The rich neighboring activities were a constant theme in my conversations with the interviewees across different age, gender and income groups. Mr. Zhang, in his twenties, recalled that:

"When I was little, after school if my parents worked late, I went to my neighbors' home for a meal, Grandma Wang, Uncle Li whoever cooked. Uncle Li's son, Li junior and I are the same age. He was my playmate since little, and then we went to same school. I still remember we walked to school together every day. After school, we joined other friends chasing around and playing hide-and-seek through hutongs. It is called 'chuan hutong'. Lots of fun! There were accidents certainly. Once, I broke my arm. I do not remember what caused it, but I do remember two neighbors took me to the hospital. Back then I was a 'famous' naughty boy, caused quite a few accidents like this. 'Naughty', en? As I grew up, I made several life-long friends and got to know almost everyone in the neighborhood. I did not say hello to all of them, I surely felt safe by knowing that they were someone living in my neighborhood though. "

Mr. Zhang's description shows us how a young man enjoyed his childhood, and further how his neighbors and friends in the neighborhood made Qianmen such a nice place for him to grow up. This was a place with the history and culture of mutual watching and supporting, which were inherited from the old generation to the young generation. When the young generation grew up, they offered what they received back to the community. Mrs. Wang, in her late thirties, told me that: 
"My family has been really close with Grandmas Wang and Wu. Wang is in her eighties, and Wu seventies. They had watched my husband grow from childhood, kind of family members to us. We did a lot of things for them. I helped them buy vegetables, clean their home... My husband helped them carry heavy things, like coal, fixed their home stuff, light for example... We were also the persons to call on first, when they were sick and their children were not available. They helped us too. I still appreciate that they took care of my son when he was little. Back then, I worked half day and my mom could not come over very often. You see, with neighbors we did not have to pay for these services. We had limited money to pay. Even though we had money, we could not get some of these services in the past when services, like property maintenance and home cleaning services, were not as usual as today. So we helped each other a lot. That was our life".

From the perspective of a seventy-year elder, Mrs. Zhao' experience further indicates how an elder perceives the social interactions in a traditional neighborhood.

"I had lived in Qianmen for decades. I was feeling like living in a cottage. We all were pretty much in a similar situation, having about the same amount of money. We knew almost everything about each other. When a family had a problem, all the neighbors would know it, many were willing to help. Last time when I was sick, my son was out of town. One neighbor, also my son's good friend since little, took me to the hospital. A couple of neighbors came over, bringing food and providing company, this way, my daughters did not have to travel from far several 
times a day to take care of me. When an emergency like this happened, we always could find someone next door to help. In everyday life, I liked to sit in the sun chatting with my old neighbors or just watching kids chasing around. Isn't that like living in a cottage? Oh, you might be a city girl, have not much idea about that...We watched the door for neighbors. We brought their clothes in when the rain came and they were not home. After cooking special foods, we would take some to the neighbors to try..."

The cottage in the words of Mrs. Zhao, presents us a community where neighboring is intense, intimate and multi-stranded. Her narrative, along with the others' above, shows us residents in Qianmen involved in far more than just superficial socializing activities. They used to rely on local social support to a large extent, in particular when other sources of support or services were constrained due to whatever reasons: absent family members (children out of town or living far away, parents needing to go to work), inadequate services in old urban areas (such as property maintenance and home cleaning services were not available in the pre-reform era, and are still inadequate nowadays), low income and so on. This is consistent with Fischer's "choice-constraint" model of community(Fischer and [et al.] 1977), which contends that the limitation on the range and number of possible social relations in the wider society due to spatial, social or other barriers forces the members to functionally depend on neighborhood relations. Although Fischer's model was widely used to explain why low SES people rely on local social support to a larger extent, the findings of this study remind us that when other sources of 
support or services were constrained due to whatever reason, everyone might need to rely on local social supports, regardless of their income or age. A supportive local community like Qianmen before the urban renewal always made their life easier.

The above narratives also indicate other reasons why Qianmen was such a supportive community before the urban renewal. On one hand, long years of common residence nurtured rich local social interactions in the Qiamen area: people got to know each other well, on which the formation of common values of mutual supporting was based; new generations were assimilated into local social networks while growing up. This echoes Janowitz and others' point that length of residence is the primary factor influencing the forming of local social networks of friendship, kinship, and association, since the assimilation process is necessarily time-consuming (Janowitz and Kasarda 1974). On the other hand, contact theory helps to explain the rich social interactions in Qianmen before the urban renewal as well. Its main argument is that in order for interactions to be positive, they usually need to involve equal-status contacts (Ford 1986; Kleit 2001). The above narratives show that the residents in Qianmen had a relatively small gap in income before the economic reform and later on it tended to evolve toward a place where many low income people concentrated. In this circumstance, residents had quite a few things in common, thereby were able to know what to expect from each other, which formed an important basis for positive interactions.

Beyond length of residence and social features, neighborhood physical features are also identified as factors affecting local interactions (Skjæveland, Gärling et al. 1996; Bridge, 
Ray Forrest et al. 2004; Volker, Flap et al. 2007). They found that the more public or semi-public spaces in the neighborhood, the greater extent to which individuals interact. For New Urbanists, neighborhood physical attributes, such as moderately higher density, mixed land uses, and better connected streets, all are important to support close-knit social communities(Yang 2007). In my conversation with the interviewees, they told me again and again about how the featured built environment in Qianmen made them feel close and propelled them to interact with their neighbors. Mrs. Ma, in her fifties, recalled that:

"You know, in the past, we needed to go outside for a lot of things, like going out into the coolness to refresh ourselves on hot summer nights... going to the public restroom, to the grocery stores around the corner. The courtyard accommodated just one family before. Later on, four families lived in it. We shared the yard and the kitchen. So, I ran into my neighbors several times a day. When I saw them, we made casual talk, or simply greeted each other with the saying of "Have you eaten?"(The featured greeting in old Beijing), sometimes gave a hand to each other whoever needed help. This made me feel warm, I really miss that feeling."

The narrative of Mrs. Ma indicates that physical environment in Qianmen before the urban renewal featured higher density, public spaces (courtyards, hutongs) and mixed land uses (housing, grocery stores), and that how these features facilitated social interactions. These are quite consistent with those attributes advocated by New Urbanist and other scholars. Some other features promoted by the scholars were mentioned by the 
respondents as well. While visiting Qianmen, I ran into Mr. Chen and his wife who were walking their dog. He, in his late twenties, told me that:

"I liked walking around after dinner. The whole area was so quiet, there were barely cars running, just a few people sitting in front of their doors, sometimes kids running by. Strolling from one hutong to another, I always could run into someone I know, which made me feel that this is the place where I lived. When I was thirsty, I just went to any store along my way to buy a drink, and chatted with the owner a little bit. Time passing by, I hardly noticed that..."

Chen's description reveals vividly the "walkable" environment of the Qianmen neighborhoods. Narrow well-connected Hutongs were initially designed for walking, not driving. Along hutongs there were shops and places where people met each other. These features invited people to walk, and further to participate in neighboring activities. Here, physical features do matter in nurturing local social interactions, which is actually echoed by studies of old urban areas in Shanghai, Guangzhou and other Chinese cities(Forrest and Yip 2007; Hazelzet and Wissink 2012).

The social interactions in Qianmen before the urban renewal were not only limited to socializing and social supports. The investigation also indentified "bridging" activities, which some researchers such as Warren and Skjaeveland et al. emphasized (Warren 1986; Skjæveland, Gärling et al. 1996). One of the interviewees, Mrs. Chen, in her fifties, told me that: 
"You see, the dessert on the table was just brought over by my neighbor...of course, we sometimes informed each other of various resources as well. My daughter's classmate used to live next door. Last year, he graduated from college and found a job in my friend's company through my referral. Actually I helped him chose his college years ago. In our courtyard, I am the only one with a bachelor's degree in the old generation. So, my neighbors turned to me for information and suggestions in many cases."

This type of "bridging" activity was mentioned in several other accounts as well. However, they were not the dominant neighboring activities, compared with socializing and social support activities. To some extent, Mr. Liu's explanation helps to understand this phenomenon:

"It is true that neighbors provide you with all sorts of minor aid, such as watching the door for you, lending you a cup of salt...However, they usually do not help you make money. To make money, you need to make friends across the city. In most cases, it is these friends who bring you opportunities to do business."

Mr. Liu's narrative shows that neighbors' role in providing social bridging --social capital that helps one "get ahead"--tended to be limited. However, his narrative and all the other ones' above clearly illustrate that in Qianmen, long years of common residence, small social status distance, and featured physical environment nurtured rich ties, many of them intimate ties, among neighbors. The social support from neighbors was very 
important for the residents coping with life's difficulties, which was valued by $74.1 \%$ of the interviewees. Close neighbors, together with friends and relatives living nearby, formed solid local close ties, an indispensable part of their overarching social network. To measure the extent to which their close social ties were based on the neighborhood, the study further investigated their local intimates within their overarching social networks.

The interviewees were asked to name their social intimates and report the places where their social intimates lived and other information. The result shows before the urban renewal $39.2 \%$ of their social intimates (relatives, friends, neighbors and other intimates) lived in Qianmen(table 7-1). The results of ANOVA tests show there are not significant differences in terms of this ratio among the three neighborhoods and across different social groups. This percentage of local social intimates is higher than the findings of other investigations. The investigation by Wellman and others on social networks of residents in Toronto shows that network members who live in the same neighborhood account for 22\% (Wellman and Gulia 1999). According to Hazelzet and Wissink, among the five neighborhoods investigated in Guangzhou, China, for residents in four of them, neighborhood social networks account for less than $20 \%$ of their whole social networks; for residents in the other neighborhood, the percentage is between $20 \%$ and $30 \%$ (Hazelzet and Wissink 2012). These raise the possibility that for the residents in Qianmen, local community was more important in terms of the extent to which their overarching 
social networks were based on the neighborhood than in those non-traditional neighborhoods in China and in those of some Western countries.

Clearly, the above qualitative and quantitative analyses demonstrate that Qianmen was regarded by most of the original residents as a friendly and supportive place, alleviating the physiological and psychological consequences of their exposure to stressors. However, the urban renewal inevitably undermined the original residents' social support networks.

Table 7-1: The residents' local intimates within their overarching social networks before the urban renewal

\begin{tabular}{lllll}
\hline & Caochang & Hongshan & Longyue & Total \\
& $\mathbf{N = 2 5}$ & $\mathbf{N = 2 0}$ & $\mathbf{N = 2 1}$ & $\mathbf{N = 6 6}$ \\
& & & & \\
\hline contacts (N) & 8.91 & 9.4 & 9.6 & 9.29 \\
Local contacts (N) & 2.95 & 4.35 & 3.65 & 3.64 \\
Local contacts' percentage (\%) & $33.1 \%$ & $46.3 \%$ & $38 \%$ & $39.2 \%$ \\
& & & & \\
\hline
\end{tabular}

\section{- After the Urban Renewal}

The urban renewal made a large portion of the original residents leave Qianmen. As discussed in chapter three, 17,000 households moved out, only some 3,000 remain. The urban renewal not only disrupted their local social networks but also damaged their overarching networks. Depending on the places where they relocated and the social groups they belong to, they are bearing bitterness to various extents. 
After the urban renewal, $22.9 \%$ of the interviewees' social intimates (relatives, friends, neighbors and other intimates) live in their current neighborhood (table 7-2), compared with $39.2 \%$ before. The result of an ANOVA test shows after the urban renewal there are significant differences in terms of this ratio among the three neighborhoods $(F=6.929$, $\mathrm{p}=.002$ ). To further investigate the social impacts of the urban renewal, the interviewees were asked to report whether their social networks were impacted by the urban renewal (table 7-3). The study also investigated the extent to which they lost their local close contacts and overarching close contacts (table 7-3). The results of ANOVA tests show among the three neighborhoods, there are significant differences in the mean of the extent to which they lost their local close contacts $(F=3.201, p=.049)$, but no significant differences in the mean of the extent to which they lost their overarching close contacts. The result of a Chi-Square test indicates that there are no significant differences among the three neighborhoods in the subject evaluation of the impacts on their social networks. From the above analyses, it seems that, among the three neighborhoods, residents relocated to Longyue suffered the most, residents relocated to Hongshan suffered the least, and residents who remained in Caochang were in the middle. Following are detailed discussions on each neighborhood. 
Table 7-2: The residents' local intimates within their overarching social networks after the urban renewal

\begin{tabular}{lllll}
\hline & Caochang & Hongshan & Longyue & Total \\
& $\mathbf{N = 2 5}$ & $\mathbf{N = 2 0}$ & $\mathbf{N = 2 1}$ & $\mathbf{N = 6 6}$ \\
\hline contacts $(\mathbf{N})$ & 8.18 & 8.6 & 8.85 & 8.53 \\
Local contacts (N) & 1.33 & 3.25 & 1.3 & 1.95 \\
Local contacts' percentage (\%) & 16.3 & 37.8 & 14.7 & 22.9 \\
& & & & \\
\hline
\end{tabular}

Table 7-3: Social impacts of the urban renewal across the three neighborhoods

\begin{tabular}{lllll}
\hline & Caochang & Hongshan & Longyue & Total \\
& $\mathbf{N = 2 5}$ & $\mathbf{N = 2 0}$ & $\mathbf{N = 2 1}$ & $\mathbf{N = 6 6}$ \\
\hline Contacts lost* (\%) & 8.2 & 8.5 & 7.8 & 8.2 \\
$\begin{array}{l}\text { Local contacts lost** (\%) } \\
\begin{array}{l}\text { Residents whose social networks were } \\
\text { impacted (\%) }\end{array}\end{array}$ & 54.9 & 25.8 & 64.4 & 46.4 \\
& & 15.0 & 41.2 & 32.8 \\
\hline
\end{tabular}

*(the number of contacts before - the number of contacts after)/ the number of contacts before

** (the number of local contacts before - the number of local contacts after)/ the number of contacts before

\section{Longyue}

As introduced before, Longyue is an affordable housing neighborhood located in a suburban area. It was built in the mid 2000s. The neighborhood features six-story buildings and modern apartments equipped with private kitchen, bathroom and gas 
heating. The residents from Qianmen are dispersed into 22 buildings. They account for a small portion of all the residents living in the neighborhood.

Clearly, relocation to Longyue means that the residents left a supportive community where they had a large portion of intimates living nearby and where neighbors were always ready to help, and moved to a totally new place, a place far away from most of their intimates and old neighbors. This explains the key reason why they suffered the most in terms of the loss of local intimates. The investigation shows, after the relocation, they lost $64.4 \%$ of their local intimates, with only $14.7 \%$ of their social intimates living nearby compared with the previous $38 \%$. Their subject evaluation of the impacts on social networks is consistent with the loss of local intimates, with $41.2 \%$ of the interviewees reporting that their social networks were affected, far above the average level. In addition, on the average the residents lost $7.8 \%$ of their overarching social intimates. Even though, for the lucky ones who did not lose any social intimates, living far away from most of their intimates is a big barrier preventing many of them from frequent face-to- face contacts. Mrs. Cao in her forties told me that:

"My brother, elder and younger sisters used to live in Qianmen. Two of my friends were in the neighborhood as well. I met them almost every day. But now, it usually takes them one and half an hour on the way to my home, and they need to hurry to catch the last light rail to go back home after dinner. So, in most cases, we call each other; we can see each other only in a few occasions during long 
weekends or holidays. You remind me that I have not seen one of my friends for the last whole year. I really miss her."

As with Mrs. Cao's experience, $87.5 \%$ of the respondents complained that they contacted their intimates less because of living far away from most of them. Certainly, there are exceptions. Mr. Zhou in his fifties explained to me why he did not feel his social interaction was impacted by the relocation:

"Except for two neighbors, none of my social intimates lived in Qianmen. We met about twice a month before. Now, I still see them often. We drive to some spot in the middle of my place and their home...you can pay for services you need in most cases. It is not like before, when neighbors need to support each other a lot because of the lack of various services".

However, almost all the interviewees felt that the style of their social interactions with the neighbors has been changed with moving from courtyard housing to self-contained modern apartment. From the last section, it is quite clear that the traditional residential environment facilitated rich local social interaction in Qianmen. By contrast, living in self-contained modern apartment, they have fewer opportunities to meet their neighbors; thus, their lives behind the door are somewhat isolated. Many interviewees complained that they did not know much about their neighbors. In this circumstance, even though they say hello to some of them, the social interactions are superficial. Mr. Wang in his sixties complained that: 
"Everyone stays inside the apartment and closes the door, so there are not many chances for the neighbors to run into each other. I have lived here for three years; I still just know a few of them. And the relations are different. When I feel like talking, I would have concerns about whether my neighbor behind the door could be available to talk, would be in the mood to talk, and some other things like this, because I do not want to bother them. When I need help, I have to knock at the door to ask for it. It is nothing like before when I ran into someone all the time and I could just call somebody passing by to give me a hand".

Mr. Wang is not alone in having this experience. Among all the interviewees, just two mentioned that they had made new friends in the neighborhood. The difficulty to develop intimate ties with their new neighbors, therefore reconstituting their active neighboring, is manifest, constrained by physical features and other factors.

\section{Caochang}

As introduced in Chapter five, Caochang neighborhood is located in the east of Qianmen area. It features courtyard houses. Of the original 3500 households, some 1000 remain. About 40 households previously living in other neighborhoods of Qianmen area were relocated to Caochang as well.

Compared with the residents relocated to Longyue, the residents who remain are happy that they were not forcedly moved out and some of their old neighbors remain as well. This way, they can still enjoy their way of social interaction in the neighborhood, such as 
watching out for each other, helping each other or even just casually chatting with each other. However, more than two thirds of the original residents left. This means that many of them have fewer neighbors and/or local close contacts to count on. The investigation shows, more than $42.9 \%$ of the interviewees reported that their social networks were affected by the urban renewal. After the renewal, they lost $8.2 \%$ of their overarching social intimates, and $54.9 \%$ of their local intimates, with only $16.3 \%$ of their social intimates living nearby compared with the previous $33.1 \%$.

These numbers show that many residents who wanted to stay to keep their way of living in Qianmen ended up losing two thirds of their neighbors and half of their local intimates. The moving out of their neighbors, in particular their intimate neighbors, made them feel lonely and helpless in many cases, especially for those disadvantaged people. Mr. Wang, in his fifties, is one of them. With one hand disabled, the moving out of his intimate neighbors made his life harder:

"There were four families in the courtyard. We got along with each other very well. We helped each other a lot! Actually, they did more for us, for none of my parents, siblings and other relatives is in Beijing, and my friends live quite far away. In particular, years ago, this hand was injured while working. For so many things since then, I always could find someone to give me a hand, like building the kitchen, caring heavy stuff...With their support, my life was a lot easier. Now, they moved out. You can imagine how hard my life would be”. 
Mr. Wang's experiences represent those of a group of residents who relied heavily on local contacts; therefore, they suffered the most from losing their local contacts. If they cannot replace this indispensable part of their social interactions in coming years, they might suffer for years, which could lead to potential social problems. Certainly, there are residents who depend on local contacts to a lesser extent, and it is hard to deny that the urban renovation did relieve some of the tensions with their neighbors due to the previous overcrowding conditions. But still, the moving out of their neighbors made them feel lonely and less safe. Mrs. Xue, in her sixties, told me:

"Here, where we are sitting, once was a shabby kitchen. It was demolished and the yard space was restored after the moving out of my neighbor. I like it now. We got our yard back, and it is much quieter than before... But, you know, it is not that easy to find someone to spend spare time with as before. Most old neighbors moved out. There are a few newcomers like the family next courtyard. I do not know them yet. They seem a little weird: always close their door, seldom talk to other people. With all these going on, I just feel somewhat unsettled..."

Many residents share similar feelings with Mrs. Xue, and some bear the bitterness of Mr. Wang. The big contrasts they experienced before and after, and between their expectation and the reality, explain to some extent their subjective evaluation of the impact on their social networks. Clearly, although the renovated infrastructure and housing conditions are desired by most residents, the urban renovation in Caochang undermined the previous close-knit traditional community to a large extent. Without rich social interactions, the 
question remains of whether traditional residential cultures can be preserved, which was one objective of the new version of "Development Plan for Qianmen Historically and Culturally Demonstration Precinct” issued in 2012.

\section{Hongshan}

Hongshan is an affordable housing neighborhood located in the central city area, just about $5 \mathrm{~km}$ to the southeast of Qianmen area. It has been built since 2006 . The neighborhood features high-rise buildings and modern apartments equipped with private kitchen, bathroom and central heating. About 3,500 residents from Qianmen have been concentrated in more than one third of the buildings since 2009.

Since a large number of residents from Qianmen were rehoused in Hongshan, there is a good chance for the residents to keep their previous neighbors and local intimates in the new place, a place still close to their non-local social intimates as well. This explains to some extent the reason why residents relocated to Hongshan suffered the least social displacement among the three neighborhoods. However, it is unlikely for them to maintain all the previous ties. Therefore, the relocation still inevitably caused their loss of some social contacts. The investigation shows, after the renewal, they lost $8.5 \%$ of their overarching social intimates, and $25.8 \%$ of their local contacts, with $37.8 \%$ of their social contacts living nearby compared with the previous $46.3 \%$. Fifteen percent of the interviewees reported that their social networks were affected by the relocation. 
It is noticeable that after the relocation, $37.8 \%$ of the interviewees' social intimates still live in their current neighborhood. This is the highest ratio among the three neighborhoods investigated. In the circumstance that a large amount of original residents of Qianmen were rehoused in Hongshan, there is no doubt that the residents were able to maintain their neighborhood ties with fewer difficulties than their counterparts in Longyue. On the other hand, the good location and the improvements of the housing in Hongshan, actually attracted a group of residents who moved out and rented out their apartments in Qianmen before urban renewal. Mrs. Liu, in her fifties, told me that:

"I have three elder sisters and three elder brothers. Except for one brother, all the others had moved out before urban renewal because of the bad residential conditions. They are going to move here in the next year. We all chose the apartments in Hongshan as compensation. It is kind of a family reunion here. I really look forward to it."

However, still the respondents in Hongshan share some similarities with their counterparts in Longyue, in that the style of their social interactions with their neighbors is different in the newly developed neighborhood featured high-rise buildings. Living in self-contained modern apartments, they have fewer opportunities to meet their neighbors, thus, the frequency of social interaction is dropping and the good tradition of "neighborhood watch" is decreasing to some extent. According to Mrs. Mi, in her fifties, relocated to Hongshan with all the sixteen families in her original courtyard: 
"We kept contacting each other for the first couple of months. However, after the excitement of moving to the new apartment had gone, we contact each other less. Because, in the past, it was nature to meet and chat, and then visit someone's home, but now, there are few places for us to meet, and the elevators, the closed doors, all these seem to be the barriers making us not as close as before.

Gradually I feel that I even do not care much about what is happening outside the door."

The narratives of Mrs. Liu and Mrs. Mi indicate (1) as the result of rehousing policy, some residents' family members and other local close contacts were able to live together in Hongshan, which are potentially useful measures to maintain their neighborhood ties; (2) it is reaffirmed that physical features do matter in nurturing local social interactions; therefore, more public places need to be created to help residents keep close social interactions with their neighbors as a method to ameliorate the negative effects of living in modern high-rise apartments on social interactions.

The above discussions reveal the factors contributing to the impacts of urban renewal on the residents' social interactions: the distance between the new location and the original location; the physical features of the places; and the extent to which they can still live together with their local contacts and neighbors rather than split into different locations. Impacted by these factors, the investigation shows, the interviewees lost $8.2 \%$ of their overarching social intimates and $46.4 \%$ of their local intimates after urban renewal (table 7-3). This is consistent with the literature. In the existing literature, researchers agree that 
in many cases relocation decreases the size of the social network because some of the previous relationships ( in particular peripheral relationships) connected to their former living environment can hardly be maintained due to the fact that visits and shared activities are no longer easily achieved (Bloem, Van Tilburg et al. 2008; Wrzus, Hanel et al. 2013).

In the sporadic studies on the topic of impacts of relocation (residential changes) on social networks, the following points are also addressed. According to Wellman, et al., for Torontonians, few intimates were neighbors which contributed to the fact that residential did do not have a significant effect on the stability of their intimate networks; long-distance moving were more likely to affect the movers' networks; people tended to reconstitute their active neighboring in new locations; the low-cost, efficient transportation and communication facilities in Toronto facilitated the persistence of some intimate ties over long distances(Wellman, Wong et al. 1997). Kleinhans found that in the Hague the movers remained in the same neighborhood, therefore they were able to maintain the original neighborhood ties without much difficulty(Kleinhans 2003). Even fewer studies look into how the residents with different social-economic or demographic status are impacted differently by relocation. The study of Bloem, et al. is an exception. According to Bloem, et al, for older Dutch adults, the ties with neighbors changed most after relocation; the farther the mover moves, the more it is likely to discontinue the relationships with fellow club members; years after, older adults restored their partial networks by creating new relationships(Bloem, Van Tilburg et al. 2008). And Bloem, et 
al., remind us the impact of the modern media (Internet, e-mail and so on) on relationship maintenance cannot be ignored, since these media allow for intense long-distance interactions, and people increasingly rely on them.

Informed by the literature, this study looks into the different levels of bitterness borne by the residents with different income and age, the two attributes widely addressed by the literature concerning the disadvantaged group. Across different social groups, the subject evaluation of the impacts on their social networks, the extent to which they lost their local close contacts and overarching close contacts are listed in table 7-4.The results of a group of ANOVA tests show across different social groups, there are significant differences in the mean of the extent to which they lost their overarching close contacts (for age: $F=3.19$, $\mathrm{p}=.048$; for income: $\mathrm{F}=3.591, \mathrm{p}=.034$ ), but no significant differences in the mean of the extent to which they lost their local close contacts. The results of a group of Chi-Square tests indicate that there are no significant differences across different social groups in the subjective evaluation of the impacts on their social networks. From the above analyses, it seems that the residents with higher income tended to suffer less, whereas the elder residents bore more bitterness. Following are more detailed discussions. 
Table 7-4: Social impacts of the urban renewal across different social groups ${ }^{11}$

$\mathrm{N}=61$

\begin{tabular}{llll}
\hline & $\begin{array}{l}\text { Contacts } \\
\text { lost* }(\boldsymbol{\%})\end{array}$ & $\begin{array}{l}\text { Local contacts } \\
\text { lost** }(\boldsymbol{\%})\end{array}$ & $\begin{array}{l}\text { Residents whose social } \\
\text { networks were impacted (\%) }\end{array}$ \\
\hline low income & -8 & -50 & 45 \\
middle income & -16 & -56 & 29 \\
high income & 1 & -22 & 22 \\
\hline 29 and below & 2 & -41 & 17 \\
$\mathbf{3 0 - 4 9}$ years & -1 & -38 & 30 \\
$\mathbf{5 0}$ and above & -13 & -54 & 32 \\
\hline$*$ (the number of contacts before - the number of contacts after)/ the number of contacts before \\
$* *$ (the number of local contacts before - the number of local contacts after)/ the number of contacts before
\end{tabular}

\section{Income}

Table 7-4 shows that the respondents with high income did not lose any overarching social contacts, but their local contacts decreased $22 \%$ and $22 \%$ of them reported that their social networks were impacted by the urban renewal. These ratios are lower than that of other income groups. The narrative of Mrs. Qian, in her fifties, gives a possible explanation of this phenomenon:

"Most of my relatives, my mother, one brother and one sister, live in Jinsong, which is not far from Qianmen. I like to be near to my relatives and keep contacts

\footnotetext{
11 In 2005, the average family income per month in Beijing was 3986 Yuan (the average individual income 1471 Yuan $\times$ the family size 2.71). For women, the age of retirement of ordinary workers is 50, in China, which could be as early as 45 in special cases; for men, it is 60, which could be as early as 50 . Based on these facts, the analyses of this part, constrained by the small sample size, combined the low and lowmiddle income groups as the low income group, the middle-high and high income groups as the high income group, the 30-39 and 40-49 age groups as the 30-49 age group, and the 50-59 and 60 and above groups as the 50 and above age group, as shown in this table.
} 
with my previous neighbors. So, I got monetary compensation and bought the current apartment in Jinsong as well. This way, I can go to my mother's home every weekend. My brother and sister also come. It is so nice that we can get together every week and I still can meet my neighbors quite often".

Mrs. Qian represents a group of people with relatively more financial resources who took into account their social networks when they made the decision on where to move. With relatively high income, people also can have more transportation and/or communication measures (car, Internet) to keep contacts with their old intimates and/or neighbors, and can pay for services rather than rely on social networks. Mr. Gao in his thirties told me that:

"I don't feel my social interactions are impacted. We have a car. I can always drive to meet my friends. But I do feel having a kid leaves me less time to hang out with my friends...Yes, I remember that neighbors supported each other a lot when I was little. But I am more comfortable to pay for home services rather than bothering my neighbors or other friends. Certainly, this is because I can pay”.

From the above narratives, the reasons why the residents with higher income tend to suffer less can be attributed to the following aspects (1) with higher income, they took into account their social networks when they made the decision on where to move; (2) with more financial resources they can have more transportation and communication measures to keep their original ties; (3) they are less likely to rely on social networks. 
In the existing literature, for lower SES sub-group, it is widely recognized that their transportation and communication resources are limited due to their uncertain financial situation, therefore, they are less integrated with the wider society (Kleit 2001). However, scholars found that social resources are especially vital to individuals with lower social economic status, because it can to some extent substitute for things that money or other human capital (education for instance) would "buy" (Stack 1974; Campbell and Lee 1992; Barnes 2003). The findings from this study can be added to the existing literature: for the sub-group with limited resources, their previous social interactions are more likely to be disrupted by relocation, since they hardly can take into account their social networks when they make the decision on where to move, their transportation and communication measures are limited, and they generally rely more on social networks.

\section{Age}

Table 7-4 shows that the respondents in their fifties and above, lost $13 \%$ of their overarching social contacts, $54 \%$ of their local contacts, and $32 \%$ of them reported their social networks were impacted by the urban renewal. These ratios are higher than that of other age groups. It is not surprising that the social networks of the elders were impacted the most, since for one thing they are less likely to be familiar with modern media (Internet, e-mail and so on), and many of them do not own a car and certainly do not know how to drive. Under the constraints of these transportation and communication measures, it is not easy for them to keep their original ties. Mr. Zhang in his seventies 
was walking his dog when I visited Longyue. His experience reflects how the social interaction of the elders was impacted by the relocation:

"When young people go to work during the day, the neighborhood is just too quiet. Walking my dog in the neighborhood is almost the only thing I can do. You can chat with your neighbors while running into each other, but the way is not what it was. In the courtyard house, I saw neighbors all the time and some of them I had known for decades, so they were more like family members rather than just neighbors... My daughter wanted to move here. If I had a chance to choose, I would rather to go back to my small unit in Qianmen where I had close neighbors and could easily take the bus to visit my friends".

His narrative also points to the fact that his daughter rather than himself made the decision to move to Longyue. It is worthwhile to mention that many elders of the older generation in China live with their adult children. For the interviewees in their fifties and above, the percentage is $38 \%$. Since generally they are no more the major source of family income, some of the important decisions (like where to move) are not always by their own choices. In this circumstance, their social interactions tend to be neglected when the decision was made. This neglecting together with their limited transportation and communication measures is very likely to undermine their original social ties. In addition, their limited mobility impacted by poor health conditions and other constraints increase their difficulties to build new ties. As a result, the elders are more likely to bear 
the social bitterness of relocation. However, having adult children around means they can have strong support from them. Mrs. Bai, in her seventies, told me that

"With many old neighbors nearby, I never felt lonely in Qianmen. Here, I even rarely go down stairs because of my old legs. I did feel lonely at first, but I got used to it gradually. After all, when you are getting older, you are more concerned about your health, you do not have extra energy to build ties, and sometimes you want to be alone... My son and daughter take turns coming over to take care of us... We do not know much about our neighbors and we do not want to bother them for sure."

The narrative of Mrs. Bai highlights the value of kin relations for the elders, which generally are more stable and not subject to changes (Kalmijn 2012; Wrzus, Hanel et al. 2013). This gives a possible explanation on why there is no big difference between the elders and the middle-aged people on their subjective evaluation of the social impacts, though the elders lost much more overarching intimates than the middle-aged people.

This section discussed the impacts of the Qianmen urban renewal project on social interactions of its original residents. Depending on the places where they live after the urban renewal and the social groups they belong to, they are bitter to various extents. Generally, except for a few, the urban renewal tended to decrease their overarching social network size, in particular their local social network size to a large extent, and most of them feel sharp differences in the way of neighboring activities between neighbors. 
However, only one third of the respondents reported that their social networks were impacted. The reasons can be attributed to (1) some residents can enjoy their previous way of social interaction by remaining in Qianmen; (2) a group of residents were facilitated to live together with their relatives and other local close contacts in Hongshan; (3) a part of them took into account their social networks when they made the decision on where to move; (4) modern transportation and communication measures offer them new ways to keep their original ties; (5) generally people tend to rely less on social networks, in particular on neighbors, in contemporary China. One of the respondents, Mr. Zhou, even concluded that "the era of rich social support among neighbors has gone forever"! Nevertheless, it is hard to deny that some people did suffer a lot from the urban renewal. The following part will look into how these social outcomes impact the residents' evaluation of their residential satisfaction.

\subsection{Do Social Networks Predict Residential Satisfaction}

The existing studies tell us neighboring is still quite important to individuals' well-being, in particular, for those with low SES status. Thus, displacement, as a number of seminal works have pointed out, means moving from a supportive long-term environment to an alien area, and the impact of its negative social effects could be a significant factor predicting their levels of residential satisfaction. Whereas, on the other hand, relocation might be an opportunity to escape from negative local social interactions, therefore, contributing to the increasing level of residential satisfaction. It seems that the 
relationship between residential satisfaction and the impacts of relocation on social interactions is not straightforward, and needs further investigation.

In the case of Qianmen, the study investigated the extent to which the residents lost their local close contacts and overarching close contacts. The interviewees were also asked to report whether their social networks were impacted by the renewal. As discussed in chapter five, the simple ordinal logistic regressions show that the subjective evaluation of the impact on social networks significantly predicts the level of residential satisfaction after urban renewal, whereas the extent to which the residents lost their local close contacts and overarching close contacts do not. Putting the subjective evaluation of the impact on social networks with other physical and economic variables together, it does not significantly predict the level of residential satisfaction any more.

However, the qualitative data shows more nuanced results. As analyzed in chapter six, a number of existing studies indicate that individuals with higher incomes have greater residential satisfaction(Galster and Hesser 1981; Galster 1987; Lu 1999; Parkes, Kearns et al. 2002; Grogan-Kaylor, Woolley et al. 2006), whereas in the case of Qianmen, the residents with middle-high income actually have a lower level of residential satisfaction than the residents with less financial resources. The narratives of the residents point to the facts that they have higher expectations for housing and are more concerned with social needs for their living environment after their physical needs were mostly satisfied; however, to realize these expectations or social needs is still beyond their financial capability, which contributes to their low level of residential satisfaction. The finding 
echoes the arguments of Fang, Turner and others that there is a housing needs hierarchy (Fang, 2005), so that different income groups show differences in their housing needs (Turner, 1972). This section will continue the discussion to look into how social factors impact residential satisfaction under this perspective.

\section{- The Housing Needs Hierarchy}

According to Fang, Turner and others, different income groups show differences in their housing needs(Turner 1972), which reflects a general tendency in housing needs -housing needs hierarchy(Fang 2005). More specifically, at the bottom of the hierarchy is the physiological needs, and then it goes up to the safety needs, the social needs, the esteem needs, and finally the self-actualization needs. Under the constraint of limited financial resources, people with low income are more concerned with basic physiological needs for living environment; and for many of them, other higher order needs, such as social needs, would remain less prominent. Along with increased income, the basic needs are largely satisfied; then, realizing higher order needs would become the concerns of behavior. Since residential satisfaction measures the distance between the actually residential conditions and the needs (expectations) for residential environment, people with different housing needs might have different levels of residential satisfaction toward similar environment conditions.

Clearly, these points can also help to explain the results of quantitative analyses that the negative impacts of relocation on social networks do not significantly predict low levels of residential satisfaction. As discussed in chapter three, before the urban renewal, the old 
residential area became marginalized during the dramatic economic growth process. The majority of the residents were low income people. The investigation by Beijing Academy of Social Sciences shows that $71 \%$ of the residents were either retired or unemployed; therefore, the average individual income was just 1000 Yuan per month(Zhu 2005). Fifty six percent of the interviewees in this study are either retired or unemployed, and $18.1 \%$ have monthly family income less than 2,000 , and $47.5 \%$ between 2,000 and 5,000.

With relatively low income, the original residents were more concerned with basic physical conditions of the living environment. This is why unit size rather than the impacts of social networks significantly contributes to the level of residential satisfaction after the renewal. Mrs. Wang's experience verifies this point very well:

"My parents and aunt, my brother and sister, my friend, and a close neighbor, all of them lived in Qianmen. Now, it is just my family living here... I do feel sad that I can't see them as often as before. But, I still appreciate that we have the opportunity to get compensation and buy this spacious apartment, otherwise, we could never afford to buy a commercial housing. I like it here.”

Mrs. Wang's narrative indicates that many of the original residents of Qianmen are more concerned with basic physiological needs for living environment under the constraint of limited financial resources. Therefore they are still satisfied with the result, though their social networks were damaged by the relocation. This group of people accounts for a large portion of the whole population, which explains to a large extent why social factors 
do not significantly predict the level of residential satisfaction, controlling physical, economic and policy variables.

The qualitative data also reflect that the residents might get away from the unpleasant social interactions with their neighbors after the relocation, though the above section shows that the relocation disrupted the rich local social networks and damaged the overarching networks to some extent as well. Therefore, the negative impacts of relocation on social networks might be mitigated by the benefits from escaping the social conflicts and annoyance in the original neighborhood. The following part will explore this aspect in detail.

\section{- Conflicts}

According to the existing literature, beyond the positive effects of neighborhood social interactions, neighboring has its negative phenomena like conflicts and annoyance as well. Annoyance, such as noises and conflicts over car parking, makes people dislike their neighbors, or even has more serious results, which can spoil their living environment, therefore, cause intense stress and do harm to their other well-being (Paquin and Gambrill 1994; Skjæveland, Gärling et al. 1996). Negative neighboring can be significant. In their study on 508 randomly selected residents in Rotterdam, Peper,and Spierings reported that 41-48 percent had had some conflict with their neighbours and 11-22 percent experienced nuisance on a weekly basis (Peper and Spierings 1999; Bridge, Ray Forrest et al. 2004). However, the negative effects are often ignored in the existing neighborhood studies. This neglect, as Skjaeveland, Garling and Maeland pointed out, might make it difficult to 
understand neighbors' relationships when negative phenomena are critical ( Skjaeveland, Garling and Maeland, p. 417).

In the case of Qianmen, long years of common residence bred both mutual help and conflicts. Forty four percent of the interviewees mentioned that they did not get along with some of their neighbors at times due to various conflicts or annoyance. The overcrowding and facilities- sharing situations were common sources of friction. There were disputes over who got what space for building an extra room, or over electricity and water bills. Mrs. Chen told me that:

"I do not know whether you watched the kind of movies showing the life in courtyard houses. Anyway, can you imagine 15 households lined up to get water for cooking and washing in the morning? People fought. You probably think that must be dramatized somehow, but I tell you that is what exactly happened. Now, many people moved out and the water and electricity facilities were updated. There is no more this kind of things happening....I like that it is quiet, even though I miss my old neighbors a little bit".

The narrative of Mrs. Chen reflects vividly how social conflicts make people dislike their residential environment. Table 7-5 further shows, before the urban renewal, 38\% of the interviewees listed "good social interaction" as a factor making them like their previous residential environment, whereas $18 \%$ of the interviewees mentioned that they were not satisfied with the "social conflicts" in the previous neighborhoods. After the urban 
renewal, an even higher percentage (28\%) of the respondents reported "escaping from the previous social conflicts" as a factor they were satisfied with. These indicate that the negative impacts of relocation on social networks were mitigated to some extent by the benefits from escaping the social conflicts and annoyance of the original neighborhood. In other words, the effect of negative neighboring on the evaluation of their residential satisfaction cannot be neglected in the Case of Qianmen.

\section{Table 7-5 The impacts of social factors on residential satisfaction}

\begin{tabular}{|c|c|c|c|}
\hline & & & $\mathrm{N}=66$ \\
\hline \multirow[t]{2}{*}{ Before } & Good social interaction & $38 \%$ & \\
\hline & Social conflicts & $18 \%$ & \\
\hline \multirow[t]{2}{*}{ After } & Worse social interaction & $33 \%$ & \\
\hline & Escaping from social conflicts & $28 \%$ & \\
\hline
\end{tabular}

\subsection{Conclusions}

The above analyses show that urban renewal inevitably causes social disturbance, in particular for those disadvantaged people (low income residents and elders). In the case of Qianmen, for many residents, the negative impacts of relocation on social networks were mitigated by the benefits from escaping the social conflicts and annoyance in the original neighborhood, and in particular were compensated by the improved housing conditions. However, in the long run, after their physical needs were mostly satisfied, realizing higher order needs such as social interactions would become the concerns of 
their behavior. Those who could not rebuild their support networks would suffer for years, which might lead to potential social problems.

Some of the policy arrangements in the Qianmen case ameliorated the negative effects. The overarching arrangement that most of the residents could choose where to move formed the base for a group of the residents to consider their social interactions when making choices. The rehousing policy facilitated a part of the residents to live together with their family members and other local close contacts in Hongshan. However, a great deal needs to be improved to facilitate the nurturing of rich local social interactions and the maintaining of long distance ties. Among possible actions are providing more lowcost, efficient transportation and communication facilities to allow some intimate ties to persist over long distances; creating more high quality public spaces and organizing neighborhood activities( such as holding events for special occasions and holidays), which will help bring residents together. 


\section{Chapter 8: Conclusions and Implications}

In the post-war years, large scale urban clearance both in the U.S. and many European countries inspired a tradition of research connected to forced moving. Since the 1980s, a substantial number of studies on the displacement problem attributed to gentrification in the new economic and social paradigm enhanced the understanding in this field. How to evaluate the effects of various urban regeneration policies since the 1990s requires new insights on forced moving (Qian 2009; Kleinhans and Kearns 2013). Recognizing the debates on the results of forced moving, scholars called for a more open, balanced perspective for analysis of urban renewal processes and outcomes, rather than a predominantly negative displacement view embedded in a gentrification discourse, for urban renewal processes and outcomes are very dependent on local social, economic and institutional contexts (Kleinhans and Kearns 2013). Inspired by similar curiosity, I am interested in investigating urban renewal outcomes in the Chinese contexts.

With the goals of informing policy makers to improve future policy arrangements and contributing to the understanding of forced moving from the experience of a developing country, this study examined the outcomes of the urban renewal project in Qianmen area, Beijing. The location and other merits of the Qianmen area made it one of a few demonstration projects under the new policy orientation of Beijing entering the new century. The local government put special efforts into the urban renewal project to achieve positive results, which makes it the perfect case to understand the impacts of 
policy arrangements. As the capital city, the experiences of Beijing would serve as a positive demonstration to other cities in the country as well.

The study employed "residential satisfaction" as an evaluative indicator to understand the original residents' experiences before and after the urban renewal. It investigated both the residents who remained in the Qianmen area and the residents who moved out of the Qianme area after the urban renewal. 72 original residents of Qianmen were interviewed. Among them, 25 live in Caochang, 20 in Hongshan(an affordable housing neighborhood in central city area), 21 in Longyue (an affordable housing neighborhood in suburban area), and 6 residents relocated to housing they bought from the market.

\subsection{Findings}

The exploratory inquiry found that the participants' level of residential satisfaction was skewed toward dissatisfaction before the urban renewal, whereas participants showed a much higher satisfaction level after the urban renewal, which means that overall the Qianmen urban renewal had positive impacts on the residents' residential environment. In other words, the residents tended to benefit from rather than suffer from the project.

Among the neighborhoods, there are variations in terms of the mean score of residential satisfaction after the urban renewal. However, the differences are not statistically significant. This is not surprising. Under the policy arrangements of the Qianmen urban renewal project, most of the residents made their own choices about whether to move and 
where to move based on their own housing needs, thus they tended to be happy with the results.

The quantitative analyses also show that among the demographic and socioeconomic variables such as age, family size, education, occupation and income, income is the only variable that significantly contributes to the level of residential satisfaction. A series of simple ordinal logistic regressions were run to test the significance of physical determinants, social attributes and policy factors predicting residential satisfaction. The results show that, unit size, residents' subjective evaluation of the impact on their social networks, and involuntary relocation significantly contribute to the level of residential satisfaction. Using these variables and income--the significant socioeconomic variable-as the independent variables, the result of an ordinal logistic regression reveals that social factors do not significantly predict residential satisfaction any more. All the other variables -- unit size, involuntary relocation and income-- account for $40 \%$ of the variance of residential satisfaction.

The qualitative elaborations further suggest the financial resources residents have tends to indicate the extent to which they can choose their residential environment congruent with their needs and expectations, and thereby the extent of their residential satisfaction. In other words, the higher the social class, the higher the level of residential satisfaction. However, this general tendency is mediated by other factors. Firstly, public policies can ameliorate the less satisfied situation of lower social class by improving policy arrangements. In the Qianmen case, the policy arrangements provided extra aid to those 
low income residents with most difficulties, helping them get more positive effects than they would otherwise achieve. However, the coverage of the public policies was limited; thus, residents with limited income who did not benefit from the arrangements are dissatisfied the most. And secondly, there is a housing needs hierarchy----the higher the social class, the more likely they have higher needs and expectations, which means the higher social class might be less satisfied, when their needs and expectations are too high to be afforded within their financial resource limits. This is clearly demonstrated in the case of residents with middle-high income. They have higher expectations for housing and are more concerned with psychological and social needs for living environment after their physical needs are mostly satisfied; however, to realize these expectations or needs is still beyond their financial capability, which contribute to their low level of residential satisfaction.

The study also found that many residents have mixed feelings about the impacts of the urban renewal on their physical residential environment. Clearly, the improvements in unit size space and housing quality are the main achievements of the urban renewal. Although the neighborhood environment has been improved in some aspects as well (space for parking across all the three neighborhoods investigated, widened and nicely paved hutongs and clean public restrooms in Caochang, more well designed outdoor spaces in Longyue and Hongshan), most residents face the shortage of community facilities in the short run and in the long run they might continue to suffer from worse accessibility to public facilities(like good public schools and healthcare facilities) and 
other resources. However, the improvement in unit size space and housing quality are more valued than neighborhood physical environment for most of the interviewees to evaluate their level of residential satisfaction in the Qianmen case.

Compared with these physical factors, the negative social impacts of the urban renewal are less valued for many interviewees when evaluating residential satisfaction. The urban renewal inevitably caused social disturbances for many residents, in particular for those disadvantaged people (low income residents, and the elderly, etc). However, in the case of Qianmen, the negative impacts of relocation on social networks were mitigated by the benefits of escaping the social conflicts and annoyance in the original neighborhood, and were compensated by the improved housing conditions. In addition, the housing needs hierarchy can also help to explain the finding that the negative impacts of relocation on social networks do not significantly predict low level of residential satisfaction. With relatively low income, most of the original residents were more concerned with basic physical conditions of the living environment, while social needs remained less prominent. Therefore they were still satisfied with the result, though their social networks were damaged by the relocation. This group of people accounts for a large portion of the whole population, which explains to a large extent why social factors do not significantly predict the level of residential satisfaction, controlling physical and economic and policy variables. Furthermore, some of the policy arrangements in the Qianmen case ameliorated the negative effects. The overarching arrangement that most of the residents could choose where to move formed the base for a group of the residents to consider their 
social interactions when making choices. The rehousing policy facilitated a part of the residents to live together with their family members and other local close contacts in Hongshan.

It is not hard to see that the policy arrangements implemented in the Qianmen urban renewal project offered more options for the households and provided extra aid to low income households helping them benefit from the relocation. Under this circumstance, although the urban renewal project was initiated by the municipal government, many households actually saw the relocation as an opportunity to improve their residential environment, and reported that they voluntarily moved to the current housing. On the contrary, a few households who remain in Qianmen complained that they wanted to move out but could not due to various barriers, and reported that they stayed involuntarily. Certainly, the infrastructure development at the first stage of the urban renewal did force a few households who would otherwise prefer to remain in Qianmen to move out involuntarily. This way, moving perceived by the interviewees as involuntary only accounts for $25 \%$. As expected, the residents who moved involuntarily reported a significantly lower level of residential satisfaction.

\subsection{Implications}

The findings indicate that overall the Qianmen urban renewal had positive impacts on the residents' residential environment; in other words, the residents tended to benefit from rather than suffer from the project. Clearly, this achievement is imbedded in its policy arrangements. 
Entering the new century, the urban renewal practices in Beijing experienced a big change around 2005. The new policy arrangements feature a government-led approach rather than a market-oriented one. It requires that the implementation of urban renewal projects is more government-led with a large amount of public investment and only very limited involvement of real-estate developers; and its purpose is not for profit but for the improvement of residents' living conditions, for the protection of historic urban areas, and for other social considerations. The new policy arrangements also require that urban renewal projects need to take into account the extensive opinions of the original residents. As a legal requirement, the urban renewal plan must be posted publicly in the neighborhood so that the residents could know what would happen next and have an opportunity to express their ideas to the decision-making body. Except in a few special cases, such as public infrastructure construction, relocation is no longer compulsory. A household can make its own decision about where to live after urban renewal: remain in the original neighborhood; get monetary compensation and find a housing unit in the market or apply for an affordable housing unit; or be re-housed in a "similar" housing unit which is located within the boundary of the urban area with floor space no less than the original housing unit.

In the Qianmen case, it is the first time that a large-scale public-funded (six billion Yuan) urban renewal action targeted this area since the founding of the People's Republic of China. The district government took overall responsibility in organizing the renewal project; a public-owned development corporation was established to undertake the project; 
and some experts and professionals were invited to give suggestions on the project proposals. Although a private real estate company was involved in the early stage, attracting private investment was no longer the prime aim. Instead, the purposes of the project, according to the public documents, were to improve the residents' living conditions and to protect the historic urban area.

Compared with many of the previous practices, the policy arrangements implemented in the Qianmen urban renewal project offered more options for the households and provided extra aid to low income households helping them benefit from the relocation. Under the new policy arrangements, the households could get monetary compensation to buy affordable housing for which they were given priority; be rehoused in Hongshan affordable housing neighborhood located in the central city area; or get monetary compensation to buy housing from the market. If households were not happy with all the compensation options, they could stay, except for a few cases when relocation was compulsory for public infrastructure construction or other public interests. They made the decision based on their own need, which formed a solid base for them to get positive results.

Moreover, the policy arrangements in Qianmen provided extra aid to low income households particularly in the second round of moving out: increasing their baseline size of compensation to 13.1 square meters (about 141 square feet), offering them up to 20 square meters (about 215 square feet) to rent with a subsidized price, and providing rental-subsidized public housing based on family size rather than original unit size to 
those low income households covered by the minimum living allowance. The above features indicate that as a demonstration project, the policy arrangements in the Qianmen project under the new policy orientation of urban renewal in Beijing showed efforts to resume more of its role in delivering welfare and redistributing wealth.

The findings in the Qianmen case remind us that we do need a more open, balanced perspective for analysis of urban renewal processes and outcomes, rather than a predominantly negative displacement view embedded in a gentrification discourse (Kleinhans and Kearns 2013); and that policy arrangements toward more redistribution and social equity are more likely to achieve positive outcomes for disadvantaged people. Therefore, the study calls for significant modifications to the extant neoliberal-oriented policy regime toward more redistribution( as some other radical studies do), though the reorientation may not be politically feasible (Freeman 2006; Lees, Slater et al. 2008).

Practically, urban renewal projects need close scrutiny to better serve the residents impacted by them and inform the improvement of future policy arrangements. In the Qianmen case, the improvements in unit size space and housing quality are the main achievements of the urban renewal project. Although the neighborhood environment has been improved in some aspects as well, most residents face the shortage of community facilities in the short run and in the long run they might continue to suffer from worse accessibility to public facilities and other resources. Therefore, more efforts are needed to improve the delivery of public services and the quality of other neighborhood attributes in all the three neighborhoods. 
The urban renewal inevitably caused social disturbance for many residents, particularly for the disadvantaged people (low income residents and the elderly). Although compared with physical factors, the negative social impacts of the urban renewal are less valued by many interviewees when evaluating residential satisfaction. In the long run, after their physical needs were mostly satisfied, realizing higher order needs such as social interactions would become the concerns of their behavior. Those who could not rebuild their support networks would suffer for years, which might lead to potential social problems. Thus, a great deal needs to be improved to facilitate the nurturing of rich local social interactions and the maintaining of long distance ties. Among them are providing more low-cost, efficient transportation and communication facilities to facilitate some intimate ties to persist over long distances, creating more high quality public spaces and organizing neighborhood activities (such as holding events for special occasions and holidays), which will help bring residents together.

In the Qianmen case, although the policy arrangements offered multiple compensation options for most of the households, the infrastructure development at the first stage of the urban renewal did force a few households who would otherwise prefer to remain in Qianmen to move out involuntarily. On the other hand, the policy arrangement did provide extra aid to those low income residents with the most difficulties, helping them to get more positive effects than they would otherwise achieve. However, the coverage of the public policies was limited, thus residents with limited income who did not benefit from the arrangement were dissatisfied the most. Furthermore, the government did not 
take much of this responsibility in providing enough information and supportive services to help the residents make decisions and reduce their suffering from relocation. These findings remind us that (1) for the residents whose relocation is compulsory for public infrastructure construction or other public interests, more efforts are needed to provide them the option of remaining in the same neighborhood whenever possible; that (2) policy makers need to pay more attention to the disadvantaged class to help them improve their residential environment by expanding the coverage of public aid to include more people rather than just the residents with the most difficulties; and that (3) the district government as the organizer of the renewal project should put more efforts to provide intensive information and supports to help the households make good use of the opportunity rather than suffer from it.

Furthermore, although under the new policy orientation, the Qianmen urban renewal project involved more public opinion by offering multiple options, we have to accept that the decision mechanism is still a top-down model-- the district government had the dominant power to make decisions on renovation objectives and strategies, as well as the allocation of most public funding and resources. Under this strongly institutional constraint, although the residents were empowered with more choices to make decisions based on their own housing needs to a greater extent rather than forced relocation, they seldom got a say on such important decisions as when they moved, how much the level of compensation standards was, how the Qianmen area was going to be developed and the affordable housing should be designed and so on. Some residents tried to express 
their opinions, but their voices were rarely heard, which means much more still needs to be done to promote public participation.

The debate over the "strengths" and the "weaknesses" of the Qianmen project is still underway. This study looked into the results through investigating the experiences of the original residents before and after the urban renewal. However, three fifths of the original residents got monetary compensation and used the compensation to purchase commercial housing or rent from the market. Except for a few, this group of residents could hardly be tracked without government records; therefore, were not focused on in the study. Future research should attempt to include this group of households to make better grounded arguments. Snowball sampling and purposive sampling were used to identify the participants in the study. These methods facilitated the access to the respondents and showed the deliberate effort to obtain representative samples through the inclusion of various groups. However, these methods are subject to numerous biases. These biases and further, the small sample size, limit the potential power of generalization of this study, which future research should try to overcome.

The long run impacts of the Qianmen urban renewal definitely need further follow-up exploration. But it is quite clear that in contemporary China, the significant widening of the income gaps between different groups of people has been becoming a growing concern. Even in the small sample of this study, quite a few residents were keenly aware of the problem and voiced fairly strong complaints about it. This reminds us that facing the widening of income gap, policy makers need to pay more attention to the 
disadvantaged class; in other words, the government needs to assume its role more actively in redistribution and social equity, which is exactly the key argument of this study. As a demonstration project, the meaning of the Qianmen case is exactly in this sense of implying the significance of the transition of policy orientation. Due to the distinctiveness of the case, its achievements might not be replicated in other cases. However, its experiences and lessons still inform the improvement of policy arrangements in future practices of urban renewal. 


\section{References:}

Acharya, S. K. (2005). "Urban development in post-reform China: Insights from Beijing." Norwegian Journal of Geography 59(3): 228--236.

Adriaanse, C. C. M. (2007). "Measuring residential satisfaction: a residential environmental satisfaction scale (RESS)." Housing Built Environ 3(22): 287-304.

America, E. o. t. P. s. R. o. C. i. t. U. S. o. (2004). Embassy of the People's Republic of China in the United States of America. http://www.chinaembassy.org/eng/gyzg/t169398.htm. W. C. s. g. s. m. years?

Amérigo, M. and J. I. Aragonés (1990). "Residential satisfaction in council housing." Journal of Environmental Psychology 10(4): 313-325.

Angus Campbell, Philip E. Converse, et al. (1975). The quality of American life Ann Arbor, ISR Social Science Archive, Institute for Social Research, University of Michigan.

Atkinson, R. (2000). "The hidden costs of gentrification: Displacement in central London." Journal of Housing and the Built Environment 15(4): 307--326.

Atkinson, R. and G. Bridge (2005). Gentrification in a global context : the new urban colonialism London; New York, Routledge.

Baker, E. and K. Arthurson (2006). Social Networks, Housing Quality or Residential Environment: What's more important for the Wellbeing of Relocating Tenants? ENHR International Conference. Ljubljana, Slovenia

Barnes, S. L. (2003). "Determinant of Individual Neighborhood Ties and Social Resources in Poor Urban Neigbhorhoods." Sociological Spectrum 23(4): 463.

Berry, H. E. and R. S. Krannich (1990). "A Longitudinal Analysis of Neighboring in Rapidly Changing Rural Places." Journal of Rural Studies 6(2): 175-186.

Birks, D. F. and J. M. Southan (1992). "An evaluation of the rationale of tenant satisfaction surveys." Housing Studies 7(4): 299-308.

Bloem, B. A., T. G. Van Tilburg, et al. (2008). "Changes in older Dutch adults' role networks after moving." Personal Relationships 15(4): 465-478. 
Bonaiuto, M., A. Aiello, et al. (1999). " Multidimensional perception of residential environment quality and neighbourhood attachment in the urban environment " Journal of Environmental Psychology 19(4): 331-352.

Bridge, G., Ray Forrest, et al. (2004). Neighbouring: A Review of the Evidence, CNR Paper 24.

Briggs, X. d. S. (1998). "Brown kids in white suburbs: Housing mobility and the many faces of social capital" Housing Policy Debate 9(1): 177-221.

Burnley, I. H., P. A. Murphy, et al. (1997). "Selecting Suburbia: Residential Relocation to Outer Sydney." Urban Studies 34(7): 1109-1127.

Cameron, S. and J. Doling (1994). "Housing neighbourhoods and urban regeneration." Urban Studies 31(7): 1211.

Campbell, A. (1981). The sense of well-being in America: recent patterns and trends. New York, NY, McGraw-Hill Book Campany.

Campbell, K. E. and B. A. Lee (1992). "Sources of Personal Neighbor Networks: Social Integration, Need, or Time?" Social Forces 70(4): 1077-1100.

Conway, M. and C. Knox (1990). "Measuring housing effectiveness: a case study in customer evaluation." Housing Studies 5(4): 257-272.

Cook, C. C. (1988). Components of Neighborhood Satisfaction: Responses from Urban and Suburban Single-Parent Women. 20: 115-149.

Crull, S., M. Bode, et al. (1991 ). "Two tests of the housing adjustment model residential mobility." Housing and Society 18(3).

Ekström, M. (1994). "Elderly people's experiences of housing renewal and forced relocation: Social theories and contextual analysis in explanations of emotional experiences." Housing Studies 9(3): 369-391.

Engels, B. (1999). "Property ownership, tenure, and displacement: in search of the process of gentrification." Environment and Planning A 31(8): 1473-1495.

Fang, Y. (2005). Residential Satisfaction Conceptual Framework Revisited: A Study on Redeveloped Neighborhoods in Inner City Beijing. University of Colorado at Denver and Health Sciences Center. 
Fang, Y. P. (2006). "Residential satisfaction, moving intention and moving behaviours: A study of redeveloped neighbourhoods in inner-city Beijing." Housing Studies 21(5): 671694.

Fauth, R. C., T. Leventhal, et al. (2004). "Short-term effects of moving from public housing in poor to middle-class neighborhoods on low-income, minority adults' outcomes." Social Science \& Medicine 59(11): 2271-2284.

Fischer, C. S. (1982). To dwell among friends : personal networks in town and city Chicago, University of Chicago Press.

Fischer, C. S. and [et al.] (1977). Networks and places : social relations in the urban setting New York, Free Press.

Ford, W. S. (1986). "Favorable intergroup contact may not reduce prejudice: inclusive journal evidence." Social science research 70(4): 256-258.

Forrest, R. and N.-m. Yip (2007). "Neighbourhood and Neighbouring in Contemporary Guangzhou." Journal of Contemporary China 16(50): 47-64.

Freeman, L. (1998). "Interpreting the Dynamics of Public Housing: Cultural and Rational Choice Explanations." Housing policy debate 9(2): 323-354.

Freeman, L. (2005). "Displacement or Succession?: Residential Mobility in Gentrifying Neighborhoods." Urban Affairs Review 40(4): 463-491.

Freeman, L. (2006). There goes the 'hood : views of gentrification from the ground up. Philadelphia, PA, Temple University Press.

Fried, M. (1967). Grieving for a Lost Home: Psychological Costs of Relocation. Urban renewal : the record and the controversy J. Q. Wilson. Cambridge, Mass., M.I.T. Press: 361.

Fried, M. (1982). "Residential Attachment: Sources of Residential and Community Satisfaction." Journal of Social Issues 38(3): 104-119.

Galster, G. (1987). "Identifying the Correlates of Dwelling Satisfaction: An Empirical Critique " Environment and Behavior 19(5): 539-568.

Galster, G. C. and G. W. Hesser (1981). "Residential Satisfaction: Compositional and Contextual Correlates " Environment and Behavior : 13(6): 735-758. 
Gans, H. J. (1982). The urban villagers : group and class in the life of Italian-Americans, New York : Free Press ; London : Collier Macmillan Publishers.

Goetz, E. G. (2002). "Forced Relocation vs. Voluntary Mobility: The Effects of Dispersal Programmes on Households." Housing Studies 17(1): 107-123.

Golant, S. M. and A. J. La Greca (1995). "The Relative Deprivation of U.S. Elderly Households as Judged by their Housing Problems." The Journals of Gerontology Series B: Psychological Sciences and Social Sciences 50B(1): S13-S23.

Grogan-Kaylor, A., M. Woolley, et al. (2006). "Predictors of Neighborhood Satisfaction." Journal of Community Practice 14(4): 27-50.

Halpern., R. ( c1995). Rebuilding the inner city : a history of neighborhood initiatives to address poverty in the United States. New York, Columbia University Press.

Hartman, C. (1979). "Displacement: A Not So New Problem." Social Policy (March/April): 22-27.

Hazelzet, A. and B. Wissink (2012). "Neighborhoods, Social Networks, and Trust in Post-reform China: the Cade of Guangzhou." Urban Geography 33(2): 204-220.

He, S. J. (2007). "State-sponsored gentrification under market transition - The case of Shanghai." Urban Affairs Review 43(2): 171-198.

He, S. J. and F. L. Wu (2007). "Socio-spatial impacts of propertyled redevelopment on China's urban neighbourhoods." Cities 24(3): 194-208.

Heywood, F. (1997). "Poverty and disrepair: Challenging the myth of ignorance in private sector housing." Housing Studies 12(1): 27.

Hidalgo, M. and B. Hernandez (2001). " Place attachment: Conceptual and empirical questions " Journal of Environmental Psychology 21(3): 273-281.

Hunter, A. (1978). Persistence of Local Sentiments in Mass Society. Handbook of contemporary urban life D. S. a. associates. San Francisco, Jossey-Bass.

Jankowiak, W. R. (1993). Sex, death, and hierarchy in a Chinese city : an anthropological account. New York, Columbia University Press. 
Janowitz, M. and J. D. Kasarda (1974). The social constrcution of local communities. Sociological theory and survey research : institutional change and social policy in Great Britain. T. Leggatt. London; Beverly Hills, Calif Sage Publications.

Kain, J. F. (1968). "Housing Segregation, Negro Employment, and Metropolitan Decentralization " Quarterly Journal of Economics 82(2): 175-197.

Kalmijn, M. (2012). "Longitudinal analyses of the effects of age, marriage, and parenthood on social contacts and support." Advances in Life Course Research 17(4): 177-190.

Kasarda, J. D. and M. Janowitz (1974). "Community Attachment in Mass Society." American Sociological Review 39(3): 328-339.

Kearns, A. and P. Mason (2013). "Defining and Measuring Displacement: Is Relocation from Restructured Neighbourhoods Always Unwelcome and Disruptive?" Housing Studies 28(2): 177-204.

Keating, W. D. (1985). "Urban Displacement Research: Local, National, International." Urban Affairs Review 21: 132-136.

Keller, S. I. (1968). The urban neighborhood, a sociological perspective. New York, Random House.

Kleinhans, R. (2003). "Displaced but still Moving Upwards in the Housing Career? Implications of Forced Residential Relocation in the Netherlands." Housing Studies 18(4): 473.

Kleinhans, R. and A. Kearns (2013). "Neighbourhood Restructuring and Residential Relocation: Towards a Balanced Perspective on Relocation Processes and Outcomes." Housing Studies 28(2): 163-176.

Kleinhans, R. and W. Van der Laan Bouma-Doff (2008). "On Priority and Progress: Forced Residential Relocation and Housing Chances in Haaglanden, the Netherlands." Housing Studies 23(4): 565-587.

Kleit, R. (2001). "The Role of Neighborhood Social Networks in Scattered-Site Public Housing Residents' Search for Jobs." Housing Policy Debate 12(3).

Kleit, R. G. and L. C. Manzo (2006). "To move or not to move: Relationships to place and relocation choices in HOPE VI." Housing Policy Debate 17(2): 271-308. 
Lee, B. A., K. E. Campbell, et al. (1991). "Racial Difference in Urban Neighboring." Sociological Forum 6(3): 525.

Lees, L., T. Slater, et al. (2008). Gentrification. New York Routledge/Taylor \& Francis Group.

Lees, L., T. Slater, et al. (2008). Gentrification. New York Routledge/Taylor \& Francis Group.

Li, L. H. (1999). "Impacts of Land Use Rights Reform on Urban Development in China." Review of Urban \& Regional Development Studies 11(3): 193-205.

Li, S.-m. and Y.-1. Song (2009). "Redevelopment, displacement, housing conditions, and residential satisfaction: a study of Shanghai." Environment and Planning A 41(5): 1090 1108.

Lian, Z. (1995). Urban Renewal in Beijing, Observation and Analysis. School of Architecture. Montreal, McGill University. Master's thesis.

Litwak, E. and I. Szelenyi (1969). "Primary Group Structures and Their Functions: Kin, Neighbors, and Friends." American Sociological Review 34(4): 465-481.

Liu, D. (2005). Factors affecting housing satisfaction of Asian and Pacific Islander households in the United States Human Development and Family Studies. Ames, Iowa State University. Doctor of Philosophy Dissertation.

Liu, Z. (2005). "Urban Renewal Projects in Old Historical Neighborhoods in Beijing Will Be Practiced in "Microcirculation"Model, the Third Transition of Goverment Role in the Last Fifteen Years." 2009, from http://news.sohu.com/20050104/n223767807.shtml.

Lu, M. (1999). "Determinants of Residential Satisfaction: Ordered Logit vs. Regression Models." Growth \& Change 30(2): 264.

Lu, X., J. Tang, et al. (2011). Annual Report on Analysis of Beijing Society-Building (2011) Beijing, She hui ke xue wen xian chu ban she.

Manzo, L. C., R. G. Kleit, et al. (2008). "'Moving three times is like having your house on fire once": The experience of place and impending displacement among public housing residents." Urban Studies 45(9): 1855-1878. 
Marans, R. W. and W. Rodgers (1975). Toward an understanding of community satisfaction. Metropolitan America in contemporary perspective. A. H. Hawley and V. P. Rock. New York, Sage Publications.

Marcuse, P. (1985). "To control gentrification: Anti-displacement zoning and planning for stable residential districts." Review of Law and Social change 13: 931-945.

Marcuse, P. and R. v. Kempen (2000). Globalizing cities : a new spatial order? . Oxford, Malden.

María Amérigo and Juan Ignacio Aragoné (1997). " A theoretical and methodological approach to the study of residential satisfaction " Journal of Environmental Psychology 17(1): 47-57.

Meeks, C. B. (1980). Housing. Englewood Cliffs, N.J., Prentice-Hall.

Merry, S. E. (1987). Crowding, conflict, and neighborhood regulation. Neighborhood and Community Environments. I. Altman and A. Wandersman. New York, Plenum Press.

Mesch, G. S. and G. Manor (1998). "Social ties, environmental perception, and local attachment." Environment and Behavior 30(4): 504-519.

Michelson, W. (1977). Environmental choice, human behavior, and residential satisfaction. New York, Oxford University Press.

Morris, E. W., S. R. Crull, et al. (1976). "Housing Norms, Housing Satisfaction and the Propensity to Move." Journal of Marriage and the Family 38(2): 309-320.

Morris, E. W. and M. Winter (1975). "A Theory of Family Housing Adjustment." Journal of Marriage \& Family 37(1): 79-88.

Oh, J.-H. (2003). " Social Bonds and the Migration Intentions of Elderly Urban Residents: The Mediating Effect of Residential Satisfaction." Population Research and Policy Review 22(2): 127-146.

Onibokun, A. G. (1976). "Social system correlates of residential satisfaction." Environment and Behavior 8(3): 323-344.

Paquin, G. W. and E. Gambrill (1994). "The Problem with Neighbors." Journal of Community Psychology 22(1): 21-32. 
Parkes, A. and A. Kearns (2003). "Residential Perceptions and Housing Mobility in Scotland: An Analysis of the Longitudinal Scottish House Condition Survey 1991-96." Housing Studies 18(5): 673.

Parkes, A., A. Kearns, et al. (2002). "What makes people dissatisfied with their neighbourhoods?" Urban Studies 39(13): 2413-2438.

Peper, B. and F. Spierings (1999). "Settling Disputes Between Neighbours in the Lifeworld: An Evaluation of Experiments with Community Mediation in the Netherlands." European Journal on Criminal Policy and Research 7(4): 483-507.

Qian, Y. (2009). Policy and Practice of Urban Neighbourhood Renewal and Regeneration: What Can China Learn from British Experiences?, Heriot-Watt University. Ph.D.

Rapoport, A. (1985). Thinking about home environments. Home environments I. Altman and C. M. Werner. New York, Plenum Press.

Riger, S. and P. J. Lavrakas (1981). "Community ties: Patterns of attachment and social interaction in urban neighborhoods." American Journal of Community Psychology 9: 5566.

Rossi, P. H. (1955). Why families move : a study in the social psychology of urban residential mobility Glencoe, Ill., Free Press.

Rossi, P. H. (c1955). Why families move : a study in the social psychology of urban residential mobility Glencoe, Ill., Free Press.

S.Jakes. (2002). Back alleys blues. Time. 11: 64-67.

Sassen, S. (c1994). Cities in a world economy. Thousand Oaks, Calif., Pine Forge Press.

Scannell, L. (2003). Natural and Civic Place Attachment and the Relation to ProEnvironmental Behaviours in Trail and Nelson, British Columbia. Department of Psychology. Vancouver, University of British Columbia. MASTER OF SCIENCE.

Sirgy, M. J. and T. Cornwell (2002). " How Neighborhood Features Affect Quality of Life." Social Indicators Research 59(1): 79-114.

Skjæveland, O., T. Gärling, et al. (1996). " A multidimensional measure of neighboring." American journal of community psychology 24(3): 413-435. 
Stack, C. B. (1974). All our kin: strategies for survival in a Black community New York, Harper \& Row.

Susnik, A. and S. Ganesan (1997). "Urban renewal and displacement in Hong Kong." Urban Geography 18 (4): 324-346.

Tomohiko Yoshida, M. F., Deng Yi, Yusuke Koyama (2005?). "Characteristics of House Removal and Transfer Programs in Historic Areas of Beijing Old City Determined by Analyses of Family Registration Data."

Turner, J. F. C. (1972). Housing as a Verb. Freedom to Build, dweller control of the housing process. , eds , 1972 ... R. Fichter. New York, Collier Macmillan: 148-175.

Varady, D. and R. Kleinhans (2013). "Relocation Counselling and Supportive Services as Tools to Prevent Negative Spillover Effects: A Review." Housing Studies 28(2): 317-337.

Varady D. P. and Carrozza M. A. (2000). " Toward a Better Way to Measure Customer Satisfaction Levels in Public Housing: A Report from Cincinnati." Housing Studies, Volume , Number , 1 November 2000 , pp.(29) 15(6): 797-825.

Vera-Toscano, E. and V. Ateca-Amestoy (2008). "The relevance of social interactions on housing satisfaction." Social Indicators Research 86(257-274).

Volker, B., H. Flap, et al. (2007). "When are neighbourhoods communities? Community in Dutch neighbourhoods." European Sociological Review 23(1): 99-114.

Wang, Y. P. (2005). "Low-income communities and urban poverty in China." Urban Geography 26(3): 222-242.

Warren, D. I. (1986). The Helping Roles of Neighbors: Some Empirical Patterns. Urban neighborhoods : research and policy. R. B. Taylor. New York Praeger.

Weidemann, S. and J. R. Anderson (c1985). A conceptual Framework for residential satisfaction. Home environments. I. Altman and C. M. Werner. New York Plenum Press.

Wellman, B. (1996). "Are personal communities local? A Dumptarian reconsideration." Social Networks 18(4): 347-354.

Wellman, B. and M. Gulia (1999). The Network Basis of Social Support: A Network Is More Than the Sume of Its Ties. Networks in the global village : life in contemporary communities. B. Wellman. Boulder, Colo, Westview Press. 
Wellman, B., R. Y. L. Wong, et al. (1997). "A decade of network change: Turnover, persistence and stability in personal communities." Social Networks 19(1): 27-50.

White, G. F. and P. T. Schollaert (1993). "Home Ownership and Well-Being." Housing and society 20 .

Whyte, M. K. and W. L. Parish (1984). Urban life in contemporary China. Chicago, University of Chicago Press.

Wirth, L. (1938). "Urbanism as a Way of Life." The American Journal of Sociology 44(1): 1-24.

Wrzus, C., M. Hanel, et al. (2013). "Social Network Changes and Life Events Across the Life Span: A Meta-Analysis." Psychological Bulletin 139(1): 53-80.

Wu, F. (2004). "Intraurban residential relocation in Shanghai: modes and stratification." Environment and Planning A 36(1): 7 - 25.

Wu, F. (2004). " Residential relocation under market-oriented redevelopment: the process and outcomes in urban China." Geoforum 35: 453-470.

Wu, F. L. (1997). "Urban restructuring in China's emerging market economy: Towards a framework for analysis." International Journal of Urban and Regional Research 21(4): 640-+.

Wu, F. L. and S. J. He (2005). "Changes in traditional urban areas and impacts of urban redevelopment - A case study of three neighbourhoods in Nanjing, China." Tijdschrift Voor Economische En Sociale Geografie 96(1): 75-95.

Ya Ping, W. and M. Alan (2000). "Social and Spatial Implications of Housing Reform in China." International Journal of Urban and Regional Research 24(2): 397-417.

Yang, Y. (2007). Neighborhood Physical Form and Residential Satisfaction: Do New Urbanist Neighborhood Physical Attributes Enhance Residential Satisfaction? United States -- New York, Cornell University. Ph.D.

Zhang, T. (2002). "Urban development and a socialist progrowth coalition in Shanghai." Urban Affairs Review 4(475-499).

Zhang, W. Z., W. H. Yin, et al. (2006). A Study of Livable Cities in China (Beijing). Beijing, Social Science Academic Press (China). 
Zhang, Y. and K. Fang (2004). "Is History Repeating Itself? From Urban Renewal in the United States to Inner-City redevelopment in China." Journal of Planning Education and Research 23(3): 286--298.

Zhu, L. Y. and G. Shelton (1996). "The relationship of housing costs and quality of housing satisfaction of older American homeowners: regional and racial differences." Housing and society 23.

Zhu, M. (2005). Investigation of urban corners in Beijing. Beijing Shi, She hui ke xue wen xian chu ban she. 


\section{Appendices}

\section{Appendix A: interview questions for the officials}

1. Please talk about what you know about the Qianmen area (the Caochang neighborhood, the Hongshan neighborhood, the Longyue neighborhood).

Its history, housing and neighborhood physical and social environment, population, etc.

2. Please introduce the Qianmen urban renewal project.

When it was started? What were the objectives? How the funding supporting the projects was raised? How the projects were implemented?

How the residents got compensated? How can they access to affordable housing (the criteria, the procedure)? To what extent the residents can take part in the process of decision making? What kind of services and information provided to help the residents make their decision?

3. Please talk about the residents after urban renewal.

How many of them stayed and moved out? Where did they move? How can they be traced? Can you introduce some of them to me to interview?

4. Please talk about the future development of Qainmen.

Any plans? What do you think the obstacles in the future? and how to address that? 


\section{Appendix B: interview questions for the residents}

The questions are arranged around four groups: housing conditions and residential satisfaction evaluation, social network questions, residents' background questions, and public policy arrangements questions. Under the general open-ended questions, a few detailed questions are listed to guide me to further ask when these contents were not covered by the respondents. The interviewing process usually started with asking the interviewees' current housing conditions, followed by the question of how they are satisfied and what they are (dis)satisfied with... and ended with the policy arranges questions. Because some of the questions are related in spite of being listed in different parts, the interviewing process did not necessarily follow the question sequence shown below. For example, while discussing their social interaction with neighbors and local intimates before the urban renewal, some respondents would also mention their intimates who lived out of their neighborhood. In this circumstance, I would ask them this information first, and then go back to the question of neighborhood social interaction after the urban renewal later. At the end of the interview, I looked over all the questions to make sure all the questions were answered.

\section{Housing conditions and residential satisfaction evaluation}

1. Please introduce your apartment:

\begin{tabular}{|l|l|l|}
\hline & Previous apartment & Current apartment \\
\hline Length of residency & Had live since__ & Have lived since__ \\
\hline Unit size & 1. Homeowner & Square Meters \\
\hline Tenure & 2. Public renter & 1. Homeowner \\
\hline Facilities & Bathroom(public/private) & Bathroom(public/private) \\
\hline
\end{tabular}


2. Compared with the previous conditions, generally the current residential conditions are?

1. Much better

2. Fairly better

3. About the same

4. Slightly worse

5. Much worse

3. To what extent were you satisfied with your previous residential environment?

1. Very satisfied

2. Fairly satisfied

3. Neither satisfied nor dissatisfied

4. Slightly dissatisfied

5. Very dissatisfied)

4. To what extent are you satisfied with your current residential environment?

1. Very satisfied

2. Fairly satisfied

3. Neither satisfied nor dissatisfied

4. Slightly dissatisfied

5. Very dissatisfied

5. Please talk about why (what) you were satisfied and dissatisfied with your previous residential environment (physically, economically, socially and any other reasons).

6. Please talk about why (what) you are satisfied and dissatisfied with your current residential environment (physically, economically, socially and any other reasons).

7. Please talk about other aspects which you think brought by the urban renewal project.

\section{$\underline{\text { Social network questions }}$}

1. Please talk about your social interactions with your neighbors in Qainmen. 
- Did you inform each other of various resources, for example, job information, or even introduce jobs )

○ Did you have any conflicts with your neighbors? And why?

2. What do your social interactions with your neighbors look like in the current neighborhood, and why?

3. How do you think the importance of the social interactions with your neighbors?

4. Please talk about your social intimates before the relocation.

- How many social intimates did you have?

○ Who were they? (Relatives? friends? neighbors? Co-workers? And who are more important)

- (Let's start from $\mathrm{xxx}$ )

- Where did $\mathrm{xxx}$ live?

- How often did you contact?

- What kind of supports did you give each other?

5. How did the urban renewal project impact your social interaction with your social intimates?

- Did you lose contacts with some of them? How many and who?

○ How often did you contact each other now?

○ How do you give each other supports now?

6. Generally speaking, do you feel your social networks were impacted by the urban renewal? And why?

\section{$\underline{\text { Residents background questions }}$}

1. The gender of the interviewee is:

- Male

- Female

2.Your age group is:

- $<30$

- $31-40$

- 41-50 
- 51-69

- $>61$

3. Your education background is:

- Illiterate

- Primary school

- Middle school

- High School

- College

- Master

- Ph.D.

4. Are you

- Have a paid job, what is it $?$

- Unemployed

- Retired

5.The family members living with you are?

- Parents

- Children, their age is ___ ?

- Other relatives

6. Your family total monthly income is Yuan?

- $\quad<1200$

- $1200-2000$

- 2000-5000

- 5000-8000

- $>8000$

\section{Public policy arrangements questions}

1. Was your staying in Qianmen(move to the current neighborhood) out of your willingness, or you were forced? And why?

2. How do you feel you were given information and helps during the relocation process from the government?

3. How do you think of the compensation? 


\section{Appendix C: sample characteristics of study participants by income and by age}

Table 1: Sample characteristics of study participants by income

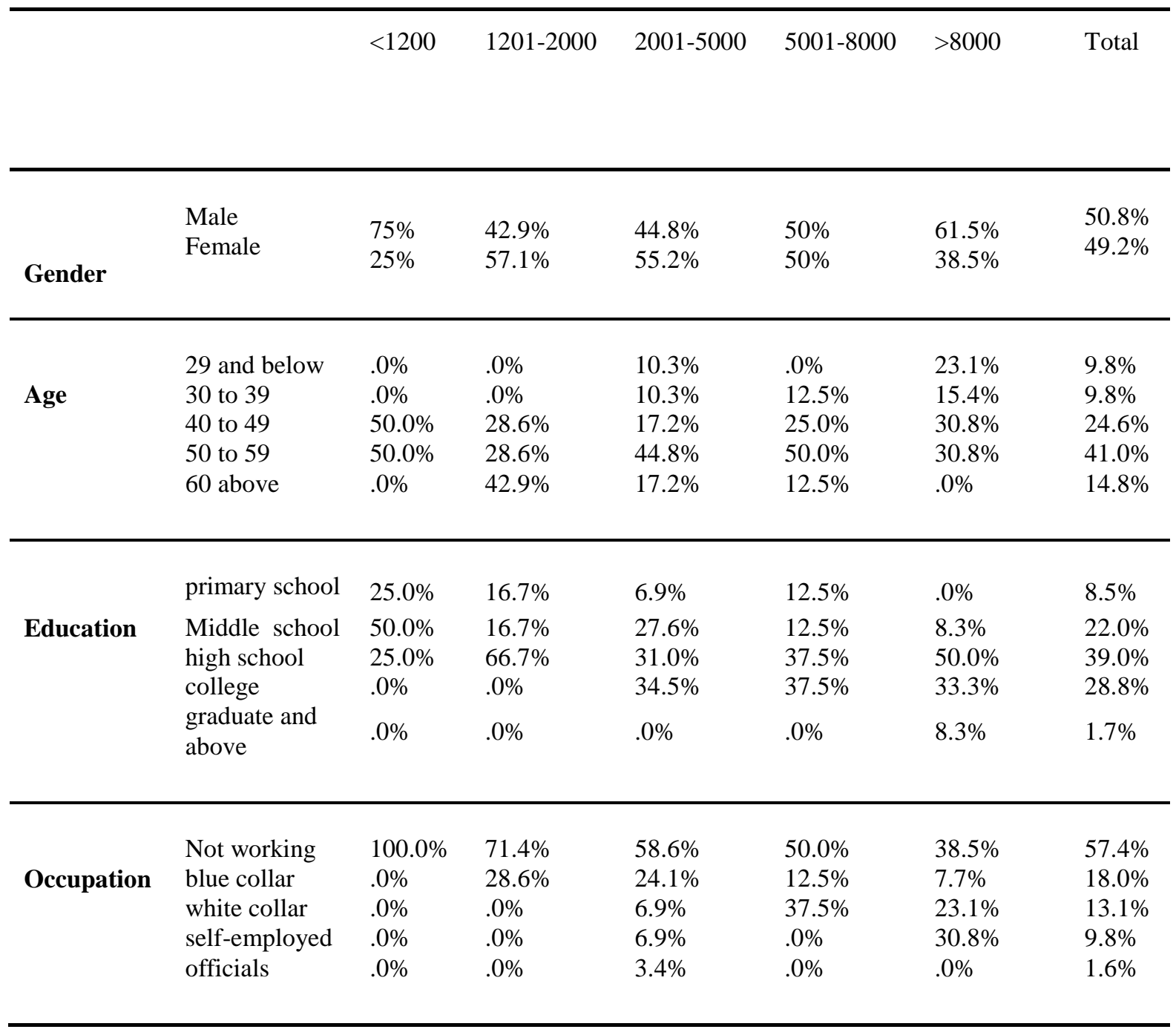


Table 2: Sample characteristics of study participants by age

\begin{tabular}{|c|c|c|c|c|c|c|c|}
\hline & & $\begin{array}{l}29 \text { and } \\
\text { below }\end{array}$ & 30 to 39 & 40 to 49 & 50 to 59 & $\begin{array}{l}60 \text { and } \\
\text { above }\end{array}$ & Total \\
\hline Gender & $\begin{array}{l}\text { Male } \\
\text { Female }\end{array}$ & $\begin{array}{l}66.7 \% \\
33.3 \%\end{array}$ & $\begin{array}{l}42.9 \% \\
57.1 \%\end{array}$ & $\begin{array}{l}52.9 \% \\
47.1 \%\end{array}$ & $\begin{array}{l}48.3 \% \\
51.7 \%\end{array}$ & $\begin{array}{l}41.7 \% \\
58.3 \%\end{array}$ & $\begin{array}{l}49.3 \% \\
50.7 \%\end{array}$ \\
\hline \multirow{3}{*}{ Education } & primary school & $.0 \%$ & $.0 \%$ & $5.9 \%$ & $3.8 \%$ & $40.0 \%$ & $9.1 \%$ \\
\hline & $\begin{array}{l}\text { middle school } \\
\text { high school } \\
\text { college }\end{array}$ & $\begin{array}{l}.0 \% \\
.0 \% \\
83.3 \%\end{array}$ & $\begin{array}{l}28.6 \% \\
42.9 \% \\
28.6 \%\end{array}$ & $\begin{array}{l}5.9 \% \\
58.8 \% \\
29.4 \%\end{array}$ & $\begin{array}{l}38.5 \% \\
42.3 \% \\
15.4 \%\end{array}$ & $\begin{array}{l}10.0 \% \\
30.0 \% \\
20.0 \%\end{array}$ & $\begin{array}{l}21.2 \% \\
40.9 \% \\
27.3 \%\end{array}$ \\
\hline & $\begin{array}{l}\text { graduate and } \\
\text { above }\end{array}$ & $16.7 \%$ & $.0 \%$ & $.0 \%$ & $.0 \%$ & $.0 \%$ & $1.5 \%$ \\
\hline Occupation & $\begin{array}{l}\text { Not working } \\
\text { blue collar } \\
\text { white collar } \\
\text { self-employed } \\
\text { officials }\end{array}$ & $\begin{array}{l}33.3 \% \\
.0 \% \\
66.7 \% \\
.0 \% \\
.0 \%\end{array}$ & $\begin{array}{l}28.6 \% \\
28.6 \% \\
14.3 \% \\
28.6 \% \\
.0 \%\end{array}$ & $\begin{array}{l}29.4 \% \\
29.4 \% \\
11.8 \% \\
23.5 \% \\
5.9 \%\end{array}$ & $\begin{array}{l}67.9 \% \\
14.3 \% \\
7.1 \% \\
.0 \% \\
10.7 \%\end{array}$ & $\begin{array}{l}100.0 \% \\
.0 \% \\
.0 \% \\
.0 \% \\
.0 \%\end{array}$ & $\begin{array}{l}56.5 \% \\
15.9 \% \\
13.0 \% \\
8.7 \% \\
5.8 \%\end{array}$ \\
\hline Income & $\begin{array}{l}<1200 \\
1201-2000 \\
2001-5000 \\
5001-8000 \\
>8000\end{array}$ & $\begin{array}{l}.0 \% \\
.0 \% \\
50.0 \% \\
.0 \% \\
50.0 \% \\
\end{array}$ & $\begin{array}{l}.0 \% \\
.0 \% \\
50.0 \% \\
16.7 \% \\
33.3 \% \\
\end{array}$ & $\begin{array}{l}13.3 \% \\
13.3 \% \\
33.3 \% \\
13.3 \% \\
26.7 \%\end{array}$ & $\begin{array}{l}8.0 \% \\
8.0 \% \\
52.0 \% \\
16.0 \% \\
16.0 \%\end{array}$ & $\begin{array}{l}.0 \% \\
33.3 \% \\
55.6 \% \\
11.1 \% \\
.0 \%\end{array}$ & $\begin{array}{l}6.6 \% \\
11.5 \% \\
47.5 \% \\
13.1 \% \\
21.3 \%\end{array}$ \\
\hline
\end{tabular}

